Third Conference on Atmospheric Radiation of the American Meteorological Society, June 28-30, 1978, University of California, Davis, Calif.

AMS National Officers

AMS 1977 Committee on Radiation Energy

Program Committee
President: George P. Cressman Executive Director: Kenneth C. Spengler
Kinsell L. Coulson, Chairperson Albert Arking

Robert Ellingson
Kirby J. Hanson

Kuo-Nan Liou

Syukaro Manabe
Lawrence A. Sromovsky Ronald F. Wachtmann Cynthia K. Whitney

Kinsell L. Coulson, Program Chairperson

Cynthia K. Whitney, Chairperson, Session 1; Kuo-Nan Liou, Alternate.

Kirby J. Hanson, Chairperson, Session 2; Harold Yates, Alternate.

Julius London, Chairperson, Session 3; Fred House, Alternate.

Robert Curran, Chairperson, Session 4; S. Roland Drayson, Alternate.

William R. Bandeen, Chairperson, Session 5; Stephen K. Cox, Alternate.

Larry Gates, Chairperson, Session 6; Jay S. Winston, Alternate.

Thomas H. Vonder Haar, Chairperson, Session 7; G. Louis Smith, Alternate.

\title{
Session Titles
}

Session 1: Radiative Transfer in Realistic Atmospheres

Session 2: Instrumentation and Measurements

Session 3: Radiative Energy Budgets

Session 4: Radiative Properties of Atmosphere and Surfaces

Session 5: Radiative Interactions in Dynamical Systems

Session 6: Radiative Effects in Climate

Session 7: Earth Radiation Budget Satellite System Studies

\section{Synopsis of Schedule}




\section{General Information}

\section{Registration}

Housing

Transportation

Program for Spouses

No-Host Cocktail Party

Conference Banquet
The Third Conference on Atmospheric Radiation, sponsored by the American Meteorological Society, will be held 28-30 June 1978 on the campus of the University of California in Davis, Calif. The AMS Committee on Radiation Energy has arranged for the technical program.

The city of Davis is located near Interstate Highway \#80, about $79 \mathrm{mi}$ northeast of San Francisco and 15 mi west of Sacramento.

Requests for further information on the conference should be addressed to the Program Chairperson: Prof. Kinsell L. Coulson, Dept. of Land, Air, and Water Resources, Univ. of California, Davis, Calif. 95616 (tel: 916-752-1450 or 916-752-1406).

The registration desk will be open Tuesday, 27 June, from 6:00 p.m. to 8:00 p.m. and on Wednesday, 28 June, at 8:00 a.m. Preregistration forms will be mailed to authors, Program Committee members, and anyone whose address is available by 1 April. Others may preregister, however, by sending name, affiliation, and complete mailing address to: Conferences and Campus Services, Univ. of California, Davis, Calif. 95616. Registration fees, including a copy of the volume of abstracts, are: $\$ 40$, AMS members, speakers, and session chairpersons; $\$ 50$, nonmembers; $\$ 15$, local undergraduate students $(\$ 10$, without volume of abstracts).

Lodging and meals are available at very nominal rates in the student dormitories on campus. In addition, there are several motels in the Davis area and many more motels and hotels at a $15 \mathrm{mi}$ distance in Sacramento. Complete information and reservation forms are included in the preregistration packet.

Air travel is most convenient through the Sacramento Metropolitan Airport, which is served by several major airlines. Bus transportation at a nominal fee will be arranged for the approximately $25 \mathrm{mi}$ from the airport to the campus.

A relatively complete slate of activities is planned for family members accompanying delegates, the first of which is a coffee get-together on Wednesday, 28 June, at 10:00 a.m. Further information will be furnished in the preregistration packet and at the time of registration.

There will be a No-Host Cocktail Party on Wednesday, 28 June, at 5:30 p.m.

A Conference Banquet will be held at the Faculty Club on Thursday, 29 June, at 6:30 p.m. Tickets will be $\$ 10.00$ per person.

\section{Plenary Session-8:30 a.m. to 10:30 a.m., Wednesday, June 28}

Methods and results in the retrieval of temperature profiles from satellite measurements. W. L. Smith, National Environmental Satellite Service/NOAA, Madison, Wis. (Survey Paper)

To be announced. (Survey Paper)

\section{Session 1: Radiative Transfer in Realistic Atmospheres}

Chairperson: Dr. Cynthia K. Whitney, Charles Stark Draper Lab., Cambridge, Mass.

Session 1A—8:30 a.m. to 10:30 a.m., Thurs., June 29

Atmospheric effects on high energy laser beams. C. B. Hogge, Air Force Weapons Lab., Kirtland AFB, N.Mex. 
Effects of particulate complex refractive index and particle-size distribution variations on atmospheric extinction and absorption for visible through middle IR wavelengths. S. G. Jennings and R. G. Pinnick, Atmospheric Sciences Lab., White Sands Missile Range, N.Mex.

The effect of cloud bimodal drop-size distributions upon the radiation field. $\mathrm{R}$. M. Welch and S. K. Cox, Colorado State Univ., Ft. Collins, Colo.

Multiple scattering corrections to the solar aureole. M. A. Box and A. Deepak, Institute for Atmospheric Optics and Remote Sensing, Hampton, Va.

The effect of air pollution on visibility, visual range, and atmospheric coloration. $\mathrm{R}$. W. Bergstrom, Systems Applications, Inc., San Rafael, Calif.

Continuous fractions vs. series for Mie scattering calculations. T. Y. Palmer, Southwest Environmental Technology Labs., Fallbrook; and J. A. Watrous, Univ. of California, Riverside, Calif.

\section{Session 1B-10:45 a.m. to 12:15 p.m., Thurs., June 29}

Scattering by irregular particles of size comparable to a wavelength: A new semi-empirical theory. J. B. Pollack and J. N. Cuzzi, Ames Research Center/NASA, Moffett Field, Calif.

A theoretical model for solar radiation transfer in a cubic cloud. S. K. S. Varma, Systems and Applied Sciences Corp., Riverdale, Md.

Visible flux variations across finite clouds. F. R. Mosher, Univ. of Wisconsin, Madison, Wis.

Computatons of radiative fluxes in clouds: Application to cloud modeling. Y. Fouquart and J. J. Morcrette, Univ. des Sciences et Techniques de Lille, Lille, France.

Theoretical predictions of nighttime minimum temperatures using radiative equilibrium calculations. R. L. Gall, B. M. Herman, and S. P. Nelson, Univ. of Arizona, Tucson, Ariz.

Long-wave radiative transfer in the atmosphere. S. K. Gupta, S. N. Tiwari, and J. T. Suttles, Old Dominion Univ., Norfolk, Va.

\section{Session 1C-1:30 p.m. to 3:30 p.m., Thurs., June 29}

Comparison of the two-flux technique with an exact technique for computing atmospheric radiation in an absorbing, emitting, and scattering medium. $\mathrm{R}$. W. Bergstrom, Ames Research Center/NASA, Moffett Field, Calif.

Comparison of numerical models and observations of solar radiation at Nashville. M. A. Atwater, The Center for the Environment and Man, Inc., Hartford, Conn.

Parameterization of reflection, absorption, and transmission of solar radiation by cloud layers. K. N. Liou and J. D. Wittman, Univ. of Utah, Salt Lake City, Utah.

Effects of natural surfaces on the radiation emerging from planetary atmospheres. B. W. Fitch, Univ. of California, Davis, Calif.

Effects of a more realistic aerosol model on radiative transfer calculations. M. A. Seagraves and R. B. Gomez, Atmospheric Sciences Lab., White Sands Missile Range, N.Mex.

Retrieval of vertical aerosol and ozone extinction profiles from simulated multispectral limb extinction measurements. D. H. Phillips, K. J. Weise, and B. M. Herman, Univ. of Arizona, Tucson, Ariz.

Study of limb transmission and emission modeling for stratospheric minor constituent measurements. R. K. Tallamraju, NCAR, Boulder, Colo.; and S. R. Drayson, Univ. of Michigan, Ann Arbor, Mich. 
The impact of atmospheric ozone variability on the accuracy of temperature profiles inferred from remote 13-15 $\mu$ m measurements. R. L. Weichel, Lawrence Livermore Lab., Livermore, Calif.

The effect of surface anisotropy on the accuracy of total ozone estimates from satellite observations. R. S. Fraser, Goddard Space Flight Center/NASA, Greenbelt; and Z. Ahmad, Systems and Applied Sciences Corp., Riverdale, Md.

\section{Session 1D-3:45 p.m. to 5:15 p.m., Thurs., June 29}

Infrared radiative scattering from nonisothermal cirrus clouds with application to remote sensing. A. C. Cogley, Univ. of Illinois, Chicago, Ill.

Remote sounding of the temperature profile and cloud thickness in cirrus cloudy atmospheres. H. Y. Yeh and K. N. Liou, Univ. of Utah, Salt Lake City, Utah.

Removal of residual cloud contamination from radiance fields. H. Fleming and M. Hill, National Environmental Satellite Service/NOAA, Washington, D.C.

A general solution to the clear radiance problem. L. M. McMillin, National Environmental Satellite Service/NOAA, Washington, D.C.

An algorithm for optimizing the information content of radiation field measurements in the presence of multiple scattering. B. R. Barkstrom and D. M. Stephenson, George Washington Univ. and Langley Research Center/NASA, Hampton, Va.

Wind speed and aerosol optical thickness estimates from aircraft observations of sea glitter. Z. Ahmad, Systems and Applied Sciences Corp., Riverdale; and R. S. Fraser and R. J. Curran, Goddard Space Flight Center/NASA, Greenbelt, Md.

\section{Session 2: Instrumentation and Measurements}

Chairperson: Dr. Kirby J. Hanson, Environmental Research Labs./NOAA, Boulder, Colo.

\section{Session 2A-8:30 a.m. to 10:30 a.m., Thurs., June 29}

Polarizing radiometer calibration. R. Walraven, Univ. of California, Davis, Calif.

Weighting functions for the TIROS-N HIRS/2 sounder. A. Arking, Goddard Space Flight Center/NASA, Greenbelt, Md.; D. Chesters, Computer Sciences Corp., Silver Spring, Md.; and M. D. Chow, SAI Comsystems Corp., McLean, Va.

On twilight polarization. W. G. Blattner, Radiation Research Associates, Ft. Worth, Tex. Effects of clouds and precipitation on Nimbus-6 SCAMS channels. K. N. Liou, A. Duff, and G. Aufderhaar, Univ. of Utah, Salt Lake City, Utah.

Solar radiation measurements from Nimbus-6. J. R. Hickey, The Eppley Labs., Newport, R.I.

Angular scattering of polarized laser light by water droplet and ice crystal clouds. K. Sassen and K. N. Liou, Univ. of Utah, Salt Lake City, Utah.

\section{Session 2B-10:45 a.m. to 12:15 p.m., Thurs., June 29}

Infrared measurement over cirrus clouds in the 10.5-12.5 $\mu \mathrm{m}$ and 6-7 $4 \mathrm{~m}$ regions. G. Szejwach, Lab. de Meteorologie Dynamique, Palaiseau, France.

Classification of clouds for the Nimbus satellite ERB experiment using THIR data. L. L. Stowe, M. Chen, H. Jacobowitz, and I. Ruff, National Environmental Satellite Service/ NOAA, Washington, D.C. 
A cloud physics radiometer. H. L. Kyle, R. J. Curran, and W. L. Barnes, Goddard Space Flight Center/NASA, Greenbelt; and D. Escoe, Computer Sciences Corp., Silver Spring, Md.

Infrared remote sensing and radiative transfer in wind shear detection. P. M. Kuhn, F. Caracena, and I. G. Nolt, Environmental Research Labs./NOAA, Boulder, Colo.; and J. Radostitz, Univ. of Oregon, Eugene, Oreg.

Remote sensing of the boundary layer over the oceans. C. Prabhakara, Goddard Space Flight Center/NASA, Greenbelt; and N. R. Nath and R. C. Lo, Computer Sciences Corp., Silver Spring, Md.

\section{Session $2 C-1: 30$ p.m. to $3: 30$ p.m., Thurs., June 29}

Optimum interpolation of radiosonde and satellite-derived temperature fields. Y. P. Yee and T. H. Vonder Haar, Colorado State Univ., Ft. Collins, Colo.

A structure function analysis of mesoscale satellite infrared soundings. D. W. Hillger and T. H. Vonder Haar, Colorado State Univ., Ft. Collins, Colo.

A statistical technique for determining rainfall over land using Nimbus-6 ESMR measurements. E. Rodgers, H. Siddalingaiah, A. T. C. Chang, and T. Wilheit, Goddard Space Flight Center/NASA, Greenbelt, Md.

Differential insolation and turbidity measurements. N. S. Laulainen, E. W. Kleckner, and J. J. Michalsky, Battelle Pacific Northwest Labs., Richland, Wash.

An automated multiwavelength sunphotometer to characterize transient aersol and water vapor events. P. B. Russell, E. J. Scribner, and E. E. Uthe, SRI International, Menlo Park, Calif.

Determination of aerosol characteristics by photographic solar aureole measurements. A. Deepak, G. P. Box, and M. A. Box, Institute for Atmospheric Optics and Remote Sensing; and R. R. Adams, Langley Research Center/NASA, Hampton, Va.

Vertical inhomogeneity in atmospheric fog and haze and its effects on IR extinction. R. G. Pinnick, D. L. Hoihjelle, G. Fernandez, E. B. Stenmark, J. D. Lindberg, and S. G. Jennings, Atmospheric Sciences Lab., White Sands Missile Range, N.Mex.; and P. Chýlek, Harvard Univ., Cambridge, Mass.

\section{Session 2D-3:45 p.m. to 5:15 p.m., Thurs., June 29}

Atmospheric turbidity determinations by skylight measurements at the Mauna Loa Observatory. K. L. Coulson, Univ. of Calif., Davis, Calif.

Description of a spectral atmospheric radiation monitoring network. M. Martin and P. Berdahl, Lawrence Berkeley Lab., Berkeley, Calif.

Measurement and modeling of shortwave radiation incident on inclined surfaces. J. E. Hay, Univ. of British Columbia, Vancouver, B.C., Canada.

The relative information content of wide, medium, and narrow angle measurements of earth radiation energy parameters from satellite altitudes. A. Arking, Goddard Space Flight Center/NASA, Greenbelt, Md.

A man-interactive technique for specifying cloud heights from sounding radiance data. W. P. Menzel, Space Science and Engineering Center; and W. L. Smith and H. M. Woolf, National Environmental Satellite Service/NOAA, Madison, Wis.

\section{Session 3: Radiative Energy Budgets}

Chairperson: Julius London, Univ. of Colorado, Boulder, Colo. 


\section{Session $3 A-1: 30$ p.m. to 3:30 p.m., Thurs., June 29}

Earth-atmosphere radiative heating based on NOAA scanning radiometer measurements: Review of a 4-year record. J. S. Winston, National Environmental Satellite Service/ NOAA, Washington, D.C.

On the determination of synoptic-scale radiative fluxes from ERB narrow-angle directional observations. H. Jacobowitz, I. Ruff, L. L. Stowe, and M. Chen, National Environmental Satellite Service/NOAA, Washington, D.C.

The first 18 months of planetary radiation budget measurements from the Nimbus-6 ERB experiment. H. Jacobowitz, W. L. Smith, H. B. Howell, and F. W. Nagle, National Environmental Satellite Service/NOAA, Washington, D.C.; and J. R. Hickey, The Eppley Labs., Newport, R.I.

The effect of measured angular variability of reflected and emitted radiance on WFOV earth radiation budget measurements. G. G. Campbell, Colorado State Univ., Ft. Collins, Colo.

Large-area representations of radiative divergence from GATE. S. K. Cox and K. T. Griffith, Colorado State Univ., Ft. Collins, Colo.

Initial determinations of GATE surface and top-of-atmospheric radiative energy budget with atmospheric heating considerations. D. C. Loranger, E. A. Smith, and T. H. Vonder Haar, Colorado State Univ., Ft. Collins, Colo.

\section{Session 3B-3:45 p.m. to 5:15 p.m., Thurs., June 29}

Accurate calculations of fluxes and cooling rates using emissivities. J. A. Coakley, Jr., and B. P. Briegleb, NCAR, Boulder, Colo.

Analytic infrared transmissivities and infrared cooling rate of the atmosphere. H. L. Kuo, Univ. of Chicago, Chicago, Ill.

Numerical radiation cooling rates using various rawinsonde densities during IFYGL. M. A. Atwater and J. T. Ball, The Center for the Environment and Man, Inc., Hartford, Conn.

Solar radiation reaching the ground determined from meteorological satellite data. J. S. Ellis, Lawrence Livermore Lab., Livermore, Calif.; and T. H. Vonder Haar, Colorado State Univ., Ft. Collins, Colo.

Preliminary results of the impact of reflection on irradiation in mountainous terrain. I. Dirmhirn, T. Diniz, W. A. Peterson, and B. A. LeBaron, Utah State Univ., Logan, Utah.

\section{Session 3C-8:30 a.m. to 10:30 a.m., Fri., June 30}

Albedo climatology analysis and the determination of fractional cloud cover. R. J. Curran and R. Wexler, Goddard Space Flight Center/NASA, Greenbelt; and M. L. Nack, Computer Sciences Corp., Silver Spring, Md.

On the effects of cumulus dimensions on long-wave irradiance and heating rate calculations. R. C. Ellingson and E. Kolczynski, Univ. of Maryland, College Park, Md.

Solar absorption in clouds of finite horizontal extent. J. M. Davis, T. B. McKee, and S. K. Cox, Colorado State Univ., Ft. Collins, Colo.

The inclusion of finite cloud radiative properties in space-and time-averaged radiative budgets. J. M. Davis, S. K. Cox, and T. B. McKee, Colorado State Univ., Ft. Collins, Colo.

The spatial variation in the upwelling radiances from clouds of finite horizontal extent. R. Davies, Univ. of Wisconsin, Madison, Wis. 
Solar radiation transfer in two-dimensional cloud layers: $Y_{1}$ approximation. S. K. S. Varma, Systems and Applied Sciences Corp., Riverdale, Md.

\section{Session 3D-10:45 a.m. to 11:45 a.m., Fri., June 30}

Cirrus clouds and solar heating of the upper troposphere. K. P. Freeman, Air Force Global Weather Central, Offutt AFB, Nebr.

Simulated radiance patterns for Mie absorbing finite clouds. J. T. Klehr and T. B. McKee, Colorado State Univ., Ft. Collins, Colo.

Transformation of surface albedo to surface-atmosphere albedo and irradiance, and their spectral and temporal averages. M. L. Nack, Computer Sciences Corp., Silver Spring; and R. J. Curran, Goddard Space Flight Center/NASA, Greenbelt, Md.

\section{Session 4: Radiative Properties of Atmosphere and Surfaces}

Chairperson: Robert J. Curran, Goddard Space Flight Center/NASA, Greenbelt, Md.

\section{Session $4 A-1: 30$ p.m. to 3:30 p.m., Wed., June 28}

Remote sensing of aerosols in the Martian atmosphere: Implications for terrestrial studies. J. B. Pollack and D. Colburn, Ames Research Center/NASA, Moffett Field, Calif.

Remote sensing of the structure of the Martian atmosphere in the presence of dust. G. E. Hunt, Univ. College of London, London, England.

Transmission measurements for very long paths of carbon dioxide and water vapor: Application to remote temperature sounding of the atmosphere of Venus. D. J. McCleese, F. W. Taylor, J. V. Martonchik, P. B. Forney, and M. H. Hanner, Jet Propulsion Lab., California Institute of Technology, Pasadena, Calif.

Atmospheric absorption spectra near $2200 \mathrm{~cm}^{-1}$ and $2400 \mathrm{~cm}^{-1}$. J. Susskind and T. Mo, Goddard Space Flight Center/NASA, Greenbelt, Md.

Radiance variations from atmospheric and surface inhomogeneities. P. A. Davis, SRI International, Menlo Park, Calif.

Earth infrared radiative transfer radiances for sun synchronous and geosynchronous meteorological satellites. H. S. Chen, Santa Barbara Research Center, Goleta, Calif.

\section{Session 4B-3:45 p.m. to 5:15 p.m., Wed., June 28}

In situ spectrophone measurements of aerosol absorption. C. Bruce, R. Brewer, and Y. Yee, Atmospheric Sciences Lab., White Sands Missile Range, N.Mex.

Effects of humidity variations on atmospheric aerosol optical properties. E. P. Shettle, Air Force Geophysics Lab., Hanscom AFB, Mass.

Variability in the stratospheric aerosol loading associated with the 1974 eruption of Volcán de Fuego. F. G. Fernald, Univ. of Denver, Denver, Colo.

Observations and measurements of the solar aureole. F. E. Volz, Air Force Geophysics Lab., Hanscom AFB, Mass.

Radiation budget for a tropical dry evergreen forest in Thailand. R. T. Pinker and O. E. Thompson, Univ. of Maryland, College Park, Md.

\section{Session $4 C-8: 30$ a.m. to 10:30 a.m., Thurs., June 29}

Some results of the UA-ARE Program. J. A. Reagan, B. M. Herman, D. M. Byrne, and M. D. King, Univ. of Arizona, Tucon, Ariz. 
Nonspherical extinction and absorption efficiencies. R. M. Welch and S. K. Cox, Colorado State Univ., Ft. Collins, Colo.

Light scattering by almost spherical particles. P. Chýlek, J. T. Kiehl, and M. K. W. Ko, Harvard Univ., Cambridge, Mass., and Purdue Univ., W. Lafayette, Ind.

Cloud measurements from satellites and aircraft. J. T. Bunting, Air Force Geophysics Lab., Hanscom AFB, Mass.

Light-scattering characteristics of an aging power plant plume. C. A. Norberg, R. B. Husar, and D. Patterson, Washington Univ., St. Louis, Mo.

The reflectance characteristics of snow-covered surfaces. E. S. Batten, Jet Propulsion Lab., California Institute of Technology, Pasadena, Calif.

Reflectional properties of natural formations. C. R. Nagaraja Rao, Oregon State Univ., Corvallis, Oreg.

Passive microwave signatures of weather-altered surfaces. M. G. Fowler, H. K. Burke, S. L. Tung, and N. K. Tripp, Environmental Research \& Technology, Inc., Concord, Mass.

\section{Session 4D-10:45 a.m. to 12:15 p.m., Thurs., June 29}

Remote sensing of the ozone profile in the lower stratosphere using $U V$ and IR measurements from Nimbus-4. C. Prabhakara and S. Chandra, Goddard Space Flight Cienter/ NASA, Greenbelt, Md.

Seasonal variation in the upper-stratospheric ozone. R. D. McPeters, Systems and Applied Sciences Corp., Riverdale; and J. A. Gatlin, Goddard Space Flight Center/NASA, Greenbelt, Md.

Global variability of total ozone: Preliminary results of the multifilter radiometer onboard the new series of DMSP-5D satellites-1, Overview. J. E. Lovill, T. J. Sullivan, R. L. Weichel, J. Korver, J. Huebel, J. S. Ellis, P. P. Weidhaas, and F. A. Phelps, Lawrence Livermore Lab., Livermore, Calif.

Global variability of total ozone: Preliminary results of the multifilter radiometer onboard the new series of DMSP-5D satellites-2, Statistical discussions. J. Huebel, J. E. Lovill, T. J. Sullivan, R. L. Weichel, P. P. Weidhaas, J. Korver, J. S. Ellis, and F. A. Phelps, Lawrence Livermore Lab., Livermore, Calif.

Ground-based remote sensing of UV-absorbing trace species in the troposphere: Vertical profile effects. K. F. Klenk, Systems and Applied Sciences Corp., Riverdale, Md.

\section{Session 5: Radiative Interactions in Dynamical Systems}

Chairperson: William R. Bandeen, Goddard Space Flight Center/NASA, Greenbelt, Md.

\section{Session 5A-8:30 a.m. to 10:30 a.m., Fri., June 30}

Influence of cloud and cloud-free radiational differences on tropical disturbance maintenance and diurnal modulation. W. M. Gray, Colorado State Univ., Ft. Collins, Colo.

The effect of cloud type on the global distribution of radiative heating. R. J. Becker, Univ. of Maryland, College Park, Md.

The sensitivity of ensemble cumulus characteristics to changes in the bulk radiative heating rate. R. G. Ellingson and G. Serafino, Univ. of Maryland, College Park, Md.

On the interaction of turbulent and radiative heat transfer in the atmospheric boundary layer. D. Etling, Technical Univ. of Darmstadt, Darmstadt, F.R.G. 
Some comments on radiative flux divergence, heating rates, and cloud droplet population dynamics. B. R. Barkstrom, George Washington Univ. and Langley Research Center/ NASA, Hampton, Va.

Sensitivity of a general circulation model to a change in shortwave radiation code. M. D. Schwarzkopf and R. T. Wetherald, Geophysical Fluid Dynamics Lab./NOAA, Princeton Univ., Princeton, N.J.

\section{Session 5B-10:45 a.m. to 12:15 p.m., Fri., June 30}

Stratospheric effects of doubled $\mathrm{CO}_{2}$ concentration in a general circulation model (GCM). S. B. Fels and M. D. Schwarzkopf, Geophysical Fluid Dynamics Lab./NOAA, Princeton Univ., Princeton, N.J.

Radiative-convective model calculations of temperature changes caused by changes in the atmospheric composition. J. A. Coakley, Jr., NCAR, Boulder, Colo.

Influence of systematic radiation differences on the dynamics of a model atmosphere. M. L. C. Wu, Goddard Space Flight Center/NASA, Greenbelt, Md.; and L. D. Kaplan, Univ. of Chicago, Chicago, Ill.

An infrared radiation routine for use in numerical atmospheric models. M. D. Chow, SAI Comsystems Corp., McLean, Va.; and A. Arking, Goddard Space Flight Center/ NASA, Greenbelt, Md.

An accurate, fast algorithm for calculating stratospheric $\mathrm{CO}_{2} 15 \mu \mathrm{m}$ cooling rates in GCMs. S. B. Fels, Geophysical Fluid Dynamics Lab./NOAA, Princeton Univ., Princeton, N.J.

\section{Session 6: Radiative Effects in Climate}

Chairperson: Prof. Larry Gates, Oregon State Univ., Corvallis, Oreg.

\section{Session 6A-10:45 a.m. to 12:15 p.m., Wed., June 28}

Effect of tropospheric aerosols upon atmospheric infrared cooling rates. Harshvardhan, Goddard Space Flight Center/NASA, Greenbelt, Md.; and R. D. Cess, State Univ. of New York, Stony Brook, N.Y.

Effect of volcanic aerosols on climate. O. B. Toon and J. B. Pollack, Ames Research Center/NASA, Moffett Field, Calif.

Possible effects of solar UV variations on ozone and climate. J. B. Pollack, W. Borucki, and O. B. Toon, Ames Research Center/NASA, Moffett Field, Calif.

\section{Session $6 B-1: 30$ p.m. to $3: 30$ p.m., Wed., June 28}

Variations in the solar constant measurements by the Smithsonian Astrophysical Observatory. D. V. Hoyt, Environmental Research Labs./NOAA, Boulder, Colo.

The paleoluminosity paradox-How much of it can be explained by a shift in the solar spectrum? W. J. Wiscombe, NCAR, Boulder, Colo.

Urban-rural solar irradiance measurements at St. Louis. J. T. Peterson and T. L. Stoffel, Environmental Research Labs./NOAA, Boulder, Colo. 
Global radiation and actiometric measurements within the St. Louis urban environment. J. M. White, Univ. of Wyoming, Laramie, Wyo.

Some considerations on the global solar radiation in Barcelona. J. T. Jiménez, J. E. Llebot, and J. Casas-Vázquez, Univ. Autonoma de Barcelona, Barcelona, Spain.

Secular trends in clear sky transmission as measured at Mauna Loa Observatory, Hawaii. B. G. Mendonca, Environmental Research Labs./NOAA, Boulder, Colo.

\section{Session 6C-3:45 p.m. to 5:15 p.m., Wed., June 28}

Development of a radiation model with interactive water vapor transport and cloud development. J. R. Hummel, W. R. Kuhn, and D. R. Kraemer, Univ. of Michigan, Ann Arbor, Mich.

The effect of ground hydrology on climate sensitivity to solar constant variations. $\mathrm{S}$. $\mathbf{H}$. Chow, Computer Sciences Corp., Silver Spring; and R. J. Curran, Goddard Space Flight Center/NASA, Greenbelt, Md.

Response of a radiative-convective temperature profile to variations in model physical parameters: Uncertainty in the calculated temperature from input data error. $\mathbf{R}$. A. Reck, General Motors Research Labs., Warren, Mich.

A technique for estimating net radiation over snow in unforested environments of a midlatitude, subarctic, and arctic site. D. E. Petzold, Univ. of Maryland, College Park, Md.; and R. G. Wilson, Ministry of the Environment, Government of British Columbia, Victoria, B.C., Canada.

Infrared characterization of some worldwide aerosol fractions. F. E. Volz, Air Force Geophysics Lab., Hanscom AFB, Mass.

\section{Session 7: Earth Radiation Budget Satellite System Studies}

Chairperson: Prof. Thomas H. Vonder Haar, Colorado State Univ., Ft. Collins, Colo.

\section{Session 7A-1:30 p.m. to 3:30 p.m., Wed., June 28}

The earth radiation budget satellite system: An overview. C. V. Woerner, Langley Research Center/NASA, Hampton, Va.

Historical review of earth radiation budget studies and the scientific rationale leading to ERBSS. R. J. Curran and H. L. Kyle, Goddard Space Flight Center/NASA, Greenbelt; and M. L. Nack and S. H. Chow, Computer Sciences Corp., Silver Spring, Md.

System implementation for the earth radiation budget satellite system. J. E. Cooper and C. V. Woerner, Langley Research Center/NASA, Hampton, Va.

Sampling analysis for the earth radiation budget satellite system mission based on orbital coverage and cloud variability. E. F. Harrison, Langley Research Center/NASA; and G. G. Gibson and P. Minnis, Vought Corp., Hampton, Va.

Thermal model of a filtered radiometer. J. R. Mahan, Virginia Polytechnic Institute and State Univ., Blacksburg; and M. R. Luther, Vought Corp., Hampton, Va.

Performance analysis of a filtered wide field-of-view radiometer for earth radiation budget measurements. J. E. Cooper, Langley Research Center/NASA; and M. R. Luther, Vought Corp., Hampton, Va.

Aperture and detector cavity considerations for wide and medium field-of-view radiometers. R. A. Babcock, Langley Research Center/NASA, Hampton, Va. 
Session 7B-3:45 p.m. to 5:15 p.m., Wed., June 28

Ground/air truth calibration techniques for the earth radiation budget satellite system scanner. K. L. Coulson, Univ. of California, Davis, Calif.

Directional models for analysis of earth radiation budget measurements. J. T. Suttles and L. M. Avis, Langley Research Center/NASA; and P. G. Renfroe, Vought Corp., Hampton, Va.

Analysis of simulated measurements of earth-emitted radiation using geometric shape factors and some results from analysis of ESSA-7 and Nimbus-6 data. W. L. Weaver and R. N. Green, Langley Research Center/NASA, Hampton, Va.

Deconvolution estimation theory applied to Nimbus-6 ERB data. R. N. Green and G. L. Smith, Langley Research Center/NASA, Hampton, Va.

\section{Plenary Session-Discussion and Planning for Possible "Complete Radiation Experiment"}

Chairperson: Kinsell L. Coulson, Univ. of California, Davis, Calif.

\section{Introduction-1:30 p.m. to 2:30 p.m., Fri., June 30}

The need and possibilities for the initiation of a complete radiation experiment in the United States. J. A. Weinman, Univ. of Wisconsin, Madison, Wis.; and B. M. Herman, Univ. of Arizona, Tucson, Ariz.

The planning and conduct of the U.S. participation in the GATE program. S. K. Cox, Colorado State Univ., Ft. Collins, Colo.

\section{Discussion-2:45 p.m. to 4:30 p.m., Fri., June 30}

It is hoped that volunteers will present short 3 min sketches of their possible participation in a "Complete Radiation Experiment." If the prospects look favorable, a Steering Committee for initial planning of the experiment will be established.

\section{ABSTRACTS}

\section{Plenary session-Survey papers}

Methods and results in the retrieval of temperature profiles from satellite measurements

W. L. SMITH
During the past decade, rapid advances have taken place in both the instrumental and dataprocessing techniques for obtaining atmospheric temperature profiles from satellite soundings. For example, the first sounding spectrometer measurements were nonscanning, low-resolution $(225 \mathrm{~km})$ measurements confined to the $15 \mu \mathrm{m} \mathrm{CO} \mathrm{CO}_{2}$ band. The sounding measurement program has evolved to a system of radiometers that provide relatively high resolution $(25 \mathrm{~km})$, spatially scanning observations covering wavelengths between the visible $(0.7 \mu \mathrm{m})$ and the microwave $(0.5 \mathrm{~cm})$, and includes many spectral observations within the $4.3 \mu \mathrm{m} \mathrm{CO}_{2}, 15 \mu \mathrm{m} \mathrm{CO}$, and $0.5 \mathrm{~cm}$ $\mathrm{O}_{2}$ absorption bands. Additional "window" observations in the visible, near and intermediate infrared, microwave portions of the spectrum, and several water vapor channel observations are now provided to account for the effects of surface, cloud, and water vapor absorption on the temperature profiling radiance measurements. The associated data-processing techniques have evolved to achieve maximum utility of the data under all weather and geographical conditions. Recent developments in man-machine interactive sounding data processing enable rapid subjective editing and enhancement with high spatial resolution soundings in meteorologically active areas.

This paper reviews the evolution of the sounding methods with particular emphasis being placed on the observed characteristics of the variety of sounding radiance data achieved to date and their individual contributions to the current state of the art of the satellite temperature profiling technique. 


\section{Session 1: Radiative transfer in realistic atmospheres}

Atmospheric effects on high Abstract not available. energy laser beams

\section{B. HOGGE}

Effects of particulate complex refractive index and particle-size distribution variations on atmospheric extinction and absorption for visible through middle IR wavelengths

\section{S. G. JENNINGS AND}

\section{R. G. PINNICK}

The effect of cloud bimodal drop-size distributions upon the radiation field

\section{R. M. WELCH AND S. K. COX}

A comprehensive sensitivity study has been made, using Mie theory, to determine the effect of realistic variations in values of real and imaginary parts of the complex index of refraction on volume extinction and absorption coefficients for a wide range of realistic lognormal particlesize distributions (defined by geometric standard radius $r_{g}$ and geometric standard deviation $\left.\sigma_{g}\right)$. Wavelengths $\lambda$ from visible $(0.55 \mu \mathrm{m})$ through middle IR $(10.6 \mu \mathrm{m})$ were considered. Extinction is independent of complex index to within $20 \%$ for the majority of realistic bimodal particle-size distributions, providing $\lambda \leq 2 \mu \mathrm{m}$. However, variations in extinction by up to an order of magnitude are caused by realistic changes in real index at $\lambda=10.6 \mu \mathrm{m}$. Similar variations are caused by changes in particle-size distribution for values of complex refractive indexes typical of atmospheric constituents. Absorption is nearly linearly dependent on imaginary index $k$ for $k \leq 0.05$, providing size distributions have $r_{g} / \lambda \leq 0.1$ and $\sigma_{g} \leq 2$. For size distributions with parameters $r_{g} / \lambda \geq 0.5, \sigma_{g} \geq 2$, absorption is independent (to within $40 \%$ ) of $k$ for $k \geq 0.05$.

The present study investigates the effects of bimodal, trimodal, quadramodal, and "flat" dropsize distributions upon the radiative characteristics of water clouds. It is shown that either large drops or small drops alone cannot reproduce the large absorptivities found in measurements (Reynolds et al., 1975). Twomey (1976) shows that the maximum theoretical cloud absorptivity is $\sim 20 \%$ for a monomodal drop-size distribution. However, for a bimodal drop-size distribution, maximum cloud absorptivities are shown to be $35-40 \%$ in agreement with observations. Absorptivities of up to $8 \%$ are found in some cases of wavelengths $<0.7 \mu \mathrm{m}$. However, the predominant region of solar absorption is located in the water vapor bands. The results are rather insensitive to the choice of the large drop distribution function but are strongly dependent upon liquid water content and drop concentration. Cloud absorptivity, however, is also strongly dependent upon scattering (i.e., the concentration of small droplets). Increased scattering is shown to increase cloud absorptivity in the wavelength region $<0.7 \mu \mathrm{m}$ and to decrease absorptivity in the water vapor band region. Therefore, the present results show that the measurement of concentrations and sizes of both large and small cloud drops is necessary for an accurate determination of the cloud radiative characteristics.

Using the spherical harmonics method of solving the radiative transfer equation, the contributions to the sun's aureole, due to multiple scattering (MS), have been computed for different optical depths and solar zenith angles and wavelengths, and have been compared with the singlescattering (SS) contributions to determine the conditions under which SS approximation is valid in the inversion problem.

This paper discusses recent attempts at modeling the effects of air pollutants on visual range and atmospheric coloration and an appropriate formulation of the interaction of visible radiation and air pollutants. Recent federal legislation establishing visibility protection for certain areas of the country has emphasized the need for understanding the effects of air pollutants from both single sources and area sources on atmospheric radiation. To determine or to predict the effect of air pollution on visibility, one must know the dispersion and transport of the pollutants, the radiative properties of the pollutants and natural constituents, and the interaction of visible radiation and the pollutants. The results presented here show the effects of a power plant in the Southwest; under most conditions, nitrogen dioxide is responsible for the brownish coloration, but the sulfates formed downwind have a greater effect on visual range.

Radiation transfer problems in the atmosphere require Mie scattering functions. A technique has been developed to obtain Mie scattering functions for a sphere using continued fractions, which has significantly reduced the computer computational times. Results are presented with comparisons for $Q_{e}, Q_{s}, Q_{a}, Q_{b k s}$, and intensity as a function of angle for varying size parameters, $x=2 \pi r / \lambda$. Computer computational times for this method will be compared with current techniques. A brief discussion of the method and the circle of convergence will also be covered.
Continuous fractions vs. calculations

\section{T. Y. PALMER AND}

J. A. WATROUS 
Scattering by irregular particles of size comparable to a wavelength: A new semi-empirical theory

\section{J. B. POLLACK AND}

J. N. CUZZI

\begin{abstract}
A theoretical model for solar radiation transfer in a cubic cloud
\end{abstract}

\section{S. K. S. VARMA}

Visible flux variations across finite clouds

\section{F. R. MOSHER}

Computations of radiative fluxes in clouds: Application to cloud modeling

\section{Y. FOUQUART AND}

\section{J. J. MORCRETTE}

We have developed a new semi-empirical theory that effectively reproduces the single-scattering behavior of ensembles of irregular (nonspherical) particles with sizes comparable to the wavelength of the scattered light. The theory is based on simple physical principles and comparison with laboratory experiments. The net phase function contains contributions from both the Mie and the geometrical optics domain and is characterized by two parameters of physical significance. The method is described, and comparisons with published data, showing good agreement, are presented.

A theoretical model is presented for solar radiation transfer in a cubic cloud. The cloud consists of a homogeneous medium, which scatters the externally incident solar radiation and contains no internal emitters of radiation of thermal or other origin. A general case is considered in which the cloud absorbs and scatters the incident solar radiation. The intensity and the source function are expanded in associated spherical harmonics. Vacuum boundary conditions are employed to solve the radiation transfer equation in first approximation. Emergent fluxes and intensities from the cloud boundaries are presented.

The visible flux variations across finite clouds have been investigated using a three-dimensional geometric doubling approach. The fluxes scattered from an initial cuboidal finite cloud are determined using a Monte Carlo cloud model. The cuboidals are stacked together, buildingblock style, to form a larger finite cloud, and the interchange of fluxes between the cuboidals are then computed. The model results show a flux variation across the top of the cloud. The fluxes from the brighter parts of the cloud top are greater than average flux resulting from Monte Carlo simulations, but are dimmer then plane-parallel models would indicate. Inhomogeneities within the cloud, such as concentrations of water droplets, show up as bright spots. Features such as towers or depressions in the cloud top result in dark spots. The model is useful in the interpretation of cloud images obtained from spacecraft.

Recent models of the planetary boundary layer (PBL) with stratocumulus clouds show that radiative cooling is a major factor governing the cloud process. Moreover, the entrainment rate of dry air into the cloud is strongly dependent on this part of the radiative cooling, which is located in the inversion turbulent layer above the mean level of the cloud top. Thus, in order to parameterize stratocumulus clouds, there is a need not only for the total cloud radiative budget but also for the profile of the radiative fluxes inside the cloud layer.

In this way, a simple approximate method (extension of $p_{1}$ approximation) has been developed to compute the radiative inputs for a radiative dynamics PBL model. The method is presented, and some results about the dependence of net radiative fluxes on temperature and liquid water content profiles are shown. The influence of the drop-size distribution is also studied, and an approximate expression of the profile of the radiative fluxes is given.

The same technique enables the computation of cloud emissivities, which are presented as a function of the total liquid water content.

Calculations for IR radiative equilibrium under calm $(<8 \mathrm{mph})$ clear conditions were performed as a prediction of nighttime minimum temperatures. Heat conduction from the ground was parameterized, while turbulent mixing was neglected. Comparisons of predicted and observed temperatures will be presented.
Theoretical predictions of nighttime minimum temperatures using radiative equilibrium calculations

\section{R. L. GALL ET AL.}

Long-wave radiative transfer in the atmosphere

\section{S. K. GUPTA ET AL.}

A fast computational model has been developed for studying long-wave radiation transfer in the earth's atmosphere. Absorption bands of all the constituents active in the $5-50 \mu \mathrm{m}$ region, namely, water vapor, carbon dioxide, ozone, methane, and nitrous oxide, have been considered. A quasi-random band model has been used for computing transmittances of the bands. Continuum absorption by water vapor has also been taken into consideration. Integrated upwelling radiance at the top of the atmosphere $(30 \mathrm{~km})$ is evaluated as a function of the zenith angle of observation, surface temperature, and emittance. Sensitivity of the outgoing radiance to changes in water vapor and ozone burdens, cloud cover, and cloud altitude is examined. 
Comparison of the twoflux technique with an exact technique for computing atmospheric radiation in an absorbing, emitting, and scattering medium

\section{R. W. BERGSTROM}

Comparison of numerical models and observations of solar radiation at Nashville

\section{A. ATWATER}

Parameterization of reflection, absorption, and transmission of solar radiation by cloud layers

\section{K. N. LIOU AND \\ J. D. WITTMAN}

Effects of natural surfaces on the radiation emerging from planetary atmospheres

\section{B. W. FITCH}

Effects of a more realistic aerosol model on radiative transfer calculations

\section{A. SEAGRAVES}

AND R. B. GOMEZ

Retrieval of vertical aerosol and ozone extinction profiles from simulated multispectral limb extinction measurements
In many infrared problems, the flux in an absorbing, emitting, and scattering medium must be determined. Since the integration over frequency can be extremely lengthy, approximations are useful. This paper discusses the errors involved in a common approximate method known as the two-flux technique. The exact technique used was that of source function approach of Cogley (1975). For a nonemitting surface, the percentage of error in the flux is small for optical thicknesses $\mathrm{O}(0.1)$, it reaches a maximum at optical thicknesses $\mathrm{O}_{(}(1.0)$, and it decreases to an asymptotic value for large optical thicknesses. The maximum error in the flux, ranging from $<5 \%$ to $15 \%$, increases with single-scattering albedo and decreases with the scattering asymmetry factor. The error in the intensity depends on the zenith angle with the largest error $(\sim 40 \%)$ at grazing angles for anisotropic scattering. The effects of an emitting surface and an inhomogeneous temperature profile are also discussed. The results show that the method can be fairly accurate in specific situations, but relatively large errors can occur.

Solar radiation data are important in the design of solar energy systems. However, the available solar radiation data are sparse and often contain inaccuracies. The National Weather Service has "rehabilitated" the observations at a total of 26 sites to increase the accuracy of the basic data for solar energy systems. Several models have also been proposed to develop radiation statistics in the absence of solar radiation observation, including percent of sunshine models used in SOLCOST and a model based on cloud amount and type, developed at The Center for the Environment and Man, Inc. Monthly statistics are compared with results of the models and with both the observed and rehabilitated solar radiation data for 20 years at Nashville from the new SOLMET tape series.

Reflection, absorption, and transmission of solar radiation by six cloud types (low cloud, middle cloud, high cloud, nimbostratus, cumulonimbus, and stratus) are computed as functions of the solar zenith angle and cloud liquid water content. The plane-parallel radiative transfer program employed is based on the discrete-ordinate method with applications to inhomogeneous atmospheres covering the entire solar spectrum and taking into account the gaseous absorption in scattering atmospheres. The resulting reflection, absorption, and transmission values will be fitted with known mathematical functions involving the solar zenith angle and cloud liquid water content as variables. Effects of the atmospheric profile and surface reflectivity on the parameterization of cloud reflection and absorption properties will be investigated. The parameterized empirical-theoretical functions for the reflection, absorption, and transmission of solar radiation by various cloud types will be presented and discussed in conjunction with climatic studies.

The purpose of this study was to investigate the effects of natural surfaces on the radiation emerging from a planetary atmosphere. Laboratory measurements of the bidirectional reflectance of soil, desert sand, and white sand were used to calculate the reflection matrices of these surfaces. The use of the reflection matrices as boundary conditions enabled the study of the intensity and degree of linear polarization of radiation emerging from a plane-parallel pure molecular atmosphere and an inhomogeneous plane-parallel atmosphere. The adding method was employed to solve for the radiation emerging from the inhomogeneous atmosphere.

In addressing the technical barrier problems involved in the remote sensing of atmospheric parameters through the inversion of the radiative transfer equation, one needs first to address its direct solution. The aerosol models generally used in radiative transfer calculations vary only the particle number density with altitude. It has been suggested that the variation of the shape of the particle-size distribution with altitude is related to the variation of the relative humidity. We have obtained radiative transfer results using a more realistic aerosol model with a bimodal distribution and for which the complex refractive index of the particles and the shape of the size distribution were varied as functions of the relative humidity and wind speed over a range of wavelength values. The results are compared, where appropriate, with the theoretical results of others. Although the methods of this study are applicable in the visible and infrared, calculations are made only in the visible region so that comparisons with the work of others may be made.

Simulated multispectral limb extinction measurements are generated for the SAGE (Stratospheric Aerosol and Gas Experiment) project. Inversion techniques are then used to retrieve vertical profiles of aerosol and ozone extinction, as well as to set limits on acceptable noise levels for various sources of error.

\section{H. PHILLIPS ET AL.}


Study of limb transmission and emission modeling for stratospheric minor constituent measurements

\section{R. K. TALLAMRAJU AND S. R. DRAYSON}

The impact of atmospheric ozone variability on the accuracy of temperature profiles inferred from remote $13-15 \mu \mathrm{m}$ measurements

\section{R. L. WEICHEL}

The effect of surface anisotropy on the accuracy of total ozone estimates from satellite observations

\section{R. S. FRASER AND}

\section{Z. AHMAD}

Infrared radiative scattering from nonisothermal cirrus clouds with application to remote sensing

\section{A. C. COGLEY}

Remote sounding of the temperature profile and cloud thickness in cirrus cloudy atmospheres

H. Y. YEH AND K. N. LIOU

Removal of residual cloud contamination from radiance fields

\section{H. FLEMING AND M. HILL}

An inversion technique to infer stratospheric distribution of water vapor, ozone, and other constituents from limb radiance measurements is examined. The numerical model assumes linear variation of pressure and constituent mixing ratio between levels and uses the CurtisGodson approximation and the "quasi-random" band model for generating synthesized data. In the iterative algorithm, measurements at a few selected altitudes are used to first retrieve the overall shape of the profile. The fine structure in the profile is obtained in the final iteration using all tangent altitude measurements. The sensitivity to measurement and model errors and efficiency of the inversion scheme are examined.

The impact of atmospheric ozone absorption due to the $14 \mu \mathrm{m}$ band is investigated as a possible cause for the less than acceptable temperature profiles retrieved from remotely sensed $13-15 \mu \mathrm{m}$ measurements. Realistic atmospheric ozone variabilities are studied by retrieving temperature profiles from sets of simulated measurements that contain the isolated effects of various ozone concentration biases. The minimum information technique with climatological transmittance adjustments for ozone is used for inverting the simulated data. The impact is analyzed for nadir views and at a zenith angle of $60^{\circ}$.

The temperature errors, resulting from the ozone variations, are discussed in terms of the impact on thicknesses derived from the retrievals and as geostrophic wind speed errors. The effects of this source of error for operational and experimental applications are also discussed.

The total amount of ozone in a vertical column of the earth's atmosphere is being derived from satellite measurements of the spectral radiance within the Huggins band of $312-380 \mathrm{~nm}$. The algorithm for deriving the total amount of ozone is based on the assumption that the base of the atmosphere reflects light according to Lambert's law of isotropic reflection. Natural surfaces, however, such as those associated with seas, snow-ice, clouds, and some terrains, reflect ultraviolet light anisotropically. These surface characteristics have been incorporated in models of the earth-atmosphere system for computations of radiances to simulate observed values. The errors in the total amount of ozone resulting from such observations will be presented.

The combined radiative transfer methods of invariant imbedding and adding (doubling) are used to compute the emission from nonisothermal and inhomogeneous cirrus clouds that scatter in the infrared. Thermal scattering functions (Cogley, 1978) are used to characterize the radiative transfer from internal sources to the bounding surfaces of the plane-parallel cloud. The results are then used to discuss remote sensing of "surface" temperatures in the atmospheric window region when clouds are present.

In the presence of a single semi-transparent cirrus cloud layer, it can be shown that the spectral infrared upwelling radiance is given by

$$
\tilde{I}_{i}=\left\{B_{i}\left(T_{s}\right) \tau_{i}(\infty, 0)+\int_{0}^{z_{b}} B_{i}[T(z)] d \tau_{i}(\infty, z)\right\} \tau_{i}^{c} / \tau_{i}\left(z_{t}, z_{b}\right)+\int_{z_{t}}^{\infty} B_{i}[T(z)] d \tau_{i}(\infty, z),
$$

where $i$ denotes the channel number, $\tau_{i}$ represents the clear-column spectral transmittance, $z_{t}$ and $z_{b}$ are cloud-top and cloud-base heights, respectively, and other notations are conventional. The cloud transmittance $\tau_{i}{ }^{c}$ is parameterized in terms of the ice crystal extinction coefficient and cloud thickness. On the basis of this parameterized equation, a modified relaxation method has been developed for the retrieval of the temperature profile and cloud thickness simultaneously in cirrus cloudy atmospheres. Seven NOAA-4 VTPR channels, including six in the $15 \mu \mathrm{m} \mathrm{CO} \mathrm{CO}_{2}$ band (for temperature iterations) and one in the window (for cloud thickness iterations), have been utilized in the preliminary investigation in which the cloud-base height and extinction coefficient are prescribed. Employing a number of synthetic cirrus cloudy atmospheres without introducing random errors in the upwelling radiance, errors in the temperature profile and cloud thickness retrieval have been shown to be within $\sim 1 \mathrm{~K}$ and $0.01 \mathrm{~km}$, respectively, for a cloud thickness $<1 \mathrm{~km}$. Verifications and applications of the present retrieval program will be carried out using the actual Nimbus-6 HIRS data for selected cirrus cloudy conditions during the period of 20-30 August 1975.

When deducing vertical atmospheric temperature profiles and surface temperatures from satellite measurements of infrared radiance, one first must remove cloud effects from the radiance data. However, even the best algorithms for removing cloud effects retain either isolated points or isolated clusters of points that have residual cloud contamination. The standard procedure for correcting these bad points is to apply global smoothing techniques such as spline smoothing. 
A general solution to the clear radiance problem

\section{M. MCMILLIN}

An algorithm for optimizing the information content of radiation field measurements in the presence of multiple scattering

\section{B. R. BARKSTROM AND D. M. STEPHENSON}

Wind speed and aerosol optical thickness estimates from aircraft observations of sea glitter

\section{Z. AHMAD ET AL.}

However, since these techniques smooth all the points, the bad data contaminate the good data. In this paper, we present an alternative method that locates and corrects the bad data without affecting the good data. This method is based on the idea that when the calculus of finite differences is applied to equally spaced data, the errors are greatly magnified in the higher differences, while the higher differences of the correct data approach zero. After describing the algorithm, we demonstrate the technique on radiance data from the Vertical Temperature Profile Radiometer (VTPR) instrument and the Scanning Radiometer (SR) instrument. The method has wide applicability to other kinds of meteorological data sets as well and generalizes from one to any number of dimensions.

In the early stages of the development of methods for deriving temperature soundings from satellite measurements, considerable effort was devoted to the procedures used to obtain temperature profiles from radiances. As a result, many of the problems in this area have been solved and the characteristics and interrelationships of the various solutions are now understood. However, the problem of attenuation of infrared measurements by clouds has not received as much attention, and errors due to clouds are now the major limitation to achieving the accuracy that is desired. Recently, more effort has been devoted to the clear radiance problem, and several solutions have appeared. These solutions propose using more than two scan spots to account for multiple cloud layers or using eigenvectors as a constraint.

A completely general solution to the cloud problem is presented. This solution demonstrates the relationships between the various algorithms. An important finding is that presently known techniques fail to take advantage of all of the desirable features that are at our disposal. A clear radiance algorithm that combines all the desirable features is presented. The new procedure is compared to existing techniques using simulated data.

Although instrumental error contaminates measured quantities, other uncertainties may also cause errors in remotely sensed data. For example, lack of knowledge regarding the ozone profile or the precise form of reflectance from the earth's surface may create large uncertainties in our estimates of aerosol concentration profiles from reflected sunlight. This paper discusses an algorithm that has been implemented to optimize the free parameters of an observing system to gain information about a quantity of particular interest, even in the presence of uncertainty about the other quantities that may influence the radiation field.

In order to use the optimization algorithm, both the radiation field and its derivatives with respect to uncertain quantities must be available. In the case of pure absorption problems, these derivatives are essentially the usual weighting functions. However, in the presence of multiple scattering, the derivatives must be computed numerically. For our implementation of the optimization, the radiation field and its derivative are calculated using the finite difference method, which includes all orders of multiple scattering and handles thick and thin inhomogeneous atmospheres without difficulty.

Our discussion will be particularly directed toward the sensing of tropospheric aerosols, including the effects of such interfering species as ozone, water vapor, and $\mathrm{CO}_{2}$.

The aerosol optical thickness of the carth's atmosphere and the surface wind speed are derived from aircraft measurements at $754 \mathrm{~nm}$ of the characteristics of the bright glitter pattern formed by the sunlight reflected from the ocean. The method used is to vary radiative transfer model parameters until the computed and measured values agree.

Herman's radiative transfer code, based on numerical integrations over optical thickness, polar angles, and azimuth angles, is modified to compute the Stokes vector of the scattered light, when the base of the atmosphere is bounded by a rough sea surface. The surface reflection matrix is based on the Cox-Munk theory of reflection from the sea. The computed intensity is in good qualitative agreement with those obtained by Plass, Kattawar, and Guinn who utilize a Monte Carlo technique. The aerosol optical thickness and variance of the surface slopes are the two principal variables in our model to obtain agreement between measured and computed radiances. The wind speed is linearly dependent on the variance, and it is $9.3 \mathrm{~m} \mathrm{~s}^{-1}$; the derived aerosol optical thickness is 0.42 . The wind speed agrees within $1 \mathrm{~m} \mathrm{~s}^{-1}$ of the measured value, but no other observation of the optical thickness was made.

\section{Session 2: Instrumentation and measurements}

Polarizing radiometer calibration

\section{R. WALRAVEN}

Two high-precision, computer-controlled, polarizing radiometers have been used for several years by the University of California at Davis to measure skylight polarization. Procedures for calibrating these two instruments will be presented, including a discussion of the dead-time correction for the photon counting system, linearity of the measured intensity and polarization, and angular intensity and polarization response. 
Weighting functions for the TIROS-N HIRS/2 sounder

\section{A. ARKING ET AL.}

On twilight polarization

W. G. BLATTNER

Effects of clouds and precipitation on Nimbus-6 SCAMS channels

\section{K. N. LIOU ET AL.}

\section{Solar radiation} measurements from Nimbus-6

\section{J. R. HICKEY}

Angular scattering of polarized laser light by water droplet and ice crystal clouds

K. SASSEN AND K. N. LIOU
Transmittances and weighting functions for the infrared sounding channels of the TIROS-N high-resolution infrared radiation sounder (HIRS/2) have been calculated for the U.S. standard atmosphere using line-by-line methods. For extending the calculations to other model atmospheres, a fast but accurate routine has been coded, based upon previously reported methods (Arking, 1976; Chow and Arking, 1978). Inversions with simulated data show the need for updating the transmittances as one processes data, in order to account for the effects of temperature and humidity on the transmittance. Tests of the above routine show that it provides adequate accuracy with reasonable speed for volume processing of satellite data.

Monte Carlo methods have been used to compute radiation transport in spherical-shell atmospheres. Several studies have been made that consider multiple scattering of the dependence of the sky polarization on wavelength and aerosol content. Calculations were performed for several model atmospheres in order to interpret measurements with respect to dust layers in the atmosphere. Some additional Monte Carlo calculations were accomplished in an attempt to achieve understanding of the second peak of the sky polarization for sun depression angles of $\sim 9^{\circ}$ and $10^{\circ}$.

The Nimbus-6 scanning microwave spectrometer (SCAMS) is a five-channel radiometer consisting of a water vapor line at $22.23 \mathrm{GHz}$, an atmospheric window at $31.65 \mathrm{GHz}$, and three channels $(52.85,53.85$, and $55.45 \mathrm{GHz})$ within the $60 \mathrm{GHz}$ oxygen band. The radiative transfer program developed at the University of Utah has been modified and applied to the microwave regions. We have investigated the effects of clouds and precipitation on these channels in conjunction with the possible cloud liquid water and rainfall rate determination from the brightness temperature observations. The SCAMS data and some corresponding profile analyses that are available cover the period of 20-30 August 1975 with a geographical coverage of $80^{\circ}-150^{\circ} \mathrm{W}$ and $20^{\circ}-50^{\circ} \mathrm{N}$. Cases involving cirrus with nonprecipitating and precipitating clouds, nonprecipitating low clouds, and rainfall have been selected for the simulation of the brightness temperature in the five SCAMS channels. Influence of clouds and precipitation on these channels will be examined from the radiative transfer point of view. Techniques for the estimate of the liquid water content and rainfall rate based on microwave transfer investigations will be presented and discussed.

The subject of this paper is the description of the solar radiation measurements from the earth radiation budget experiment (ERB) on the Nimbus-6 satellite. These measurements started on 2 July 1975 and are continuing at this time (January 1978). The primary solar channel has detected that the solar variability over this time period has been less than $\pm 0.15 \%$. The absolute value, which was originally measured as $1392 \mathrm{~W} \mathrm{~m}^{-2}$, has been corrected to $1367 \mathrm{~W} \mathrm{~m}^{-2}$ as a result of a rocket underflight. All of the remaining channels, which contain spectral filters and sense over the range from $0.25 \mu \mathrm{m}$ to $5.0 \mu \mathrm{m}$, have degraded over the course of the mission. The data for all channels have been corrected for these degradation effects and will be presented. At the time of this abstract, the data through October 1976 only are available. It is expected that all corrected data through December 1977 will be available by the time of the conference. The corrections applied to the data for 1) degradation, 2) off-axis viewing, 3) temperature effects, and 4) ephemeris-related considerations will be described.

Described are the results of laboratory studies of the angular scattering behavior of water droplet and ice crystal clouds. The measurement has been performed using a linearly polarized laser source and a polar nephelometer designed to monitor the scattered intensities in the vertical and horizontal polarization planes simultaneously through scattered angles from $10^{\circ}$ to $175^{\circ}$. Angular scattering patterns for water droplet clouds obtained with vertically and horizontally polarized incident laser light show good agreement with the results predicted by Mie theory, with the actual cloud droplet-size distributions measured during the experiments as input into the computations. Angular scattering patterns for ice crystal clouds display significant differences from those for spherical scatterers, most notably in the presence of considerably more intense side scattering and in the absence of cloud bows. These differences become particularly apparent in successive scans of clouds that gradually changed from primarily ice- to water-particle compositions. Scattering theory results using the long cylinder shape approximation are more appropriate for comparison to ice crystal cloud scattering than the results from spherical particles, but still fail to adequately predict the experimental measurements from ice clouds.

From the analysis of the polarization properties of the scattered energy, the generation of some slight depolarization is shown to result from multiple scattering activity with cloud droplet assemblies, while significant depolarization is generated in the back- and side-scatter directions through the multiple internal reflections involving the nonspherical ice crystals. 
Infrared measurement over cirrus clouds in the 10.5$12.5 \mu m$ and $6-7 \mu m$ regions

\section{G. SZEJWACH}

Classification of clouds for the Nimbus satellite ERB experiment using THIR data

\section{L. STOWE ET AL.}

A cloud physics radiometer

H. L. KYLE ET AL.

Infrared remote sensing and radiative transfer in wind shear detection

\section{P. M. KUHN ET AL.}

Remote sensing of the boundary layer over the oceans

\section{PRABHAKARA ET AL.}

Optimum interpolation of radiosonde and satellitederived temperature fields

\section{Y. P. YEE AND}

T. H. VONDER HAAR
Abstract not available.

It is desirable to know the amount and type of cloud within each ERB (earth radiation budget) scanning channel field of view. This paper describes an investigation into the use of the Nimbus satellite THIR (temperature/humidity infrared radiometer) $11 \mu \mathrm{m}$ window and $6.7 \mu \mathrm{m}$ water vapor absorption channels for this purpose.

An existing passive cloud physics radiometer (CPR), of a design suitable for space flight, will be briefly described, and some results will be shown for a series of aircraft flights in the summer of 1976. In addition, a proposed cloud climatology and radiation budget experiment combining the CPR with a cloud lidar system and an orbital plane radiation budget radiometer will be outlined.

The six-channel CPR instrument is designed to obtain the following six cloud parameters: scattering optical thickness, cloud-top altitude, thermodynamic phase, temperature, volume scattering coefficient, and water vapor amount. Cloud-top temperature is obtained from an $11 \mu \mathrm{m}$ channel, while five near-infrared channels from $0.754 \mu \mathrm{m}$ to $1.64 \mu \mathrm{m}$, sensing reflected solar radiation, are used to obtain the other five parameters. Four of these parameters (scattering optical thickness, cloud-top temperature, altitude, and thermodynamic phase) have been successfully retrieved from the 1976 data, and results will be shown. Algorithms to retrieve the cloud-top volume scattering coefficient and water vapor amount are still under development.

Climate can be very sensitive to changes in cloud amount and/or type. Therefore, a special study is proposed in which an earth radiation budget instrument would be flown in conjunction with the CPR and a cloud lidar system. The passive CPR is not effective with thin cirrus clouds, which may be of considerable climatological importance. Therefore, it should be operated in conjunction with a lidar system for optimal results. The proposed radiation budget instrument is of a new design, and the proposed package will give much more detailed and valuable earth radiation budget and climate information than present and planned instruments.

An airborne radiometer system, sensing in two or more bands of the carbon dioxide portion of the electromagnetic spectrum, is developed to provide in-flight alerts of subsequent hazardous, vertical wind shear during glide path approach. The development of the system was based upon radiative transfer calculations of the horizontal transfer of radiant power in selected intervals of the $\mathrm{CO}_{2}$ pass band. The noise equivalent radiance of the radiometer is $2.5 \times 10^{-\tau} \mathrm{W} \mathrm{cm}^{-2} \mathrm{sr}^{-1}$. Filters were selected by horizontal weighting to sense cold, shear-producing "downbursts" at ranges of $0.4,3.0$, and $13.0 \mathrm{~km}$. The radiometer system readily detects low-temperature cores only $400 \mathrm{~m}$ wide and $<1.5 \mathrm{~K}$ below ambient temperature.

Remote infrared spectral measurements in the water vapor $9 \mu \mathrm{m}$ window region, at a resolution of $\sim 3 \mathrm{~cm}^{-1}$, contain useful information about the temperature and water vapor vertical stratification of the atmosphere within the first $2 \mathrm{~km}$ above the water bodies. The water vapor lines in the $9 \mu \mathrm{m}$ region are strong over water bodies where a deep moist convective layer with nearadiabatic vertical temperature gradients prevail in the lower layers of the atmosphere. These lines are weak when the convection is inhibited by stable conditions such as temperature inversions in the lower layers of the atmosphere.

A simple infrared radiative transfer model of the $9 \mu \mathrm{m}$ water vapor lines is developed to delineate regions of oceans according to the stability of the boundary layer with the help of Nimbus-4 infrared interferometer spectral measurements. The important regions of trade wind inversion and the intertropical convergence zones over all the oceans are clearly mapped with this method.

An optimum interpolation scheme that interpolates temperature measurements to a specified mesoscale network of grid points is proposed. The analysis incorporates conventional synopticscale radiosonde observation at 0000 GMT for 31 consecutive days in May 1976 and VTPR satellite-derived temperatures for a particular case study day. Structure functions were determined from the statistical nature of the $700 \mathrm{mb}, 500 \mathrm{mb}$, and $300 \mathrm{mb}$ temperature fields for this period. From these meteorological field samples, normalized autocorrelation and normalized 
mutual-correlation functions for the raobs and satellite-retrieved temperatures were calculated assuming general isotropic and homogeneous conditions over the region. Root-mean-square instrumentation errors were estimated by fitting the unnormalized structure function to a linear regression curve to find the zero distance intercept. By applying the smoothed correlation functions, the mutual correlation functions, and the instrumentation errors to a simultaneous set of algebraic equations, the associated $\mathrm{RAOB}$ and satellite weighing factors for each grid point were computed. This study matches the vertical resolution of the radiosonde data to the horizontal resolution of the satellite radiance retrievals to produce a statistically better objective analysis.

A structure function analysis of mesoscale satellite infrared soundings

\section{W. HILLGER AND}

T. H. VONDER HAAR

A statistical technique for determining rainfall over land using Nimbus-6 ESMR measurements

\section{E. RODGERS ET AL.}

Differential insolation and turbidity measurements

\section{N. S. LAULAINEN ET AL.}

A statistical analysis of satellite infrared radiances and retrieved temperatures was performed following the ideas outlined by Gandin (1963). Both structure functions and correlation functions were used to analyze the information content of satellite soundings on the mesoscale. Radiances from all eight VTPR (vertical temperature profile radiometer) channels were analyzed for the period 10 May-12 June 1976. In a similar manner, the retrieved temperatures and moisture were analyzed. The structure functions and correlation functions were then compared to similar results calculated for the 1976 NSSL (National Severe Storms Laboratory) sounding period. Differences between the structure and correlation functions can be attributed to inherently different vertical averaging depths for the two instruments.

When analyzed on a daily basis, the structure functions signify mean daily temperature and moisture gradients. Days with the largest changes in structure with distance for radiances and temperatures are the most likely days for significant weather events. Conventional soundings can supply the same information, but the VTPR radiances for channels 6 and 7 can also detect such gradients without the aid of conventional data.

At $37.0 \mathrm{GHz}$, the frequency at which the Nimbus-6 electrically scanning microwave radiometer (ESMR-6) measures radiance, it has been shown theoretically that the scattering and the relative independence of polarization of the hydrometeor make it feasible to monitor rain over land areas using remote sensing techniques. To verify these theoretical findings, ESMR-6 digitized data were statistically examined.

The Bayesian classification technique was used to derive algorithms to detect rain over land from that of wet and dry ground. The training data were composed of the ESMR-6 measured horizontally and vertically polarized brightness temperature of wet ground, dry ground, and rain over land, as determined from radar- and rain-recording stations. These observations were obtained over the southeastern United States during the daylight hours where surface temperatures were $>5^{\circ} \mathrm{C}$.

The results of the Bayesian classification show that the chances of misclassifying rain over land as wet or dry ground was $\sim 10 \%$. These algorithms were tested for an independent case during the daylight hours of 14 September 1976 over the southeastern United States. The area of rain over land as depicted by radar-and ground-recording stations coincided with a $70 \%$ confidence with the rain areas that were classified from the algorithms.

An experiment to examine differential turbidity effects on measured insolation at the surface was conducted during summer 1977 using several types of solar radiation instruments at the Rattlesnake Observatory (RSO) at $1090 \mathrm{~m} \mathrm{msl}$ and at the Hanford Meteorological Station (HMS) at $220 \mathrm{~m} \mathrm{msl}$. The instrumentation included a precision spectral pyranometer, several portable field pyranometers, two multiwavelength sunphotometers, and an active cavity radiometer. Nearly simultaneous observations were made frequently at both observing sites. Periodically (about once per month), the instruments were intercompared at the same location. Results are presented that show dramatic temporal variability of aerosol loading at HMS and significant isolation and turbidity differences between RSO and HMS. Ratios of measured to maximum insolation and the measured turbidities are examined for correlations. Although some difficulty was encountered in maintaining the calibration of a few of the instruments, this experiment demonstrated the usefulness of measuring insolation and turbidity simultaneously.

A sunphotometer and associated software have been developed for detailed monitoring of aerosol and water vapor events. The instrument features automatic, unattended operation with frequent sampling and recording to capture the transient, unexpected events that can occur in urban and other studies. Associated software provides a set of efficient procedures for reducing and analyzing the large volumes of collected data.

Eight of the sunphotometer's 12 chamels are defined by narrow-band interference filters. The filter locations span the near-ultraviolet to near-infrared spectrum at wavelengths not affected by major atmospheric gaseous absorbers. An exception is the $0.942 \mu \mathrm{m}$ channel, which is used to measure water vapor optical thickness. The remaining four channels use glass cut-off filters. 
The sunphotometer uses an individual semiconductor diode and filter for each channel, rather than the rotating filter wheel and single detector that have been employed in some previous designs. The new arrangement permits the output of all channels to be sampled and recorded rapidly (in $<2 s$ ) in order to document transient events.

When operating in the field, the sunphotometer is mounted on a preprogramed sun tracker. Incoming radiation is mechanically chopped by a shutter, to permit alternating measurements of the full sun and dark current outputs of each channel. This permits measurement of signalto-noise ratio and subtraction of dark current before data analysis. A temperature-controlled heater maintains the detectors and filters at a constant temperature, thus preventing variation in detector sensitivity and filter characteristics. Each sensor channel is periodically recalibrated using a lamp with calibration traceable to NBS.

The sunphotometer is interfaced to a digital data system and a magnetic tape recorder for automatic data recording in the field. Outputs are usually sampled every $1 \mathrm{~min}$ or $2 \mathrm{~min}$, at a scan rate of 10 channels per second. The shutter position and temperature signals are included in the data scan and recorded along with the detector outputs.

Off-line computer programs perform least-squares Langley-plot analyses on each channel and derive optical depth as a function of time, with automatic correction for Rayleigh scattering (and ozone absorption, if desired). Other programs derive water vapor column content and aerosol-size distribution parameters for each time of interest. A variety of methods are available for the aerosol-size distribution analysis, ranging from the Angström-Junge-Volz slope method to a complete matrix inversion. Examples of results obtained in field studies are shown.

Determination of aerosol characteristics by photographic solar aureole measurements

\section{A. DEEPAK ET AL.}

Vertical inhomogeneity in atmospheric fog and haze and its effects on IR extinction

\section{R. G. PINNICK ET AL.}

Atmospheric turbidity determinations by skylight measurements at the Mauna Loa Observatory

\section{K. L. COULSON}

Description of a spectral atmospheric radiation monitoring network

\section{MARTIN AND P. BERDAHL}

This paper describes the results of the photographic solar aureole measurements made in May 1977 during the University of Arizona Aerosol and Radiation Experiment to determine aerosol characteristics. Comparison of the multispectral measurements of almucantar radiance with those obtained, simultaneously, with the photoelectric scanning device shows excellent agreement. Aerosol characteristics determined by the inversion of solar aureole data are compared with the ground-truth measurements.

Vertical structure of the size distribution and number concentration of particulates in atmospheric fog and haze near Grafenwöhr, West Germany, were measured with a tethered balloonborne, light-scattering aerosol counter for periods spanning parts of 8 days in February 1976. For haze $(\approx 15 \mathrm{~km}$ visibility) conditions, little vertical variation is seen, but for low visibility $(<1 \mathrm{~km})$ fog conditions, significant vertical increases in concentration of particles with radii $>4 \mu \mathrm{m}$ are seen over the first $150 \mathrm{~m}$ altitude. For haze, the particle-size distribution is approximated by a lognormal with geometric mean radius $r_{g} \approx 0.2 \mu \mathrm{m}$ and geometric standard deviation $\sigma_{g} \approx 1.9$. For fog, a bimodal distribution is found with a relative maximum for the larger particle mode at radii of $4-6 \mu \mathrm{m}$ and corresponding values $r_{g} \approx 5 \mu \mathrm{m}$ and $\sigma_{\mathrm{g}} \approx 1.6$. Liquid water content values for haze and fog range from $10^{-4} \mathrm{~g} \mathrm{~m}^{-3}$ to $0.45 \mathrm{~g} \mathrm{~m}^{-3}$. Extinction inferred from the particle-size distributions shows an approximate $1 / \lambda$ wavelength dependence for haze conditions, but nearly neutral (wavelength independent) extinction for heavy fog. At a definite wavelength, determined by the radius of the largest droplets present, it is shown that there is a unique linear relationship between extinction coefficient and liquid water content, independent of particle-size distribution.

An extensive series of measurements of the intensity and polarization of light from the sunlit sky was made at an altitude of $3460 \mathrm{~m}$ at the Mauna Loa Observatory, Hawaii, during the period February-June 1977. The data show that skylight polarization is a sensitive indicator of atmospheric turbidity at Mauna Loa. Reflection of sunlight by the usual low-level clouds surrounding the island also has a significant effect any time the clouds are illuminated by the direct solar beam. Measurements indicate, however, that for the near infrared wavelengths, cloud reflection effects are very minor during periods of twilight, and that the polarization of skylight under these conditions is mainly a function of aerosol content of the atmosphere. It is suggested that the installation and use of a two-wavelength polarimeter at the Mauna Loa Observatory would be a simple and effective method of monitoring high altitude turbidity over Hawaii.

The feasibility of using direct radiative cooling to replace or supplement refrigerative air conditioning systems depends largely on the atmospheric infrared radiation characteristics of a given location. Spectral information is desirable in order to assess the effects of using different spectrally selective radiating surfaces. Such data have not until now been recorded as part of a routine measurement program. Four infrared radiometers have been adapted for unattended field operation and are scheduled to collect data through the summer of 1978. The instruments 
are designed around a Barnes model 12-880 radiometer with an eight-position filter wheel. Filters have been selected to provide coarse spectral resolution of the atmospheric radiation in the $7-14 \mu \mathrm{m}$ region. Readings from each of the eight channels are recorded at $\frac{1}{2} \mathrm{~h}$ intervals and are stored in the random access memory of an on-site microcomputer, which also controls filter positioning, calibration by means of an external blackbody reference cavity, and timing of the measurements. A MODEM telephone link permits interrogation and analysis of the gathered data on a day-to-day basis. Preliminary measurements will be presented.

Measurement and modeling of shortwave radiation incident on inclined surfaces

\section{J. E. HAY}

Since November 1976, integrated hourly values of the following shortwave radiation fluxes have been measured at both Toronto, Ont., and Vancouver, B.C.: normal incidence direct, diffuse and total for a horizontal surface, total reflected, and total on south-facing surfaces inclined at $30^{\circ}$, $60^{\circ}$, and $90^{\circ}$ to the horizontal. Short-term measurements of the total shortwave radiation incident on a vertical north-facing surface have also been made at Vancouver.

Comparisons of the observed inclined surface values with those calculated using published numerical techniques have shown the need to develop a model that provides more accurate estimates of the diffuse radiation incident on the inclined surface. Subsequent work has met this requirement by varying the anisotropy of the diffuse radiation from the sky hemisphere according to the transmissivity of the atmosphere to direct shortwave radiation. The observed data have been used to show not only the superior performance of this anisotropic model when determining the radiation incident on an inclined surface, but also its application to the development of a more realistic form of the correction factor, which is required when making measurements of diffuse radiation with a shade ring.

The objective of an earth radiation energy budget monitoring system is the determination of the fluxes of outgoing and incoming radiation energy at the top of the atmosphere. In addition to the globally integrated fluxes, there is a requirement for fluxes on a horizontal scale of 500$1000 \mathrm{~km}$. Wide angle measurements at typical satellite altitudes $(600-1500 \mathrm{~km})$ provide a true measure of flux, but for fields of view several thousand kilometers in diameter. (Even at the extremely low altitude of $600 \mathrm{~km}$, more than half the energy comes from outside a circle of $1000 \mathrm{~km}$ diameter.) Medium angle measurements can meet the horizontal resolution requirements, but do not provide a true measure of outgoing flux. Narrow angle measurements yield intensity, which can be integrated to provide fluxes at the required horizontal resolution, provided that the angles of outgoing radiation are adequately sampled. The relative merits of the three measurement schemes will be compared using angular distribution models derived from TIROS-4 and -7 MRIR visible channel measurements to represent the angular distribution of solar radiation scattered from the earth and its atmosphere.

A technique is presented where man interacts with computer for specifying cloud heights from $\mathrm{CO}_{2}$ channel radiance data. The computer algorithm is based on the $\mathrm{CO}_{2}$ absorption method, which allows cloud pressure to be determined from the ratio of the deviations in cloud produced radiances and the corresponding clear air values for two spectral channels. Man's role in the processing is to select the proper cloud-covered and neighboring clear air fields of view necessary for the cloud pressure computation. Man can also quality control the end results.

Sample results are presented that are obtained from the application of this technique on Nimbus-6 data using the University of Wisconsin McIDAS (Man-computer Interactive Data Access System). Verifications based on conventional radiosonde, radar, and aircraft reports are presented to demonstrate the viability of the results.

\section{Session 3: Radiative energy budgets}

Earth-atmosphere radiative heating based on NOAA scanning radiometer measurements: Review of a 4-year record

\section{J. S. WINSTON}

Estimates of outgoing long-wave radiation and reflected solar radiation based on scanning radiometers aboard the NOAA satellites have been produced on a global basis continuously since June 1974. Monthly, seasonal, and annual means of these data have been examined over various parts of the globe, particularly with respect to interannual variations. Many of these year-to-year differences are relatively small and cannot be distinguished from some long-period biases in the data. In general, however, the geographical patterns of differences are very coherent and are undoubtedly representative of meaningful fluctuations in the radiative energy budget associated principally with variations in cloudiness, snow, and ice. Some specific yearto-year fluctuations over the tropical and subtropical oceans, Asia, and North America are illustrated and discussed. 
On the determination of synoptic-scale radiative fluxes from ERB narrowangle directional observations

\section{H. JACOBOWITZ ET AL.}

The first 18 months of planetary radiation budget measurements from the Nimbus-6 ERB experiment

\section{H. JACOBOWITZ ET AL.}

The effect of measured angular variability of reflected and emitted radiance on WFOV earth radiation budget measurements

\section{G. G. CAMPBELL}

Large-area representations of radiative divergence from $G A T E$

\section{S. K. COX AND \\ K. T. GRIFFITH}

Initial determinations of GATE surface and top-ofatmospheric radiative energy budget with atmospheric heating considerations

\section{C. LORANGER ET AL.}

Accurate calculations of fluxes and cooling rates using emissivities

\section{J. A. COAKLEY, JR., AND}

B. P. BRIEGLEB
Selected angular distributions of reflected and emitted radiation from various geographical areas, including the influence of clouds, are presented, derived from Nimbus-6 ERB (earth radiation budget) scanning channel data. Techniques are discussed for deriving mathematical models from the observed angular distributions, as well as the utilization of these models to obtain synoptic-scale radiative fluxes.

The Nimbus-6 satellite earth radiation budget (ERB) experiment has continuously monitored the solar radiation input and the reflected shortwave and emitted long-wave radiation exitance from the earth-atmosphere system since July 1975. In this paper, the planetary radiation budget parameters observed during the first 18 months in orbit (July 1975-December 1976) are presented. The results show that the annual mean planetary albedo and long-wave radiation flux are $31 \%$ and $234 \mathrm{~W} \mathrm{~m}^{-2}$ (radiative equilibrium temperature of $254 \mathrm{~K}$ ), respectively. The earthatmosphere system is observed to be in complete radiation balance over a 1-year period to within the experimental error of observation. There is an annual cycle of the mean monthly planetary net radiation, which is due predominately to the annual cycle of incoming solar radiation caused by the time variation of earth-sun distance and the sun's declination. Monthly variations in outgoing long-wave radiation due to variation in global cloudiness and snow and ice cover are generally compensated by the simultaneous variations in the planetary albedo so that there is generally little monthly variability of the total radiation to space compared to that of the net radiation.

Large regional composites of the scanner measurements of the Nimbus-6 earth radiation budget experiment have been examined for August 1975. The effect of the angular variability on wide field-of-view integrating sensor measurements is estimated by a direct comparison of the WFOV and scanner results and from the structure of the reflection and emission patterns. Due to the axial symmetry of the emitted flux, top-of-the-atmosphere emitted flux can be estimated to meet most requirements for climate studies from WFOV measurements by a deconvolution or height rectification. Estimation of the top-of-the-atmosphere albedo from the WFOV sensors meets fewer scientific requirements because of the poorer spatial resolution possible.

Subsynoptic fields of radiative divergence constructed from multiple data sources applied to radiative transfer calculations will be presented. The effect of large solar absorption in uppertropospheric clouds previously reported by Griffith and Cox will be examined and shown, on some occasions, to completely compensate for infrared cooling. A complete diurnal cycle of both solar heating and infrared cooling of the entire troposphere, including effects of diurnal cloud variations, will be presented for several specific meteorological cases. These daily budgets will also be compared to climatological estimates of the same components given in previous studies.

Surface and top-of-atmosphere (satellite-derived) radiative energy budgets for selected case study days in the 1974 GARP Atlantic Tropical Experiment (GATE) have been obtained. Instantaneous and diurnal variations of shortwave (SW) and long-wave (LW) components and net (N) radiation comprise the initial results. The high temporal frequency radiation budget determinations have not been available from earlier studies. GATE B-scale fixed ship hourly averaged radiation measurements form the data base for GATE surface radiation budgets. Twicedaily top-of-atmosphere budgets are obtained using NOAA-2 scanning radiometer (SR) radiation measurements. The NOAA-2 SR "visible" channel $(\sim 0.5 \rightarrow 0.9 \mu \mathrm{m})$ has been calibrated, and a bidirectional reflectance model has been applied to obtain the incoming shortwave energy component. Various analogs are applied to the NOAA-2 "window" channel $(\sim 10.2 \rightarrow 12.8 \mu \mathrm{m})$ measurements to obtain the terrestrial outgoing long-wave energy. Hourly satellite-derived radiation budgets are obtained for GATE using SMS-1 radiation data. The SMS-1 "visible" channel has been calibrated using the calibrated NOAA-2 visible data and a colocation-correlation method utilizing nearly simultaneous NOAA-2 and SMS-1 digital radiation data. Selected surface and topof-atmosphere budgets, in terms of both spatial and temporal variation, along with some inferences as to atmospheric heating rates and effects on atmospheric dynamics will also be presented.

It has been recognized that cooling rates and fluxes calculated using emissivities for water vapor can differ substantially from those obtained using band models. The magnitudes of the differences are sufficiently large (cooling rate errors $>10 \%$ and flux errors $>1 \%$ ) that the usefulness of emissivities in general circulation models has been questioned. In principle, cooling rates and fluxes obtained using emissivities should agree exactly with those obtained using band 
Analytic infrared transmissivities and infrared cooling rate of the atmosphere

\section{H. L. KUO}

Numerical radiation cooling rates using various rawinsonde densities during IFYGL

\section{A. ATWATER} AND J. T. BALL

Solar radiation reaching the ground determined from meteorological satellite data

\section{J. S. ELLIS AND T. H. VONDER HAAR}

Preliminary results of the impact of reflection on irradiation in mountainous terrain

\section{DIRMHIRU ET AL.}

Albedo climatology analysis and the determination of fractional cloud cover

\section{R. J. CURRAN ET AL.}

On the effects of cumulus dimensions on long-wave irradiance and heating rate calculations

\section{R. G. ELLINGSON AND E. KOLCZYNSKI}

models. The agreement is lost, however, when approximations are invoked to simplify the emissivity parameterization. Often it has been assumed that the water vapor absorption lines are in a strong line regime and that the temperature dependence of their strengths and halfwidths can be ignored. We find that while the errors caused by the strong line approximation are acceptably small, the errors caused by ignoring the temperature dependence of the strengths and half-widths can cause cooling rate errors of as much as $20 \%$ in the troposphere and flux errors of as much as $5 \%$ at the earth's surface. We also find that the absorption spectrum of water vapor may be divided into two segments, one for which the absorption is rather insensitive to temperature and the other for which the absorption exhibits a common temperature dependence. By allowing for the temperature dependence of the temperature sensitive segment, the errors in the fluxes and cooling rates calculated using emissivities are substantially reduced.

The generalized absorption coefficients of the various water vapor, carbon dioxide, and ozone absorption bands are found to vary exponentially with the wave number within these bands. When this property is utilized, it is found that the transmissivities of these radiatively active constituents of the atmosphere are given by an analytic function of the effective absorbing mass and the width of the band interval in question. This method has been used to calculate the infrared cooling rate of a realistic atmosphere.

During the International Field Year of the Great Lakes (IFYGL), rawinsondes were released at six sites around Lake Ontario on a regular basis in the fall. Verification of the downward radiation fluxes at the surface was undertaken at 10 stations surrounding the lake. The differences were noted from previous results based solely on the Buffalo radiosonde.

Sensitivity analyses using one to six rawinsondes at time intervals extending from every $3 \mathrm{~h}$ to every $24 \mathrm{~h}$ are given for both radiation fluxes at the surface and for radiative cooling rates. The analysis shows the space and time intervals needed for rawinsondes to accurately compute a mesoscale radiation budget. This assessment should have a broad impact on the spacing and frequency of upper air observation in further meteorological field programs and in mesoscale analyses of radiation fluxes.

The results of a study are emphasized in which satellite-determined planetary albedo data have been applied to a method for computing insolation at the ground. Composite minimum albedo, or cloud-free albedo, derived from the planetary albedo data, and the planetary albedo data for a cloudy atmosphere are the satellite data inputs to the technique. The cloudy and cloud-free albedo are combined with conventionally determined atmospheric water vapor and ground-level global insolation data to arrive at an estimate of the atmospheric transmission. The system is calibrated against the global pyranometer data of the ground-based network. This technique has been applied to a 1 -month set of satellite data encompassing the contiguous United States.

Direct and multiple reflection are phenomena that can increase diffuse, and consequently global, irradiance considerably. Results from experimental (simulation) and mathematical models are compared to data measured in a Rocky Mountain valley.

In a previous paper, we developed a transformation of surface albedo to albedos at the top of clear, totally cloud-covered, and fractionally cloud-covered realistic atmospheres. In this paper, we present monthly and zonally averaged surface cover climatology data, which we use to construct monthly and zonally averaged surface albedos. Our albedo transformations are then applied to the surface albedos, using solar zenith angles characteristic of the Nimbus-6 satellite local sampling times, to obtain albedos at the tops of clear and totally cloud-covered atmospheres. We then combine these albedos with measured albedo data to solve for the monthly and zonally averaged fractional cloud cover. The measured albedo data were obtained from the wide field-of-view channels of the Nimbus- 6 earth radiation budget (ERB) experiment, and consequently our fractional cloud cover results are representative of the local sampling times. These fractional cloud cover results are compared with recent studies.

The standard technique for calculating bulk values of the long-wave irradiance and heating rate in the presence of cumulus clouds consists of taking the cloud amount weighted average of the clear and complete cloud cover values without regard to the physical sizes of the individual cloud elements. We have estimated the effects of neglecting the cloud dimensions by comparing irradiance and heating rate calculations performed with a randomly distributed field of spectrally black cylindrical clouds of uniform radii and thickness to those performed 
with the standard technique. The calculations show that the irradiance and heating rates depend upon the cloud amount and the ratio of the cloud thickness to radius (aspect ratio) in a nonlinear fashion. However, the standard technique is easily modified to account for the cloud dimensions.

The cloud dimensions have little effect on the irradiances or heating rates until the aspect ratio exceeds unity and the cloud amount is between $30 \%$ and $70 \%$. In the aspect ratio range of 1-3, the downward irradiance at the surface with cloud base at $0.6 \mathrm{~km}$ may be underestimated by $4 \%$ if the cloud dimensions are neglected. The upward irradiance at the top of the atmosphere is not affected as greatly until the cloud tops reach $5 \mathrm{~km}$. The heating rate for the subcloud layer may be underestimated by $0.8^{\circ} \mathrm{C}$ per day by neglecting the cloud dimensions, whereas the heating rate above the cloud tops is overestimated by at most $0.1^{\circ} \mathrm{C}$ per day.

Solar absorption in clouds of finite horizontal extent

\section{J. M. DAVIS ET AL.}

The inclusion of finite cloud radiative properties in space- and time-averaged radiative budgets

\section{J. M. DAVIS ET AL.}

The spatial variation in the upwelling radiances from clouds of finite horizontal extent

\section{R. DAVIES}

Solar radiation transfer in two-dimensional cloud layers: $Y_{1}$ approximation

\section{S. K. S. VARMA}

Cirrus clouds and solar heating of the upper troposphere

\section{K. P. FREEMAN}

The effect of solar absorption by water vapor and cloud droplets on the total spectral $(0.3-8 \mu \mathrm{m})$ directional reflectance of finite and infinite clouds is evaluated. Total spectral solar absorption is computed for cubic, finite clouds and compared to the analogous quantity calculated for a volume element of infinite cloud, which is geometrically identical to the finite cloud. Information concerning the vertical and horizontal distribution of absorbed solar radiation is presented for regions within and adjoining the finite cloud.

The radiative transfer characteristics of finite clouds are shown to have a significant impact on the time- and space-averaged radiation budget of a region partially covered by finite clouds. Exposure of the vertical sides of the cubic, finite cloud to direct solar radiation is primarily responsible for higher values of reflectivity and lower values of transmissivity when finite rather than infinite cloud radiative characteristics are used. The added contribution of the vertical walls may be expressed as an "effective cloud cover," which is greater than the geometric cloud cover by the factor $(1+\tan \theta)$, where $\theta$ is the solar zenith angle. Additionally, it is shown from purely geometrical considerations that the vertical extent of finite clouds, through the exaggeration of cloud-cover estimates obtained from satellite imagery, may have a significant impact on the calculated radiative budget of a region partially covered by finite clouds.

Analytical and Monte Carlo models have already been developed that provide the fractions of incident solar irradiance emerging through the various faces of an isolated cuboidal cloud.

These models are being extended to include the effect of the spatial variation of the emerging radiance across the cloud's surface. The effect of spatial resolution in observing the radiances from clouds can thus be simulated. Results will be presented both for the case when the cloud subtends a fraction of the field of view and for the case when the field of view intercepts a fraction of the cloud surface.

A theoretical model for solar radiation transfer in a two-dimensional cloud is presented. This model assumes a cloud that has finite extent in the $X$ and $Z$ directions and an infinite extent in the $Y$ direction. The analytical method, which is employed to solve the relevant radiative transfer equation, involves the use of expansions in associated spherical harmonic functions. Using Marshak's vacuum boundary conditions, an analytical solution is obtained in $Y_{1}$ approximation.

Diffuse intensity and fluxes emerging from the cloud boundaries are calculated. It is observed that a cloud with similar extent in $X$ and $Z$ directions reflects several percent less solar radiation as compared to the plane-parallel results. Results are also compared with the Monte Carlo results for a finite cloud. For a finite cloud layer, there are significant differences between the results obtained using this two-dimensional model and a plane-parallel model.

Another feature of this model is that it provides a means of rapidly calculating the intensities and fluxes within as well as emerging from the cloud boundaries.

The role of cirrus clouds in the heating of the upper troposphere and lower stratosphere is investigated with detailed computations of the radiative transfer through a realistic model atmosphere. The solar heating of the clear atmosphere is compared to that of realistic climatological atmospheres containing a variety of cloud scenes. In addition, the effects of atmospheric type (tropical, mid-latitude, and subarctic) and season are evaluated. The computations of radiative transfer in a vertically inhomogeneous atmosphere were performed with an analytic four-stream solution and the method of discrete ordinates. Scattering properties of cloud and aerosol particles were obtained from the exact Mie solution.

Heating rates on the order of $0.5^{\circ} \mathrm{C}$ per day are computed in the vicinity of cirrus clouds with no clouds below. The effects of middle and lower clouds are to modify the heating 
slightly, since additional radiation is reflected back into the cirrus clouds from below. The reflection from cirrus clouds leads to a small increase in heating of the upper stratosphere. The presence of a very light aerosol concentration has only a minor effect upon heating at the altitude of cirrus clouds.

Simulated radiance patterns for Mie absorbing finite clouds

\section{J. T. KLEHR AND T. B. MCKEE}

Effects of the absorption of solar radiation by particles in clouds on the scattered radiance field have been evaluated for finite clouds and semi-infinite clouds for a range of single-scattering albedo, incident solar zenith angle, and optical depths. Comparisons of the radiance fields are presented for changes in geometry, optical depth, and single-scattering albedo. Finite clouds absorb a smaller fraction of incident light than semi-infinite clouds at all sun angles and values of single-scattering albedo. Radiance patterns are shown to be primarily determined by cloud and solar geometries with absorption causing reduced radiance values and flattened radiance patterns.
Transformation of surface albedo to surface-atmosphere albedo and irradiance, and their spectral and temporal averages

M. L. NACK AND

R. J. CURRAN
The dependence of the albedo at the top of a realistic atmosphere upon the surface albedo, solar zenith angle, and cloud optical thickness is examined for the cases of clear sky, total cloud cover, and fractional cloud cover. The radiative transfer calculations of Dave and Braslau (1975) for particular values of surface albedo and solar zenith angle and for a single value of cloud optical thickness are used as the basis of our parametric albedo model. The question of spectral and temporal averages of albedos and reflected irradiances is addressed, and unique weighting functions for the spectral and temporal albedo averages are developed.

\section{Session 4: Radiative properties of atmosphere and surfaces}

Remote sensing of aerosols in the Martian atmosphere: Implications for terrestrial studies

\section{J. B. POLLACK AND D. COLBURN}

Remote sensing of the structure of the Martian atmosphere in the presence of dust

\section{G. E. HUNT}

We have used photographs of the Martian sky and sun taken with the Viking lander cameras to determine a number of properties of the particles in the Martian atmosphere. By directly viewing the sun with a special diode, the optical depth of the atmosphere was found. By way of contrast, determination of the optical depth from orbiter observations of the combined brightness of the atmosphere and ground proved to be extremely difficult. The optical depth was found to be never less than several tenths above both landers and rose to a value on the order of 5 at the start of two global dust storms. Observations of the variation of sky brightness with angular distance close to the sun permitted a sensitive determination of the cross-section weighted mean particle radius, which was found to be $\sim 0.4 \mu \mathrm{m}$. However, numerical sensitivity experiments showed that in practice, this was the only information about the particle-size distribution that could be recovered. Even errors as small as a percent prevented recovery of the variance of the size distribution function. Observations of the sky brightness at large angular distances from the sun provided information on the shape of the particles. It was found that Mie scattering gave a poor fit to these data, but that they could be fit quite well with a semi-empirical theory that we have recently developed to treat single scattering by nonspherical particles. The two free parameters of this theory, determined from the data, gave a crude estimate of the shape and roughness of the particles. Finally, the imaginary index of refraction of the particles as a function of wavelength in the visible was determined by fitting the observed absolute brightness of the sky in a number of narrow-band channels. A very essential element of this estimate was our ability to accurately model the contribution of light first reflected off the ground and then reflected off the aerosols. This ability was obtained by also fitting, in an iterative fashion, observations of the ground reflectance. We found a very high imaginary index $(\sim 0.05)$, which had a local minimum near $0.8 \mu \mathrm{m}$. This behavior was attributed to the presence of magnetite in the particles. All the above modeling of the sky and ground brightness was performed with an accurate multiple-scattering program that incorporated the effects of light reflected from the surface.

Abstract not available. 
Transmission measurements for very long paths of carbon dioxide and water vapor: Application to remote temperature sounding of the atmosphere of Venus

\section{J. MCCLEESE ET $A L$.}

Atmospheric absorption spectra near $2200 \mathrm{~cm}^{-1}$ and $2400 \mathrm{~cm}^{-1}$

\section{J. SUSSKIND AND T. MO}

Radiance variations from atmospheric and surface inhomogeneities

\section{P. A. DAVIS}

Earth infrared radiative transfer radiances for sun synchronous and geosynchronous meteorological satellites

\section{H. S. CHEN}

In situ spectrophone measurements of aerosol absorption

\section{BRUCE ET AL.}

Effects of humidity variations on atmospheric aerosol optical properties

\section{E. P. SHETTLE}

Measurements of the transmission function $T(p)$ have been made for carbon dioxide in the 11-15 $\mu \mathrm{m}$ region, and for water vapor in the $40-60 \mu \mathrm{m}$ region, using a large White cell with a total path length of $1.08 \mathrm{~km}$. The amounts of each gas employed were chosen to represent the atmosphere of Venus above the clouds so that the results could be used to interpret experimental remote sensing of temperature and humidity on Venus. Computation of transmission profiles on Venus is more difficult than for the corresponding terrestrial problem because the very long $\mathrm{CO}_{2}$ paths render the results more sensitive to the intensities of very weak lines and to the shapes of strong lines in the wings. Comparisons between computed and measured transmission curves are presented to illustrate the problem. The differences between weighting functions for remote sensing of Venus and Earth are briefly discussed.

Observed high resolution $\left(0.059 \mathrm{~cm}^{-1}\right)$ atmospheric absorption spectra, from $2180-2240 \mathrm{~cm}^{-1}$ and 2385-2340 $\mathrm{cm}^{-1}$, taken from earth with the sun as a source, have been compared with calculated spectra based on line parameters from the AFCRL compilation. The agreement in general was excellent, both in the quantitative and in the qualitative sense. Particular attention was given to continuum background features such as absorption due to $\mathrm{N}_{2}$ and wings of distant $\mathrm{CO}_{2}$ lines.

Use of Lorentz $\mathrm{CO}_{2}$ line shapes seriously overestimated absorption in both spectral regions. Various sub-Lorentz line shapes were tested, and it was found that the Burch $\chi$ line shape gave best agreement with experiment. The $\mathrm{N}_{2}$ continuum absorption was shown to be significant even at $2180 \mathrm{~cm}^{-1}$, and its inclusion in the calculation was essential in obtaining quantitative agreement between calculated and observed spectra.

These considerations, as well as the general accuracy of the AFCRL line compilation in this spectral region, will be discussed.

The effects of atmospheric and surface inhomogeneities on upwelling infrared and microwave radiances are examined for several spectral intervals using models that include water vapor, carbon dioxide, and oxygen absorption. Magnitudes of the effects are described in the context of remote sensing, especially from the viewpoint of inferences derived from multispectral radiance comparisons.

Infrared radiances at $2.0-2.5 \mu \mathrm{m}, 3.3-4.16 \mu \mathrm{m}$, and $10.3-12.8 \mu \mathrm{m}$ were chosen for the infrared radiative transfer computation for sun synchronous and geosynchronous meteorological satellites. Seven model atmosphere regions of the earth-atmosphere system and seven zenith angles of the slant path to the meteorological satellites were selected to cover the computation. Limb darkening of the earth-atmosphere system as a function of infrared wavelength has been found in the computed results.

The absorption of IR radiation by aerosol particles is important to radiative transfer processes in the atmosphere and effective operation of military electro-optical devices such as forward looking infrared (FLIR) or high-energy laser (HEL) systems. To date, in situ measurements of aerosol absorption have been made primarily by indirect techniques. In this presentation, measurements obtained using a calibrated differential $\mathrm{cw} \mathrm{CO}_{2}$ laser source spectrophone are compared with calculated results based on particle-size distributions and known complex indices of the bulk materials. With the in situ spectrophone, absorption measurements are made more directly, bypassing the dependency on particle shape, size, and complex refractive index. Response of the spectrophone system to particulate, as well as gaseous constituents, will be briefly discussed. Spectral absorption properties in the $9-11 \mu \mathrm{m}$ atmospheric transmission window for some prominent atmospheric aerosol constituents are presented. Predictions of absorption coefficients (using the Lorentz-Mie theory) as a function of time after dispersion of the dust material in an environmental chamber are discussed along with the time decay measurements of the spectrophone.

The changes in the aerosol optical properties due to variations in the relative humidity will be discussed. The aerosol models of Shettle and Fenn (1975) have been extended to include a dependence on the relative humidity. The optical properties of these models for different humidities will be described. The effect of humidity on the transfer of radiation will also be briefly discussed. 
Variability in the stratospheric aerosol loading associated with the 1974 eruption of Volcán de Fuego

\section{F. G. FERNALD}

Observations and measurements of the solar aureole

\section{F. E. VOLZ}

Radiation budget for a tropical dry evergreen forest in Thailand

\section{R. T. PINKER AND \\ O. E. THOMPSON}

Some results of the UA-ARE Program

\section{J. A. REAGAN ET AL.}

Nonspherical extinction and absorption efficiencies

\section{R. M. WELCH AND}

S. K. COX

Light scattering by almost spherical particles

\section{P. CHÝLEK ET AL.}

Lidar observations collected at Boulder, Colo., from November 1974 through January 1978 have monitored the development and decay of the stratospheric aerosol enhancement attributed to the October 1974 eruption of Volcán de Fuego in Guatemala. Time histories of the integrated aerosol backscattering cross sections and the optical depths of the stratospheric aerosol layer inferred from these data are presented. They indicate that the stratospheric aerosol loading decayed exponentially from a peak in December 1974 to roughly pre-Fuego levels in October 1976 with a half-life of 6 months. From October 1976 through January 1978, a much more gradual decay has brought the net stratospheric aerosol loading to probably the lowest levels since records of this type were first collected in the early 1960s.

For the quick characterization of brightness (and shape) of the solar aureole at the sun's border, it is recommended that one look from the shadow edge of a roof through a neutral density (ND) step filter at the sky at the sun's edge. The ND value that gives the aureole in comfortable brightness may be called its brightness (ND of solar disk is $\sim 5.8$ ). Shape and color distribution in the aureole allow estimates of the aerosol-size distribution for $r \gtrsim 1 \mu \mathrm{m}$. For quick hand-held measurements of the skylight scattering function at scattering angles $3^{\circ}$ and at $\lambda 0.5$ and $0.8 \mu \mathrm{m}$, corresponding optics and sight have been incorporated in amplified sunphotometers. Some results from Korea and central Africa will be presented.

The detailed radiation budget of a tropical dry evergreen forest situated in Thailand will be discussed. A wide range of broad-and narrow-band short wavelength data and long wavelength data was taken over a period of nearly a year in conjunction with a major forest micrometeorological experiment, conducted through the sponsorship of the U.S. Army Research Office. Measurements were taken both above and within the forest canopy with instruments directed upward and downward.

This paper will concentrate on the variations of incoming and outgoing shortwave and longwave radiation fluxes during the monsoon cycle, which dominates the region, as well as on the attenuating effects of the forest canopy on the different fluxes. The seasonal variation of the forest albedo and the general radiation budget for the forest canopy will be discussed.

During the period 6-16 May 1977, the University of Arizona Aerosol Research Group conducted an Aerosol and Radiation Experiment (UA-ARE Program) in Tucson, Ariz. Ground-based optical remote sensing measurements were made with a multiwavelength solar radiometer, a multiwavelength direct/diffuse flux sensor, and a combined monostatic-bistatic lidar system. These measurements are being processed to infer aerosol-size distributions, refractive indices, and vertical extinction profiles. The aerosol inferences will be used as inputs in radiative transfer models to compute ground-level fluxes (direct and diffuse components) at selected visible wavelengths, and the calculations will be compared with measurements of the same. Analyses completed to date will be reported.

The scattering and absorption of electromagnetic radiation by nonspherical particles are examined by suppression of particle resonances (surface waves) in classical Mie scattering theory. The importance of the particle resonance phenomenon and, thus, of the nonspherical corrections is related to the three classical variables $n_{i}, n_{r}$, and $x$, the imaginary and real components of the index of refraction and the size parameter, respectively.

The resonance phenomenon becomes increasingly restricted to small values of $x$ as $n_{r}$ increases. For solar wavelengths and cloud-size particles, the resonance phenomenon may be neglected for $n_{r} \gtrsim 2$. As $n_{r}$ decreases, the effect of nonsphericity becomes increasingly significant to both scattering and absorption. For $n_{r} \lesssim 2.0$ and $n_{i} \simeq 10^{-5}$, nonsphericity may lead to increases in absorption efficiency of several orders of magnitude in the region of the absorption peak.

Perturbation technique is applied to the problem of light scattering by a slightly deformed sphere. Analytical expressions for the first order perturbation corrections are derived, and several examples of scattering cross sections, differential scattering cross sections, backscattering, and polarization are calculated. Results of perturbation technique are compared with the exact solutions for the light scattering by spherical and spheroidal particles and with the results of microwave scattering experiments. 
Cloud measurements from satellites and aircraft

\section{J. T. BUNTING}

Light-scattering characteristics of an aging power plant plume

\section{A. NORBERG ET AL.}

The reflectance characteristics of snow-covered surfaces

\section{E. S. BATTEN}

Reflectional properties of natural formations

\section{R. NAGARAJA RAO}

Simultaneous measurements of clouds by satellite and aircraft sensors are described. These measurements were made so that cloud properties including total mass and thickness could be inferred from satellite measurements by empirical methods. Satellite sensors are the infrared and visible imagers on NOAA's ITOS and GOES, while aircraft sensors are cloud physics instrumentation to count and size particles. Visible reflectances are normalized to approximate the reflection geometry of both sun and satellite directly over the cloud. Infrared radiances are converted to equivalent blackbody temperatures. Cloud parameters are related to infrared and visible satellite data by nonlinear equations. The most accurate estimates of cloud parameters use both visible and infrared data; however, the areal mean temperature from the infrared imagery data tends to be the most significant single predictor.

During the summers of 1974, 1975, and 1976, the EPA MIST T project collected detailed, timecoordinated aerosol physics and chemistry data in power plant plumes in the St. Louis area. Aircraft mapped the plumes by monitoring integral size parameters (condensation nuclei, nephelometry, and aerosol charging) and gaseous chemistry within and outside the plumes as they aged downwind. The integral size parameters enter a computer routine that first synthesizes the acrosol-size distribution and then proceeds to approximate the electromagnetic scattering pattern based upon Mie scattering theory for spherical particles. It is found that $0.4-0.7 \mu \mathrm{m}$ radiation realized an average backscatter albedo of $12 \%$ for the characteristic particle. The characteristic particle albedo decreases, and the generally elipsoidal scattering pattern elongates while the plume ages.

The extent, duration, and albedo of snow-covered surfaces are important variables in the heat balance of the earth/atmospheric system. A data base for the albedo of snow-covered surfaces can be established by quantifying the subjectively determined reflectivity zones derived from satellite measurements and used in the NOAA weekly snow and ice charts.

There are several problems encountered in determining the albedo of snow-covered surfaces from satellite measurements. First, the type, density, and height of vegetation will affect the albedo of the scene and will produce temporal variations as the amount of vegetation showing through the snow changes with time. The NOAA reflectivity classes are to a degree a consequence of vegetation. Second, the reflectivity of the snow changes as the snow ages, melts, refreezes, etc., necessitating repetitive coverage. Third, the reflectivity of a snow surface and, more importantly, of a mixed snow-vegetation surface are anisotropic. Because the surface is viewed in a limited range of viewing angles and solar zenith angles, an algorithm must be derived to determine the total hemispheric reflectance from the measured bidirectional reflectance. Fourth, some satellite systems (NOAA's VHRR, for example) measure radiance in only a small wavelength interval, and the data must be extrapolated to the entire solar spectrum. Finally, measurements at the satellite include the effects of atmospheric scattering and absorption. If the surface albedo is desired, the data must be corrected for these atmospheric effects.

Both surface and airborne measurements in the spectral range from $0.45 \mu \mathrm{m}$ to $2.55 \mu \mathrm{m}$, with the Jet Propulsion Laboratory portable field reflectance spectrometer, were used to address the problem of the directional and spectral characteristics of the reflectance from snow-covered surfaces. The results of these field measurements and their use in determining surface albedo from satellite data will be discussed.

The dependence of the intensity and polarization of visible radiation reflected by natural formations, such as soils and sands, on the wavelength of illuminating radiation and on the geometrical and material parameters has been investigated in the laboratory. The anisotropy of reflected radiation is such that attempts to describe the dependence on geometrical parameters in terms of simple photometric functions have met with limited success. The reciprocal relationship between the intensity and polarization of the reflected radiation-the Umov effect -is generally observed. The polarization changes appreciably with wavelength and is affected considerably by changes in the index properties of the reflecting surface such as texture, composition, and moisture content.

Simple techniques for the determination of the characteristic Mueller reflection matrices will be described, and inclusion of these reflection matrices in radiative transfer computations will be discussed. Some computations of the intensity and polarization of the diffuse radiation at the top of a planetary atmosphere with a partially polarizing lower boundary will be presented. 
Passive microwave signatures of weather-altered surfaces

M. G. FOWLER ET AL.

Remote sensing of the ozone profile in the lower stratosphere using $U V$ and IR measurements from Nimbus-4

\section{PRABHAKARA} AND S. CHANDRA

Seasonal variation in the upper-stratospheric ozone

R. D. MCPETERS AND

\section{J. A. GATLIN}

Global variability of total ozone: Preliminary results of the multifilter radiometer onboard the new series of DMSP-5D satellites-1, Overview

\section{J. E. LOVILL ET AL.}

The application of passive microwave measurements to the study of the earth's surface and atmosphere requires a knowledge of the emissivities of various land surfaces and of the changes in these emissivities due to wetting, freezing, and coverage by snow and ice. Such data were collected during 1976 on a series of mapping missions, which flew a $35 \mathrm{GHz}$ radiometer over an area that contained open fields, forests, roads, ponds, and other features. In conjunction with these flights, detailed information was collected on the atmospheric conditions and on the moisture content, temperature, snow cover, and other characteristics of the surface.

Analysis of the experimental data showed that maps of the earth's surface could be obtained through several inches of dry snow and that the optimum surface maps were obtained under light rain conditions. The results also showed that the effects of snow on brightness temperature were strongly dependent upon the temperature of the snow and that frozen soil appeared dry. Radiometric models developed to simulate weather-altered surfaces show close agreement with the measured data and permit simulation of a wide variety of land signatures.

The vertical distribution of ozone in the lower stratosphere is determined, with a threeparameter representation, from the measurements made by backscattered ultraviolet (BUV) and infrared interferometer spectrometer (IRIS) experiments that were flown on Nimbus-4. The meridional cross sections of ozone concentration, derived from this technique for 1 day in each season, show good agreement with the climatological balloon ozone sonde observations. In the tropical stratosphere, the height at which this maximum concentration occurs displays a local minimum near the equator suggesting the presence of Hadley-type circulation cells on either side of the equator.

Ozone above a pressure of $1 \mathrm{mb}$ is found to be distributed approximately exponentially with altitude. We assume an exponential form for the cumulative ozone distribution and express it as a function of pressure $X(p)=C p^{1 / \sigma}$. We have used backscattered ultraviolet radiance data at wavelengths $2555 \AA$ to $2876 \AA$ from the Nimbus- 4 satellite to obtain $C$ and $\sigma$. Using these parameters, we obtain total ozone above $1 \mathrm{mb}$ averaged for the first year of data (1970-71), to show latitudinal and seasonal variation in the upper-stratospheric ozone distribution.

Preliminary global total ozone analyses, derived from radiometric measurements of a new series of satellite sensors, will be presented. Data transmission from the cross-track scanning, multi filter radiometer (MFR) onboard the U.S. Air Force DMSP-5D satellite began in March 1977. A series of spacecraft with the MFR instrument are planned in order to maintain a continuous data flow into the 1980s. Each of the MFR instruments sense in the $9.8 \mu \mathrm{m}$ ozone band as well as in 15 other IR regions. The raw data are read out to the Air Force Global Weather Central (AFGWC) from the spacecraft and are mailed to SOAC on archive tapes. AFGWC calibration software has been modified and implemented to preprocess the data. Processing software specific to the 5D MFR has been developed that employs regression coefficients to derive a total ozone value from each set of measurements. Calibration software has been developed to process the raw data into radiance units that are appropriate for an ozone inversion algorithm. Extensive software development and calculations, specific to the DMSP 5D MFR spectral intervals, were required in order to provide the appropriate inputs to a multiple regression model.

Regression coefficients have been calculated for 11 latitudinal bands for specific seasons. These coefficients are a function of the best linear fit of theoretically calculated radiances (for sets of sample atmospheres-ozonosondes) at one ozone channel $\left(1022 \mathrm{~cm}^{-1}\right)$, two $\mathrm{CO}_{2}$ channels $\left(668.5 \mathrm{~cm}^{-1}\right.$ and $\left.676.0 \mathrm{~cm}^{-1}\right)$, and a window channel $\left(835 \mathrm{~cm}^{-1}\right)$.

Each satellite MFR returns $\sim 60000$ observations per day. The data are spline-fitted (quadratic) to a $2^{\circ}$ global grid. Quality control of the processed satellite total ozone data is provided by a special participating Dobson Observatory calibration network. Each of these high quality Dobson observatories is sent a daily prediction of the MFR passage time to permit nearly coincident total ozone measurements. The statistical results of the Dobson/satellite MFR comparison will be shown.

The global total ozone daily analyses indicate a close relation to conventionally derived height analyses. Total ozone planetary wave features will be discussed. Synoptic- and subsynopticscale features, which are observed for the first time because of the relatively fine resolution of the sensor, will be discussed. 
Global variability of total ozone: Preliminary results of the multifilter radiometer onboard the new series of DMSP-5D satellites-2, Statistical discussions

\section{J. HUEBEL ET AL.}

\author{
Ground:based remote \\ sensing of $U V$-absorbing \\ trace species in the \\ troposphere: Vertical \\ profile effects
}

\section{K. F. KLENK}

Satellite-derived total ozone data are compared with Dobson spectrophotometer total ozone observations. The Dobson observatories are in a specially selected network of 33 stations that take observations nearly coincident in time with the predicted satellite total ozone measurement at the station. Statistics are generated that geographically arrange the coinciding measurements into regions that are incremented at $50 \mathrm{~km}$ intervals between $0 \mathrm{~km}$ and $500 \mathrm{~km}$. Temporal increments range from observations coincident in time to observations $12 \mathrm{~h}$ apart in time. Statistics will be discussed of various latitudinal bands.

Klenk and Green (1977) have shown that the ratio of the downward diffuse irradiance to the directly transmitted solar irradiance is sensitive to the amount of UV-absorbing tropospheric species such as sulfur dioxide and ozone. The results of an investigation to determine how the ratio depends on the altitude distribution of the absorbing constituent are presented. Also, the feasibility of using the ratio measurements as a ground-based remote sensing technique is discussed.

\section{Session 5: Radiative interactions in dynamical systems}

Influence of cloud and cloud-free radiational differences on tropical disturbance maintenance and diurnal modulation

W. M. GRAY

The effect of cloud type on the global distribution of radiative heating

\section{R. J. BECKER}

The sensitivity of ensemble cumulus characteristics to changes in the bulk radiative heating rate

\section{R. G. ELLINGSON AND G. SERAFINO}

On the interaction of turbulent and radiative heat transfer in the atmospheric boundary layer

\section{ETLING}

Our extensive observational studies of conservative ( $>1$ day) mesoscale tropical disturbance in the West Pacific and Atlantic reveal a deep layer inflow into these systems and a pronounced diurnal modulation in mass convergence and heavy rainfall. It is hypothesized that radiational differences between these disturbances and their surroundings (as has been discussed by Cox and his group) are a primary component to the maintenance and diurnal modulation of these systems. These radiational influences have recently been modeled by Fingerhut (1978).

A review of observational and modeling evidence to support this hypothesis will be given. Such radiational influences have yet to be generally realized by the modelers.

Cloud statistics for the five cloud types, cumulonimbus, cumulus congestus, cirrus, middle level or frontal type, and low (stratus and stratocumulus), were obtained using daily infrared and visible satellite imagery. These data were compiled, on a global basis, for one mid-winter and one mid-summer month. The distribution of cloudiness for each cloud type shows a tendency to occur at preferred locations within the framework of the general circulation, for example, the association of the frontal type cloudiness with the long-wave features of mid-latitudes, the fields of low cloudiness within the subtropical highs of the eastern oceans, and the relationship of the cirrus to both the mid-latitude and subtropical jet streams. Seasonal changes in the cloud pattern follow seasonal changes in the general circulation. A most striking example may be seen in the seasonal shift of the tropical cirrus of the eastern hemisphere as the monsoonal circulation shifts from southern Asia to northern Australia.

These cloud statistics are used for the numerical computation of the global distribution of radiative heating rates for seven layers in the troposphere. Katayama's method was followed, with some modification to allow a more complex cloud structure.

Each individual cloud type, or combination of several cloud types, resulted in a unique heating rate profile. The resulting global pattern of radiative heating thus reflects the character of the large-scale cloud structure and suggests that a strong relationship exists between the spatial variations in heating and the large-scale features of the general circulation.

The importance of the bulk radiative heating rate used in diagnostic models to determine cloud populations has been recognized in the analysis of GATE data. However, these diagnostic models use climatological heating rates rather than values representative of the convection occurring in the large-scale area. Rodenhuis (1977), using an ensemble of convection that simultaneously satisfies the large-scale mass and heat-plus-moisture budgets, has shown that the choice of the radiative heating rate profile strongly influences the shape of the cloud spectrum.

This paper summarizes the changes in the characteristics of ensemble convection when the bulk radiative heating rate is modified in an iterative fashion in order to account for the cumulus population determined from the large-scale budgets. Preliminary results show that the cloud fraction density function and the boundary layer mass flux are particularly sensitive to the radiative heating rate in the subcloud and low-cloud layers.

The theory of the stationary and horizontally homogeneous boundary layer of the atmosphere leads to the conclusion that the turbulent heat flux should be constant with height. In contrast to this, measurements show a decrease of the magnitude of the turbulent heat flux with height. Steady-state theories of thermal boundary layer so far neglect the effect of radiative heat transfer on the turbulent heat flux and on the temperature profiles in the atmosphere.

In the paper presented here, the interaction of long-wave radiative transfer and turbulent 
heat transfer is investigated using vertical profiles of water vapor, temperature, and turbulent heat transfer coefficients obtained by a steady-state planetary boundary layer model. The calculations were carried out for different thermal stratifications and Bowen ratios, which can be found in a realistic atmospheric boundary layer. The effect of a viscous sublayer between the underlying surface and the turbulent boundary layer was also included.

The computational results show that the consideration of radiative heat transfer in the boundary layer model leads to vertical variations of turbulent heat flux profiles, resulting in temperature profiles different from a nonradiative case. The overall effect of radiation on the thermal boundary layer in the atmosphere depends on the relative magnitude of turbulent and radiative heat fluxes.

Some comments on radiative flux divergence, heating rates, and cloud droplet population dynamics

\section{B. R. BARKSTROM}

Sensitivity of a general circulation model to a change in shortwave radiation code

\section{D. SCHWARZKOPF AND R. T. WETHERALD}

Stratospheric effects of doubled $\mathrm{CO}_{2}$ concentration in a general circulation model (GCM)

\section{S. B. FELS AND M. D. SCHWARZKOPF}

Radiative-convective model calculations of temperature changes caused by changes in the atmospheric composition

\section{J. A. COAKLEY, JR.}

Influence of systematic radiation differences on the dynamics of a model atmosphere

M. L. C. WU AND

L. D. KAPLAN
There is a general tendency to convert radiative flux divergence directly into a heating rate for the gas in the atmosphere. However, in a cloud, this direct conversion is false because radiative flux divergence in the droplets causes water to evaporate or condense, rather than affecting the temperature of the gas. As a result, the interaction of radiation and clouds is much more complex than is often assumed.

This paper will describe the magnitude of heating rates and latent heat transfers resulting from radiative flux divergences in a cloud. Among the interesting effects are those in which radiation affects the growth rates of cloud droplets to a significant amount, since these growth rates enter directly into the droplet spectrum dynamics and, thereby, into the overall mass and energy budget of a given volume of a cloud.

A study of the sensitivity of a general circulation model to a change in the shortwave radiation algorithm is made. For this purpose, the Geophysical Fluid Dynamics Laboratory nine-level "SECTOR" general circulation model, incorporating cloud prediction as developed by Wetherald and Manabe, is used. The solar radiation code is changed to include the Lacis-Hansen parameterization of ozone absorption and Rayleigh scattering and the multiple reflections from clouds. An analysis is made of the energy balance of the new model, including the global albedo and the poleward heat transport, and the results are compared to those of Wetherald and Manabe. The change in sensitivity of these models to an increase in the solar constant has been evaluated.

Simple radiative equilibrium models suggest that a twofold increase in atmospheric $\mathrm{CO}_{2}$ concentration will substantially decrease the atmospheric temperature near the stratopause but give no reliable indication of the local temperature changes to be expected. To begin an exploration of this question and to clarify the nature of the stratospheric radiative-dynamic interaction, we have run a simulation using a GCM that extends from $0 \mathrm{~km}$ to $80 \mathrm{~km}$. A comparison of runs using $\mathrm{CO}_{2}$ concentrations of $330 \mathrm{ppm}$ and $660 \mathrm{ppm}$ under conditions of annual average insolation will be presented, and the results will be discussed in light of simpler, purely radiative models.

A radiative-convective model of the earth's atmosphere has been used to compute temperature changes caused by changes in the atmospheric concentrations of $\mathrm{H}_{2} \mathrm{O}, \mathrm{CO}_{2}$, and $\mathrm{O}_{3}$. The results show that the temperature changes are rather sensitive to the temperature dependencies assumed for the optical properties of the gases. These temperature dependencies have sometimes been ignored in previous radiative-convective model studies. Uncertainty in the temperature dependencies remains, however, because of the lack of formal treatments for temperature variations along optical paths within wide-band transmission models. In addition to these findings, the radiative-convective model results have led to the development of a simple scheme for estimating the model's surface temperature response to arbitrary perturbations. This simple scheme explains why for some perturbations, vertical column energy balance models (models in which the stratospheric temperature profile is specified rather than computed) give fairly accurate estimates of the surface temperature change obtained using a radiative-convective model, while for other perturbations, the energy balance models give unreliable estimates.

A long-wave radiation parameterization using the strong line version of the statistical band model and the Curtis-Godson approximation was developed. Calculations with this parameterization showed good agreement with theoretical line-by-line calculations and were within the observational error of long-wave radiation flux measurements.

The parameterization was incorporated into the Goddard Space Flight Center (GSFC) atmospheric general circulation model, and the model results for January and July were compared with those obtained with the old GSFG radiation parameterization scheme. Systematic differ- 
ences were found in the mean zonal temperatures, in the location and shape of the zonal west wind maximums, in the strength of the Hadley and Ferrel cells, and in the cloud and precipitation distributions. The simulations of temperature and circulation in low and middle latitudes, made with the new radiation parameterization, were significantly closer to observations.

An infrared radiation routine for use in numerical atmospheric models

\section{D. CHOW AND}

\section{A. ARKING}

An accurate, but computationally efficient, infrared radiation routine has been developed for use in numerical atmospheric models. The routine uses: 1) the wing approximation/k-distribution method previously reported (Chow and Arking, 1978) for dealing with the water vapor and ozone portions of the spectrum, where the mixing ratios are variable; and 2) the linear expansion method (Arking, 1976) for the remaining portions of the spectrum, where the mixing ratios are constant. Calculations of transmittance and cooling rate for a number of wide-ranging atmospheric models are compared with line-by-line calculations. Maximum errors are $<0.01$ in transmittance and $\lesssim 0.2^{\circ} \mathrm{C}$ per day in cooling rate. The computing times are less than or comparable to the computing times for routines currently used in general circulation models.
An accurate, fast algorithm for calculating stratospheric $\mathrm{CO}_{2} 15 \mu \mathrm{m}$ cooling rates in GCMs

S. B. FELS
We call attention to the availability (in several forms) of accurate $\mathrm{CO}_{2}$ transmission functions, tabulated for a certain standard set of levels. By using simple interpolation procedures, these can be mapped onto other level schemes, allowing use to be made of a "high accuracy" algorithm to be described briefly for calculating cooling rates. We will also attempt to assess the uncertainty in such calculations by comparing our results with those found by other investigators.

\section{Session 6: Radiative effects in climate}

Effect of tropospheric aerosols upon atmospheric infrared cooling rates

HARSHVARDHAN AND R. D. CESS

Effect of volcanic aerosols on climate

\section{O. B. TOON AND} J. B. POLLACK

Possible effects of solar $U V$ variations on ozone and climate

\section{J. B. POLLACK ET AL.}

An investigation has been made of the impact of wind-blown dust particles upon local climate of arid regions. The case of northwest India is specifically considered, where a dense layer of dust persists for several months during the summer. In order to examine the effect of this dust layer on the infrared radiative flux and cooling rates, a method is presented for calculating the infrared flux within a dusty atmosphere that allows the use of gaseous band models and is applicable in the limit of small single-scattering albedo and pronounced forward scattering. The participating components of the atmosphere are assumed to be water vapor and spherical quartz particles only. The atmospheric window is partially filled by including the water vapor continuum bands for which empirically obtained transmission functions have been used. It is shown that radically different conclusions may be drawn on dust effects if the continuum absorption is not considered. The radiative transfer model, when applied to a dusty atmosphere, indicates that there is a moderate enhancement in the atmospheric greenhouse and a $10 \%$ increase in the mean infrared radiative cooling rate, relative to the dust-free case, within the lower troposphere. These results have been compared with previous work by other authors in the context of the possibility of dust layers inhibiting local precipitation.

Large volcanic explosions inject particles and gases that are converted to particles into the stratosphere. These particles upset the earth's radiation budget and so influence weather and climate. We carefully model the aerosols formed after an explosion using a sophisticated physical-chemical aerosol model. We then perform calculations of the effect of the aerosols on the radiation budget using the modeled aerosol properties, a doubling routine for visible radiation calculations, and a sophisticated infrared model. The results are compared with observations.

Satellite observations have shown that solar radiation in the ultraviolet region of the spectrum shows a marked variation over a solar rotation period ( 27 days) and perhaps over a solar cycle $(\sim 11$ years), with very little variation occurring at longer visible wavelengths. We have explored the consequences of such variations on the concentration of ozone and nitrogen dioxide and the joint effect of the radiation and concentration variations on the global temperature. The solar ultraviolet oscillations were modeled alternatively as having an amplitude dependent on the depth in the solar atmosphere from which the radiation originated and a simple wavelength dependence, corresponding to two plausible mechanisms for such variations. In both cases, the solar luminosity was held constant by slightly altering the visible radiation. Periodic variations 
on time scales of 27 days, 11 years, 22 years, and hundreds of years were considered. The concentration variations induced by the radiation oscillations were calculated with a time-marching, to determine the resultant modifications to the solar energy deposition profile and vertical temperature structure, the latter being estimated under conditions of radiative-convective one-dimensional photochemical code. These results were then used in radiative transfer codes equilibrium. We find that little change in ozone column density occurs for periods of 27 days, although significant changes in stratospheric heating rates do occur, that the ozone column density changes by $\sim 10 \%$ for an 11-year variation, and that it changes by $\sim 20 \%$ for a several hundred year variation. Resultant changes in surface temperature in the latter case are a few tenths of a degree.

Variations in the solar constant measurements by the Smithsonian

Astrophysical Observatory

\section{V. HOYT}

The paleoluminosity paradox-How much of it can be explained by a shift in the solar spectrum?

\section{W. J. WISCOMBE}

The Smithsonian Astrophysical Observatory conducted long-term monitoring of the solar constant from 1902 to 1957. A statistical analysis is made of the solar constant measurements made at four locations between 1923 and 1954 in order to set an upper limit on the solar constant variations. A long-term secular increase and oscillations with 6 -month and 3 -month periods are found to be in common between the two stations with the longest record of observation and to be statistically significant. From 1923 to 1954, the sun increased in brightness by no more than $0.1 \%$. The measured solar constant values appear to be nearly independent of most indices of solar activity such as the Wolf sunspot number, but the increasing solar constant values are consistent with an increase in solar activity during this period. The solar constant values depend partly on atmospheric turbidity and total precipitable water so that not all the common features between the stations can be attributed to real solar variations. The quality of the Smithsonian observations and the method used in the "short method" solar constant reduction scheme will be discussed.

All reasonable solar models predict that several billion years ago the sun was some tenths of a percent less luminous than at present. All reasonable models of climate concur that, with such a luminosity decrease, the earth would be completely ice covered. Yet the existence of microfossils and sedimentary rocks from these ancient times proves that the earth could not then have been ice covered and, hence, the paleoluminosity paradox.

We present calculations from a detailed model of solar radiation to examine the extent of the following negative feedback: as the sun cools, its spectrum shifts toward the near IR, so that relatively more of its radiation is absorbed by the earth-atmosphere system. This partially compensates for the decrease in total solar energy available to the system. Results of "control" experiments using three current measured solar spectra (Thekaekara, Labs-Neckel, and ArvesenGriffin), as well as a blackbody spectrum yielding the same solar constant, are first presented to show the "noise level" in current calculations. Then various altered solar spectra that may be typical of a cooler sun are used, and it is shown that they cause the earth-atmosphere albedo for both cloudy and clear regions to fall by several percent, without invoking any change in atmospheric composition.
Urban-rural solar irradiance measurements at St. Louis

\section{J. T. PETERSON AND T. L. STOFFEL}

As part of the Environmental Protection Agency's Regional Air Pollution Study, measurements of incident global solar irradiance were made continuously at six sites in metropolitan St. Louis, Mo. The sites were in an approximate north-south line of $65 \mathrm{~km}$ from the southern edge of the urban area to rural countryside north of the city. Nearly two years of data were obtained, from mid-1975 through March 1977. For this report, the data were stratified into two partsfor cloudless conditions only and for all periods regardless of weather conditions-and were analyzed for spatial and temporal differences of measured irradiance. Urban-rural variability of incident irradiance during cloudless periods primarily reflects variability of radiatively important urban-induced atmospheric pollutants. For 60 such days during 1976, the average urban depletion of global solar irradiance was only $\sim 3-4 \%$. On individual days, however, average daily depletions up to $10 \%$ were measured. For the full year, 1976, the rural site north of the city received $\sim 5 \%$ more radiant energy than did the site just east of downtown St. Louis. This evident indication of more cloudiness over the urban area is in accordance with the precipitation, radar echoes, etc., anomalies identified by others from the St. Louis METROMEX project data. 
Global radiation and actiometric measurements within the St. Louis urban environment

\section{J. M. WHITE}

Some considerations on the global solar radiation in Barcelona

\section{J. I. JIMÉNEZ ET AL.}

Secular trends in clear sky transmission as measured at Mauna Loa Observatory, Hawaii

\section{B. G. MENDONCA}

Development of a radiation model with interactive water vapor transport and cloud development

\section{J. R. HUMMEL ET AL.}

The effect of ground hydrology on climate sensitivity to solar constant variations

\section{S. H. CHOW AND}

R. J. CURRAN
Investigations of incoming solar radiation, consisting of direct and global measurements, were pursued under the auspices of Project METROMEX, on cloudless days in St. Louis during August 1976, to determine the effects of a polluted atmosphere on incoming solar radiation.

Global radiation measurements were acquired by a ground-based pyranometer along with a pyranometer mounted on an aircraft, which flew at various levels within the urban atmosphere and adjoining rural atmosphere. The vertical variations of the global radiation are compared for urban vs. rural atmospheres.

Pyrheliometric measurements of direct solar radiation, for specified spectral regions, using filters OG1, RG2, and RG8, were used in computations of various aerosol extinction coefficients (turbidity). Also the actiometric measurements permitted the investigation of the spectral distribution of radiant energy received at the surface in St. Louis.

This paper presents the analyses conducted on the collected data and addresses the relevance of the behavior and composition of incoming solar radiation with regard to the St. Louis urban environment.

Fluctuations of the daily solar radiation are examined in an unbroken 3-year sequence of measurements at Bellaterra, within the metropolitan area of Barcelona. Decadic means present large fluctuations, particularly in late spring and early summer. The extreme values of global solar radiation occur in June and July and in December and January. Monthly means were also analyzed and show small fluctuations with the extreme values in July and December. The percent of number of days with solar radiation values below a certain prefixed value analyzed each month leads to a grouping in pairs symmetric to the solstices. On the other hand, seasonal effects are shown by separate studies of eight $1 \frac{1}{2}$ month periods of the year defined by standard solar declination values. The corresponding frequency distributions are studied for both, and they show increasing skewness and scattering from winter to summer. The time series of daily totals of global solar radiation at Bellaterra is analyzed as a second-order random process, and the observed annual frequencies of runs of consecutive days with solar radiation below the prefixed values are given. Finally, some calculations of the attenuation of solar radiation in the atmosphere are carried out for the studied period.

Twenty years of historical atmospheric transmission data from Mauna Loa Observatory (MLO) show secular decreases at irregular intervals. In addition, a regular annual and biannual period is present during unperturbed as well as perturbed periods. These variations in transmissions can be measured to a few tenths of a percent, and the data record is one of the best available for such studies.

Decreases in transmission of magnitudes twice the annual variation show strong correlations with explosive volcanic eruptions that eject effluent into the stratosphere. Recovery times from these ejections are as long as 8 years and show a linear curve to recovery. Observations in 1977 at MLO show for the first time since the Agung eruption that atmospheric transmission has returned to values measured in 1958-62, the pre-Agung period. This result suggests no anthropogenic influences on the transmissions measured at MLO.

Many radiation models are available for use in climate studies. In most cases, the water vapor distribution in the models is held fixed. If clouds are included, they are assigned specific altitudes and amounts. We present results with a detailed radiation model that includes a transport model for water vapor and that allows for cloud generation at thermodynamically defined heights.

Comparisons are presented with other model results, as well as a discussion of the usefulness of the model for climate studies.

The effect of ground hydrology on the climate sensitivity to solar constant variations was investigated by using a two-level quasi-geostrophic zonally averaged annual model. The model included the parameterizations of solar radiation, long-wave radiation, convection, evaporation, latent heat release, oceanic transport, and ice-albedo feedback. Clouds are parameterized into a single cloud layer with top, base, and amount specified according to the observations.

The effects of changing solar constant on the model climates corresponding to two different evaporation parameterizations were compared. One employed the evaporation formulation of 
Saltzman (1968), in which a linear relationship between the potential evaporation and sensible heat flux at the earth's surface was assumed. The other adopted a nonlinear formulation with the Bowen ratio determined by the vertical gradients of water vapor and temperature near the earth's surface.

It was found that both the surface and the $500 \mathrm{mb}$ temperatures decreased with decreasing solar constant and that the surface temperatures at high latitudes had a maximum change due to the ice-albedo feedback. A $1 \%$ decrease in solar constant induced a decrease of $1.45 \mathrm{~K}$ in hemispheric mean surface temperature for the model with the linear formulation of evaporation, and a $0.86 \mathrm{~K}$ decrease for the nonlinear evaporation formulation. This indicated that the sensitivity of surface temperature to the variation in solar constant was reduced by $\sim 40 \%$ with the use of the nonlinear evaporation formulation as compared to the use of the linear evaporation formulation.

It was also found that the intensity of the hydrologic cycle was more sensitive to the change in solar constant for the nonlinear formulation of evaporation than for the linear formulation and that the response of surface heat budget to the variation in solar constant was quite different due to the difference in the evaporation formulation.

Response of a radiative convective temperature profile to variations in model physical parameters: Uncertainty in the calculated temperature from input data error

\section{R. A. RECK}

\section{A technique for} estimating net radiation over snow in unforested environments of a mid-latitude, subarctic, and arctic site

\section{E. PETZOLD AND}

R. G. WILSON

Infrared characterization of some worldwide aerosol fractions

\section{F. E. VOLZ}

In our atmospheric studies, we have used the Manabe-Wetherald radiative-convective model to calculate the steady-state temperature profile of the atmosphere and the earth's surface for a variety of atmospheric conditions. We have determined the uncertainty in the calculated temperature due to the uncertainties in the input values of the physical parameters included in the model. The probable error in the measurement of input parameters adds uncertainty to our calculated average surface temperature as follows: surface albedo, $\pm 0.5 \mathrm{~K}$; solar constant, $\pm 0.5 \mathrm{~K}$; surface relative humidity, $\pm 0.5 \mathrm{~K}$; dry heat capacity, $\pm 0.2 \mathrm{~K}$; and remaining 10 parameters less than $\pm 0.1 \mathrm{~K}$.

The fluxes of solar and long-wave radiation are important components of the energy balance of a snowpack and are recognized by some as a major source of energy in the annual production of snowmelt runoff. The difficulty of maintaining accurate radiation measurements has often led to the use of generalized and perhaps outmoded empirical estimates in snowmelt calculations.

In recent years, a number of studies have successfully related net radiation over various vegetated and exposed earth surfaces to incoming solar radiation by using simple regression models. The analysis of daily radiation balance data over snow surfaces indicates that a similar relationship exists for both the accumulation and melt seasons of a snowpack. The extreme day-to-day variability in snow albedo, particularly during the melt season, necessitates the inclusion of this parameter into the predictive equation. Three latitudinally dissimilar sites in Canada have been chosen as the basis of this study: Toronto, Ont.; Goose Bay, Labrador; and Resolute, N.W.T.

In view of the fact that net long-wave radiation $\left(L_{n}\right)$ dominates net radiation for periods of relatively low absorbed solar radiation $\left(Q_{A}\right)$ in the winter or snow-covered season of the year, the regression model takes the form: $L_{n}=c+d Q_{A}$.

IR optical constants have been determined for maritime (Azores, Canton Island, Guam, Hawaii) and continental (Boston area, Mt. Washington, Mainz and Meppen in Germany) locations. Large particles $(r \gtrless 0.1 \mu \mathrm{m})$ in amounts of $5-100 \mathrm{mg}$ were collected in the first felt filter of a high volume sampler and the small Aitken fraction on glass fiber (and later on nonleaching polystyrene) filters. Distilled water extracts were dried, the fraction of ethanol soluble organics $(20-50 \%)$ were determined, and infrared spectra $(2.5-40 \mu \mathrm{m})$ were obtained by the $\mathrm{KBr}$ pellet method and specular reflection. Vigorous washing of the felt filters dislodged soot and dust. The absorption index $n_{i}$ (imaginary part of refractive index) of the water solubles mostly peaks at $9 \mu \mathrm{m}$ with $n_{i} \sim 0.2-0.3$, but is lower in the large particle fraction of maritime aerosols and higher in some continental situations. The $6.2 \mu \mathrm{m}$ and $7.2 \mu \mathrm{m}$ bands are mainly from the organics. Absorption of dusts exhibits large spectral variations. For many samples, the real part of the refractive index has been derived by dispersion analysis of reflectance or transmittance spectra.

\section{Session 7: Earth radiation budget satellite system studies}

The earth radiation budget satellite system: An overview

\section{V. WOERNER}

The importance of the earth's radiation budget in determining climate has long been recognized. This paper provides an overview of the earth radiation budget satellite system through which NASA/NOAA are planning to provide earth radiation budget data during the $1980 \mathrm{~s}$. The paper shows an example of U.S. science activities, specifically noting the need for radiation budget measurements, from which the scientific objectives were developed. The associated mission and system analyses, instrument designs, and data analysis methods to meet the scientific objectives 
are summarized. The study results show that a multiple satellite system with intruments having several spatial resolutions on the earth (top of the atmosphere) is required in order to meet the scientific objectives.

Historical review of earth radiation budget studies and the scientific rationale leading to ERBSS

\section{R. J. CURRAN ET AL.}

System implementation for the earth radiation budget satellite system

\section{J. E. COOPER AND C. V. WOERNER}

Sampling analysis for the earth radiation budget satellite system mission based on orbital coverage and cloud variability

E. F. HARRISON ET AL.

Thermal model of a filtered radiometer

\section{J. R. MAHAN AND} M. R. LUTHER
The earth radiation budget satellite system (ERBSS) is the next step in an evolutionary process leading from early guesses at the radiation energetics of the earth to accurate satellite determinations. Before 1959, several authors attempted to estimate the amount of solar irradiance absorbed and the amount of thermal, infrared energy emitted from the earth-atmosphere system. These estimates were based on available surface observations and theoretical analyses. The artificial earth satellite made it possible to observe many different geographic locations around the earth in a small amount of time, with the same radiometer. Observations made with the earliest satellites helped to establish the magnitudes of the various flux components. The series of radiometers on ITOS, Nimbus, and NOAA satellites shows a progression in quality and dedication to determining this parameter.

Studies of the physical processes that affect the climate of the earth have motivated the desire for improved accuracy of the determination of the earth's radiation budget components. Further, the problem of sampling a parameter that varies quite rapidly in time and position has strongly affected the capability of any proposed system. The requirements that guided the development of the present system will be reviewed in the forum of past history and in the nature of the problem.

Knowledge of the earth's radiation budget is an integral part of climate studies; however, present data are inadequate in spatial and temporal coverage, instrument spectral coverage, and sensor stability. Yet, the earth-orbiting satellite provides a platform outside the earth's atmosphere that is capable of simultaneously monitoring the outgoing reflection of the sun's energy from the earth surface and atmosphere and the long-wave radiation emitted by the earth and its atmosphere. Therefore, NASA and NOAA are planning an earth radiation budget satellite system, beginning in the early 1980s, composed of instruments on NOAA's TIROS-N series of near-polar operational satellites and on a NASA mid-inclination satellite. This paper describes the instrument system requirements and a conceptual design of an instrument approach to meet these requirements for providing the earth radiation budget data.

Obtaining accurate measurements of earth's radiation budget requires spatial and temporal sampling that accounts for variation in the solar elevation angle, cloud conditions, and surface features. Satellite concepts with various field-of-view sensors and orbital inclinations and altitudes were analyzed to define sampling and temporal-geographical coverage capabilities. These satellite systems were also evaluated by simulating flight measurements over an earth radiation model that included diurnal effects. The ability of the system to adequately sample cloud variability, which has a significant effect on reflected radiation, was analyzed by use of cloud-cover statistics and recent satellite cloud data from THIR and SMS/GOES. Results indicate that multiple satellites, in low- and high-inclined orbits, are required to obtain accurate monthly mean radiation values on regional, zonal, and global scales. The proposed system involves two TIROS-N satellites and one AEM satellite, each with medium and wide field-of-view sensors along with a scanner.

Filtered radiometers are either used or proposed for use in a variety of earth radiation budget applications. They generally consist of a receiver that converts incident thermal radiation into an electrical signal, an aperture that limits the field of view of the receiver, and a hemispherical filter dome through which the receiver views its surroundings. The purpose of the filter dome is to limit the radiation heat flux incident to the receiver of the solar spectrum. Unfortunately, the dome absorbs some of the radiant energy incident from the environment and from the other surfaces of the radiometer and reemits it as long wavelength thermal radiation, a portion of which finds its way to the receiver. Also, the other surfaces under the dome are able to communicate with the receiver by reflection of long wavelength radiation from the dome. In short, the dome acts as a source of long wavelength radiation that contaminates the short wavelength measurement.

It is clear that solar spectrum radiation measurements by a filtered radiometer must be corrected for long wavelength contamination from the dome if highly accurate results are to be obtained. One such correction technique has been developed and validated using a detailed thermal model for the filtered radiometer in conjunction with a realistic earth radiation source field. Described is the derivation and qualification of the thermal model of a filtered radiometer 
used in the development of the correction technique. The paper emphasizes the assumptions and physical principles inherent in the model and presents the solution and qualification strategies as well.

Performance analysis of a filtered wide field-of-view radiometer for earth radiation budget measurements

\section{J. E. COOPER AND} M. R. LUTHER
The proposed earth radiation budget satellite system (ERBSS) of the 1980s will include a wide field-of-view (WFOV) fixed axis earth radiation discriminator consisting of a shortwave channel and a total (unfiltered) channel. In conceptual design studies, the broad-band spectral isolation required for the shortwave channel (i.e., $\lambda \leq 5 \mu \mathrm{m}$ ) is achieved by use of a hemispherical fused silica dome filter (Suprasil $W$ ) placed in front of a wire-wound thermopile radiation detector, similar to the earth radiation budget experiment on Nimbus-6 and Nimbus-G. It is shown that the dome maintains neither a uniform nor constant temperature distribution as it responds to changes in the earth's long-wave component. Accurate determination of shortwave irradiance requires knowledge of the dome thermal response since the thermopile responds to changes in the dome temperature as well as the shortwave scene. Data are presented that show that the normal variations over an orbit in the dome temperature distribution could result in a significant uncertainty in the shortwave irradiance determination if disregarded in the data reduction process. An iterative data reduction technique that accounts for these variations due to changes in long-wave terrestrial irradiance is presented.

Requirements for wide and medium field-of-view apertures will be reviewed. A novel aperture configuration will be described and shown to fulfill all ERBSS criteria. Various possible absorbing or reflecting surface treatments for aperture components will be discussed. Requirements for mating detector cavities to these apertures will be presented. It will be demonstrated that a simple axial plane graphical procedure can be used to test a candidate cavity geometry even though the impinging radiation primarily is composed of skew rays. Several suitable cavity geometries will be shown in which the choice is primarily one of available width or depth of the cavity enclosure.

One of the methods of checking the calibration of narrow-field satellite radiometers in orbit is to use the independent estimates of the radiation field at satellite altitude derived from a combination of surface or aircraft measurements and radiative transfer calculations for the intervening atmosphere. Emphasis here is on the solar radiation scanning channels, as the long-wave channels have onboard calibration. For calibration checks from only ground-based data, the minimum required measurements are incident irradiance at ground level, surface reflectance, atmospheric optical thickness, and amount and distribution of water vapor. Expressions for use of these data in radiative transfer calculations, as well as results of some calculations, of the space-directed radiation are given. Measurements of the radiation field at aircraft altitudes obviously require smaller atmospheric corrections and, thereby, have the possibility of yielding higher accuracy in calibration checks of satellite radiometers. Some of the measurement problems inherent in aircraft instruments are reviewed, and the accuracies of calibration checks for satellite radiometers under different conditions are estimated.

Data analysis algorithms for satellite measurements of earth radiation budget contain assumed directional characteristics of radiation emitted and scattered from the earth-atmosphere system. Baseline directional models have been generated from existing measurements for application to feasibility studies of data reduction algorithms, in particular to studies of the sensitivity of flux estimates to errors in the empirical directional models. The emitted radiation baseline directional models were generated from published Nimbus-2 MRIR data, while the scattered solar radiation models were derived from airborne MRIR measurements reported in the literature. In this paper, the baseline models are compared to scanning, narrow field-of-view satellite measurements made by the Nimbus-6 earth radiation budget (ERB) experiment. The ERB data were processed in terms of earth targets and discrete angular intervals (bins) and were used to evaluate the baseline models for both the long-wave earth emission and the shortwave solar spectral ranges. Results show that the baseline long-wave models are adequate for most conditions, while the shortwave models are inadequate. Progress toward improved directional models based on Nimbus-6 ERB data and theoretical considerations for various surface and cloud conditions will be discussed. The concomitant problem of identification of surface/cloud conditions for the selection of the appropriate directional models to be employed for a given earth target at a given sampling time will be addressed. 
Analysis of simulated measurements of earthemitted radiation using geometric shape factors and some results from analysis of ESSA-7 and Nimbus-6 data

W. L. WEAVER AND

R. N. GREEN

Deconvolution estimation theory applied to Nimbus-6 ERB data

R. N. GREEN AND

G. L. SMITH
A study is reported in which simulated irradiance measurements made with satellite-borne, wide field-of-view radiometers are reduced to earth-emitted fluxes using geometric shape factors. Spherical and horizontal flat plate detectors with unrestricted and restricted earth fields of view are considered, and the earth radiation model is derived from Nimbus- 6 data. Estimates of the average flux are determined for global and zonal scales and for areas smaller than the radiometer field of view, and the estimates are compared to the average fluxes derived directly from the model. Effects of errors due to measurement sample, satellite altitude, and directional characteristics of radiation field are considered.

Wide field-of-view radiometer measurements from the ESSA-7 and Nimbus-6 satellite are analyzed using the shape factor method, and some results for global, zonal, and regional scales are discussed.

Deconvolution, or resolution enhancement, of wide field-of-view (WFOV) data to the top-ofthe-atmosphere may be accomplished by use of spherical harmonics. The coefficients of the spherical harmonics may be computed by use of the onthogonality relation for spherical harmonics or by parameter estimation, which is a statistical approach accounting for random variations and sampling and providing measures of the accuracy of the results. A third approach is to analyze data by use of a shape factor, with no attempt at resolution enhancement. The resolution that is attainable by deconvolution of WFOV data is limited. This limit is a function of sampling and is demonstrated for the Nimbus-6 ERB WFOV data. The accuracy for derived regional flux is presented as a function of the region size for application of Nimbus-6. Parameter estimation to deconvolution is demonstrated for the case of incomplete data coverage of the earth. Results include flux and accuracy maps.

The theoretical, numerical, and practical differences among the three approaches are discussed, including accuracies. Use of the orthogonality relations is simple, fast, and inexpensive. The disadvantages of the method are that it ignores the statistical nature of the problem and requires interpolation between measurement points. Parameter estimation has the advantage of allowing for the statistical nature of the problem and of accounting for the distribution of the measurements. However, the method is time consuming computationally, and thus expensive.

\section{JOINT CONFERENCE ON APPLICATIONS OF AIR POLLUTION METEOROLOGY}

The Joint Conference on Applications of Air Pollution Meteorology was held November 29December 2, 1977, in Salt Lake City, Utah, under the sponsorship of the American Meteorological Society and the Air Pollution Control Association. "The Conference was called to meet the perceived need for a larger forum for disseminating information on application-oriented activities in air pollution meteorology."

The Preprint Volume contains 70 papers arranged under the following topics:

Observational Studies of Dispersion in the Atmosphere - Measures of Atmospheric Dispersion Capacity - Observations of Dispersion in Complex Terrain • Modeling in Complex Terrain • Air Quality Modeling Techniques $\bullet$ Validation and Standardization of Models $\bullet \mathrm{Ob}$ structions to Flow and Their Air Quality Consequences • Long-Range Transport and Fate of Pollutants

\section{AMERICAN METEOROLOGICAL SOGIETY 45 BEACON ST., BOSTON, MASS. 02108}


Conference on Cloud Physics and Atmospheric Electricity of the American Meteorological Society, July 31-August 4, 1978, Issaquah, Wash.

\section{AMS National Officers President: George P. Cressman President-Elect: Chester W. Newton Executive Director: Kenneth C. Spengler}

\author{
AMS 1977 Committee \\ on Cloud Physics
}

\begin{abstract}
AMS 1977 Committee on Atmospheric Electricity
\end{abstract}

Program Committee

Local Arrangements Committee

\section{Synopsis of Sessions}

Gabor Vali, Chairman

Kenneth V. Beard

William R. Cotton

James E. Jiusto

Arthur A. Few, Chairman

Robert V. Anderson

Marx Brook

Peter V. Hobbs, Chairman

Peter V. Hobbs, Chairman
G. Garland Lala Alexis B. Long

Byron B. Phillips

William A. Hoppel

E. Philip Krider

W. David Rust

E. Philip Krider

Lawrence F. Radke
Hans R. Pruppacher

R. R. Rogers

Kenneth C. Young

July 30, Sun., 7:00 p.m. Registration Sun., 8:00 p.m. Meeting of Session Chairmen

July 31, Mon., 8:00 a.m. Registration (continued) Mon., 8:45 a.m. Opening Remarks

Mon., 9:00 a.m. Session 1: Cloud Active Nuclei and Atmospheric

Mon., 10:00 a.m. Spouses' Coffee

Mon., 1:30 p.m. Session 2: Cloud Particles: Liquid

Mon., 4:15 p.m. Session 3: Cloud Particles: Solid

Mon., 6:00 p.m. Icebreaker (cash bar)

Aug. 1, Tues., 8:30 a.m. Session 4: Precipitation Particles: Growth and Size Spectra

Tues., 11:00 a.m. Session 5: Precipitation Particles: Hailstones

Tues., Afternoon Free for Recreation

Tues., 6:30 p.m. Session 6: Fogs

Tues., 8:40 p.m. Session 7: Orographic Clouds and Precipitation

Aug. 2, Wed., 8:30 a.m. Bergeron Memorial Lecture

Wed., 9:00 a.m. Session 8: Cyclonic Storms

Wed., 10:45 a.m. Session 9: Microstructure of Convective Clouds-I

Wed., Afternoon Free for Recreation (Laboratory and Aircraft "Show and Tell” by Univ. of Washington's Cloud Physics Group)

Wed., 6:30 p.m. Session 10: Microstructure of Convective Clouds-II

Wed., 8:15 p.m. Session 11: Interactions of Convective Clouds with Near-Environment-I

Aug. 3, Thurs., 8:30 a.m. Session 12: Interactions of Convective Clouds with Near-Environment-II

Thurs., 10:00 a.m. Session 13: Interactions of Convective Clouds with Meso- and Regional-Scales-I

Thurs., 1:30 p.m. Session 14: Interactions of Convective Clouds with Meso- and Regional-Scales-II

Thurs., 3:00 p.m. Session 15: Severe Convective Storms

Thurs., Evening Boat Tour, Indian Salmon Bake, and Indian Dances

Aug. 4, Fri., $\quad \mathbf{8 : 3 0}$ a.m. Session 16: Atmospheric Electricity-I

Fri., $\quad$ 1:30 p.m. Session 17: Atmospheric Electricity-II

Fri., $\quad$ 4:45 p.m. Closing Remarks 


\section{General Information}

\section{Accommodations}

\section{Registration}

Transportation

\section{Spouses' Coffee}

\section{Icebreaker}

Social Arrangements
The American Meteorological Society's quadrennial Conference on Cloud Physics and Atmospheric Electricity will be held 31 July-4 August 1978 at the Providence Heights Education and Conference Center, Pine Lake, Issaquah (near Seattle), Wash. The University of Washington's Cloud Physics Group is the arranger.

All sessions will be held at the Providence Heights Center, which is a $1 / 2 \mathrm{~h}$ drive from both the Seattle-Tacoma International Airport and downtown Seattle. Accommodations and/or meals are available at Providence Heights, but they must be reserved as soon as possible (and in no case later than 30 June 1978) by sending reservation forms (obtainable from Prof. Peter V. Hobbs, Atmospheric Sciences Dept., AK-40, Univ. of Washington, Seattle, Wash. 98195-tel: 206-543-6027) directly to: Providence Heights Center, 4221 228th, S.E., Issaquah, Wash. 98027 (tel: 206-392-6471). The costs per person (excluding Washington State Sales Tax at 5.4\%) for accommodations and three meals per day (served buffet style) are: $\$ 25$, single-occupancy sleeping room with shared bath (140 available); $\$ 29$, single-occupancy sleeping room with private bath (24 available); and $\$ 24$, doubleoccupancy sleeping room with private bath (24 available). Those not wishing to stay at Providence Heights must make their own accommodation arrangements.

Providence Heights is located in a large timbered-acre site in the foothills of the Cascade Mountains. Recreational facilities, which are free, include indoor swimming pool, gymnasium, tennis courts, recreation room, cocktail lounge, etc.

The AMS registration desk, to be located at Providence Heights, will be open Sunday, 30 July, from 7:00 p.m. to 9:00 p.m., and on Monday through Thursday from 8:00 a.m. to 5:00 p.m. Registration fees, including a copy of the preprint volume, are: \$45, AMS members, speakers, and session chairmen; \$55, nonmembers; \$25, AMS Puget Sound Chapter members; $\$ 15$, local students $(\$ 5$, without preprint volume). We urge you to preregister by sending the appropriate remittance together with your name, affiliation, and complete mailing address to: American Meteorological Society, 45 Beacon St., Boston, Mass. 02108, Attn: Cloud Physics Conference. The preprint volume will be sent to those preregistrants (in U.S. and Canada) whose remittances are received prior to 30 June 1978.

There is no regular public transportation to or from the Providence Heights Conference Center from either Seattle-Tacoma Airport or downtown Seattle. However, the Suburban Airporter Limousine leaves the airport (Western Airlines Baggage pickup area, Carousel 8) for Issaquah and goes to Providence Heights on request at 2:45 p.m., 8:00 p.m., 8:45 p.m., and 9:40 p.m. on Sundays. On weekdays, the limousine leaves at 8:00 a.m. in addition to the above times. The limousine fare is $\$ 6$ per person (minimum of 2 fares@ \$12). Taxi fare from airport to Providence Heights is about $\$ 25$. Those wishing to make private excursions away from Providence Heights during the week should rent a car. Group transportation will be provided for any formal conference excursions.

A Spouses' Coffee is planned for Monday, 31 July, at 10:00 a.m. The get-together will enable spouses and their families to become acquainted and to plan tours together, should they so wish. There is no formal social program planned.

An Icebreaker (cash bar) will be held on Monday, 31 July, from 6:00 p.m. to 7:30 p.m.

The afternoons of Tuesday, 1 August, and Wednesday, 2 August, will be left free for recreation (scientific sessions are scheduled for Tuesday and Wednesday evenings). The "Treasures of Tutankhamun" exhibition will be at the Seattle Center at the time of the conference. Those interested should make their own arrangements to see this exhibition. The conference also coincides with Seattle's Seafair Week, which provides many events of interest to vacationing families.

If there is sufficient interest, a narrated boat trip across Puget Sound, followed by an Indian Salmon Bake and Indian Dances, will be arranged for Thursday evening, 3 August. 
The University of Washington's Cloud Physics Group will conduct a "Show and Tell" of its laboratory (on the University of Washington campus in Seattle) and of its B-23 Cloud Physics Research Aircraft (at Boeing Field, Seattle) on Wednesday, 2 August, from 2:00 p.m. to 4:00 p.m.

\section{PROGRAM}

Sun., July 30 , 7:00 p.m.

\section{Sun., July 30, 8:00 p.m. \\ Mon., July 31, 8:00 a.m. \\ Mon., July 31, 8:45 a.m. \\ Mon., July 31, 9:00 a.m.}

Mon., July 31,

10:00 a.m.

\section{Mon., July 31, 10:16-10:45 a.m.}

\section{Mon., July 31,} 10:45 a.m.

\section{Registration}

\section{Meeting of Session Chairmen}

\section{Registration (continued)}

\section{Opening Remarks}

\section{Session 1: Cloud Active Nuclei and Atmospheric Aerosol}

Chairman: Sean A. Twomey, Univ. of Arizona, Tucson, Ariz.

1.1 A saturation hygrometer. H. E. Gerber, U.S. Naval Research Lab., Washington, D.C.

1.2 Detailed evaluation of Allee-type CCN counter. G. Langer, B. Baird, and J. Baird, NCAR, Boulder, Colo.

1.3 A comparison of hydrophobic and hydrophilic filters using a continuous flow filter chamber. Robert R. Czys, Univ. of Chicago, Chicago, Ill.

1.4 Relationship between dry aerosol size, critical supersaturation, and size at high relative humidity. William A. Hoppel, U.S. Naval Research Lab., Washington, D.C.

1.5 Concentration fluctuation of marine aerosol in the planetary boundary layer. Josef Podzimek, Univ. of Missouri-Rolla, Rolla, Mo.

1.6 Evidence of mass transport through West Coast inversion. Jindra Goodman, San José State Univ., San José, Calif.

\section{Spouses' Coffee}

\section{Coffee Break}

\section{Session 1 (continued)}

1.7 Summer climatology of aerosols and nuclei in the central High Plains in the United States. David C. Rogers and Gabor Vali, Univ. of Wyoming, Laramie, Wyo.

1.8 Giant nuclei and warm rain initiation. David B. Johnson, Univ. of Chicago, Chicago, Ill.

1.9 Ice pellet melting: Ejection of microdroplets. Roger J. Cheng, State Univ. of New York at Albany, Albany, N.Y.

1.10 Meteorological impact of the pollutants from a copper smelter. Farn Parungo, Rudolph Pueschel, and Dennis Wellman, Environmental Research Labs./NOAA, Boulder, Colo.

1.11 Precipitation scavenging of aerosol particles. Lawrence F. Radke, Mark E. Eltgroth, and Peter V. Hobbs, Univ. of Washington, Seattle, Wash.

1.12 The hydrodynamic infuence on phoretic scavenging of aerosol particles by cloud drops. K. H. Leong and Kenneth V. Beard, Illinois State Water Survey, Urbana, Ill. 


\section{Mon., July 31, 12:00 p.m. \\ Mon., July 31, 1:30 p.m.}

\section{Mon., July 31,} 3:42 p.m.

Mon., July 31, 3:42-4:15 p.m.

Mon., July 31, 4:15 p.m.

\section{End of Session 1}

\section{Session 2: Cloud Particles: Liquid}

Chairman: Kenneth C. Young, Univ. of Arizona, Tucson, Ariz.

2.1 Realism of droplet and crystal populations in laboratory clouds-A review and suggested future work. Edward E. Hindman II and W. G. Finnegan, Naval Weapons Center, China Lake, Calif.

2.2 An improved droplet generator. Theodore W. Cannon and Walter W. Grotewold, NCAR, Boulder, Colo.

2.3 Water droplet growth on NaCl nuclei. M. A. Vietti, Univ. of Maine, Orono, Maine.

2.4 The collision and coalescence of cloud droplets. T. S. Tung and Kenneth V. Beard, Illinois State Water Survey, Urbana, Ill.

2.5 Further numerical studies on the effect of electric charges and electric fields on the collision efficiency of cloud drops. R. J. Schlamp, S. N. Grover, and Hans R. Pruppacher, Univ. of California, Los Angeles, Calif.; and A. E. Hamielec, McMaster Univ., Hamilton, Ont., Canada.

2.6 Height dependence and volume definition of the collision kernel function for cloud droplets. Fausto Carlos de Almeida, NCAR, Boulder, Colo.

2.7 The influence of cloud base temperature on droplet concentration. David B. Johnson, Univ. of Chicago, Chicago, Ill.

2.8 The influence of turbulent mixing on droplet evolution in clouds. R. C. Corbin, J. Latham, C. Mill, R. L. Reed, and I. M. Stromberg, UMIST, Manchester, England.

2.9 Small-scale variability of the cloud droplet spectra in cumulus clouds. Alfred R. Rodi, Univ. of Wyoming, Laramie, Wyo.

2.10 Three-dimensional numerical simulations of cloud-base turbulence with condensation theory. Terry L. Clark and William D. Hall, NCAR, Boulder, Colo.

2.11 On the microstructure-stability characteristics of clouds over an equatorial region. K. K. Kanuga, Univ. of Nairobi, Nairobi, Kenya.

\section{End of Session 2}

\section{Coffee Break}

\section{Session 3: Cloud Particles: Solid}

Chairman: Robert I. Sax, National Hurricane and Experimental Meteorology Lab./ NOAA, Coral Gables, Fla.

3.1 Ice crystal growth kinetics and accommodation coefficients. N. Fukuta, Univ. of Utah, Salt Lake City, Utah.

3.2 The influence of the carrier gas velocity, diffusivity, and thermal conductivity on ice crystal habit. Vernon W. Keller, National Hurricane and Experimental Meteorology Lab./NOAA, Coral Gables, Fla.; and John Hallett, Desert Research Institute, Reno, Nev.

3.3 An observational study of the accretional habits of ice crystals having a simple geometric shape. Robert E. D'Errico, Environmental Research \& Technology, Inc., Concord, Mass.; and August H. Auer, Univ. of Wyoming, Laramie, Wyo.

3.4 Formation mechanism of ice crystals in the cloudless atmosphere. T. Ohtake, $\mathrm{K}$. Jayaweera, and K. Sakurai, Univ. of Alaska, Fairbanks, Alaska. 
3.5 Observations of cirrus particle characteristics occurring with halos. Morton Glass and Donald J. Varley, Air Force Geophysics Lab., Hanscom AFB, Bedford, Mass.

Mon., July 31, 5:30 p.m.

Mon., July 31, 6:00 p.m.

Tues., Aug. 1, $8: 30$ a.m.

Tues., Aug. 1,

10:41 a.m.

\section{Tues., Aug. 1,} 10:41-11:00 a.m.

\section{End of Session 3}

\section{Icebreaker (cash bar)}

\section{Session 4: Precipitation Particles: Growth and Size Spectra}

Chairman: J. S. Marshall, McGill Univ., Montreal, Que., Canada.

4.1 Terminal fall velocity and drag coefficient of deformed drops. Thomas E. Hoffer and Phillip Gillaspy, Desert Research Institute, Reno, Nev.

4.2 Raindrop breakup: The energy of disruption. Yean Lee and A. N. Dingle, Univ. of Michigan, Ann Arbor, Mich.

4.3 The collection efficiency of similarly sized precipitation drops. H. T. Ochs and Kenneth V. Beard, Illinois State Water Survey and Lab. for Atmospheric Research, Urbana, Ill.

4.4 A wind tunnel study on the growth of graupel. J. C. Pflaum and Hans R. Pruppacher, Univ. of California, Los Angeles, Calif.

4.5 An analytical model of snowflake growth in stratiform clouds. Richard E. Passarelli, Jr., Univ. of Chicago, Chicago, Ill.

4.6 Warm rain showers in Hawaii. T. Takahashi, Univ. of Hawaii, Hilo, Hawaii.

4.7 Drop-size distributions in Kenyan rain showers. K. K. Kanuga and F. O. Agumba, Univ. of Nairobi, Nairobi, Kenya.

4.8 Characterization of raindrop-size distributions. D. M. Takeuchi, Meteorology Research, Inc., Altadena, Calif.

4.9 The evolution of raindrop spectra in warm-based convective storms as observed and numerically modeled. R. E. Carbone, NCAR, Boulder; and Loren D. Nelson, Bureau of Reclamation, Denver, Colo.

4.10 Airborne measurements of particle-size distributions in frontal clouds. Robert A. Houze, Jr., Peter V. Hobbs, Paul H. Herzegh, and David B. Parsons, Univ. of Washington, Seattle, Wash.

End of Session 4

\section{Coffee Break}

\section{Session 5: Precipitation Particles: Hailstones}

Chairman: Roland List, Univ. of Toronto, Toronto, Ont., Canada.

5.1 Total hydrometeor spectra in a hailstorm and implications for precipitation growth processes. D. J. Musil and P. L. Smith, Jr., South Dakota School of Mines and Technology, Rapid City, S.Dak.; and Andrew J. Heymsfield, NCAR, Boulder, Colo.

5.2 Airborne vs. ground hail sizes. J. R. Miller, Jr., D. J. Musil, G. N. Johnson, J. L. Halvorson, and P. L. Smith, Jr., South Dakota School of Mines and Technology, Rapid City, S.Dak. 
Tues., Aug. 1, 12:00 noon

Tues., Aug. 1, Afternoon

Tues., Aug. 1, 6:30 p.m.

Tues., Aug. 1, 8:30 p.m.

Tues., Aug. 1, $8: 30-8: 40$ p.m.

Tues., Aug. 1, 8:40 p.m.
5.3 Analysis parameters for accreted ice. E. Ashworth and T. Ashworth, South Dakota School of Mines and Technology, Rapid City, S.Dak.; and Charles A. Knight, NCAR, Boulder, Colo.

5.4 Experiments on the factors involved in interpreting natural hail crystal textures. Charles A. Knight and Nancy C. Knight, NCAR, Boulder, Colo.; and T. Ashworth, South Dakota School of Mines and Technology, Rapid City, S.Dak.

5.5 South African Lowveld hailstone embryos. Nancy C. Knight and Charles A. Knight, NCAR, Boulder, Colo.

\section{End of Session 5}

Free for Recreation

\section{Session 6: Fogs}

Chairman: Robert Ruskin, U.S. Naval Research Lab., Washington, D.C.

6.1 Fog microphysical measurements on the West Coast. James G. Hudson, Desert Research Institute, Reno, Nev.

6.2 Microphysics of stratocumulus clouds as revealed by the real-time CCN spectrum measurements. V. K. Saxena and N. Fukuta, Univ. of Utah, Salt Lake City, Utah.

6.3 Particle size distributions in three fogs. Gary L. Trusty and Thomas H. Cosden, U.S. Naval Research Lab., Washington, D.C.

6.4 Cloud and fog studies using remote sensors in San Diego. V. R. Noonkester, Naval Ocean Systems Center, San Diego, Calif.

6.5 Airborne measurements in marine stratus. P. B. Wagner and J. W. Telford, Desert Research Institute, Reno, Nev.

6.6 On the formation of convective marine fog. Steven K. Chai and James W. Telford, Desert Research Institute, Reno, Nev.

6.7 Cloud physics and boundary layer measurements in radiation fogs. G. Garland Lala, M. Meyer, and James E. Jiusto, State Univ. of New York at Albany, Albany, N.Y.

6.8 Vertical inhomogeneity in atmospheric fog and haze. R. G. Pinnick, D. L. Hoihjelle, G. Fernandez, E. B. Stenmark, J. D. Lindberg, and S. G. Jennings, U.S. Army, White Sands Missile Range, N.Mex.; and Petr Chýlek, Harvard Univ., Cambridge, Mass.

End of Session 6

Coffee Break

\section{Session 7: Orographic Clouds and Precipitation}

Chairman: Roger A. Pielke, Univ. of Virginia, Charlottesville, Va.

7.1 Microphysical and dynamical characteristics of winter storms over the Sierra Nevada. John D. Marwitz and Ronald Stewart, Univ. of Wyoming, Laramie, Wyo.; and Larry Vardiman, Bureau of Reclamation, Auburn, Colo.

7.2 The needle anomaly in Sierra Nevada snowfall. Roger F. Reinking, Environmental Research Lab./NOAA, Boulder, Colo. 
7.3 Modification of orographic flow in winter by precipitation. G. E. Hill, Utah State Univ., Logan, Utah.

7.4 Numerical simulation of clouds and snowfall over mountainous terrain. C. F. Chappell, D. R. Smith, and E. C. Nickerson, Environmental Research Lab./NOAA, Boulder, Colo.

Tues., Aug. 1, 9:40 p.m.

Wed., Aug. 2, 8:30-9:00 a.m.

\section{Wed., Aug. 2, 9:00 a.m.}

Wed., Aug. 2,

10:15 a.m.

\section{Wed., Aug. 2, 10:15-10:45 a.m.}

Wed., Aug. 2, 10:45 a.m.

\section{End of Session 7}

\section{Bergeron Memorial Lecture}

Chairman: Roscoe R. Braham, Jr., Univ. of Chicago, Chicago, Ill.

Review of the late Professor Tor Bergeron's contributions to meteorology with particular reference to cloud physics. $\mathrm{H}$. Weickmann, Environmental Research Lab./NOAA, Boulder, Colo.

\section{Session 8: Cyclonic Storms}

Chairman: Carl W. Kreitzberg, Drexel Univ., Philadelphia, Pa.

8.1 Some observations of precipitation systems associated with cyclones based on ground observations of snow crystals. Akira Ono, Nagoya Univ., Nagoya, Japan.

8.2 The University of Washington's CYCLES Project: An overview. Peter V. Hobbs, Univ. of Washington, Seattle, Wash.

8.3 Air motions, mesoscale structure, and cloud microphysics associated with a cold front. Peter V. Hobbs, John D. Locatelli, Thomas J. Matejka, and Robert A. Houze, Jr., Univ. of Washington, Seattle, Wash.

8.4 Generating cells and precipitation growth in mesoscale rainbands. Paul $\mathrm{H}$. Herzegh and Peter V. Hobbs, Univ. of Washington, Seattle, Wash.

8.5 Microphysical and dynamical structure of mesoscale cloud features in extratropical cyclones. Thomas J. Matejka, Robert A. Houze, Jr., and Peter V. Hobbs, Univ. of Washington, Seattle, Wash.

\section{End of Session 8}

\section{Coffee Break}

\section{Session 9: Microstructure of Convective Clouds-I}

Chairman: Bernice Ackermann, Illinois State Water Survey, Urbana, Ill.

9.1 Relationship of ice to water at $-10^{\circ} \mathrm{C}$ during initial penetrations of a population of Florida cumuli. Robert I. Sax and Vernon W. Keller, National Hurricane and Experimental Meteorology Lab./NOAA, Coral Gables, Fla.

9.2 Microphysical characteristics of individual tropical cumuli developing over land and over water: A comparison case study. Paul T. Willis and Robert I. Sax, National Hurricane and Experimental Meteorology Lab./NOAA, Coral Gables, Fla.

9.3 Microphysics of invigorated cumulus development. D. Lamb and J. Hallett, Desert Research Institute, Reno, Nev.; and Robert I. Sax, National Hurricane and Experimental Meteorology Lab./NOAA, Coral Gables, Fla.

9.4 Microstructure of an "accumulation zone" in a tropical Cb cloud. J. F. Gayet and R. G. Soulage, Univ. de Clermont, Lannemezan, France.

9.5 Time duration of the microstructure of a Cb cloud in middle latitude. J. F. Gayet, Univ. de Clermont, Lannemezan, France. 
9.6 Single-level microstructure of prefrontal and postfrontal Illinois cumuli. Robert I. Sax and Jane C. Eden, National Hurricane and Experimental Meteorology Lab./ NOAA, Coral Gables, Fla.; and Bernice Ackerman, Illinois State Water Survey, Urbana, Ill.

Wed., Aug. 2, 12:03 p.m.

Wed., Aug. 2, Afternoon

Wed., Aug. 2, 6:30 p.m.

Wed., Aug. 2, 7:50 p.m.

Wed., Aug. 2, 8:15 p.m.

\section{End of Session 9}

\section{Free for Recreation}

(Laboratory and Aircraft "Show and Tell" by University of Washington's Cloud Physics Group)

\section{Session 10: Microstructure of Convective Clouds-II}

Chairman: Bernard A. Silverman, Bureau of Reclamation, Denver, Colo.

10.1 21 June 1976: Case study of precipitation initiation in the NHRE observational area. Peter N. Johnson and Andrew J. Heymsfield, NCAR, Boulder, Colo.; and Gabor Vali, Univ, of Wyoming, Laramie, Wyo.

10.2 A possible transient ice collection zone in a singular continental mountain cumulus cloud. John L. LeCompte, Colorado Water Conservation Board, Denver; and Gerald J. Mulvey, Colorado State Univ., Ft. Collins, Colo.

10.3 Phase detection of convective cloud hydrometeors using lidar. Kelvin S. Danielson, Colorado State Univ., Ft. Collins; and Vernon E. Derr, Environmental Research Lab./NOAA, Boulder, Colo.

10.4 Precipitation mechanisms in summertime storms in the Montana HIPLEX area. William A. Cooper, Univ. of Wyoming, Laramie, Wyo.

10.5 Turbulent rates of dispersion of ice particles in convective clouds. R. P. Lawson, Colorado International Corp., Boulder, Colo.

10.6 Cumulus cloud measurements in northern Canada. G. A. Isaac, R. S. Schemenauer, R. A. Stuart, and A. J. Chisholm, Atmospheric Environment Service, Downsview; and J. I. MacPherson, National Research Council, Ottawa, Ont., Canada.

\section{End of Session 10}

\section{Session 11: Interactions of Convective Clouds with Near-Environment-I}

Chairman: William R. Cotton, Colorado State Univ., Ft. Collins, Colo.

11.1 Observations of moist adiabatic ascent in northeast Colorado cumulus congestus clouds. Andrew J. Heymsfield, Peter N. Johnson, and James E. Dye, NCAR, Boulder, Colo.

11.2 Entrainment in some Colorado multicell storms. Ilga R. Paluch, NCAR, Boulder, Colo.

11.3 Evidence of convective cloud base entrainment of surface suspensoids. James A. Heimbach, Jr., Montana State Univ., Bozeman, Mont.; and Newton C. Stone, Water Resources Development Corp., Palm Springs, Calif.

11.4 Time scales of convective clouds. G. E. Hill, Utah State Univ., Logan, Utah.

11.5 Effects of evaporation, water load, and wind shear on cloud development in a three-dimensional numerical model. Man Kong Yau, McGill Univ., Montreal, Que., Canada.

11.6 Application of VHF pulsed Doppler radar to cloud physics research. K. S. Gage, J. L. Green, and T. E. VanZandt, Aeronomy Lab., ERL/NOAA, Boulder, Colo. 
Wed., Aug. 2, 9:35 p.m.

Thurs., Aug. 3, 8:30 a.m.

Thurs., Aug. 3,

9:30 a.m.

Thurs., Aug. 3,

9:30-10:00 a.m.

\section{Thurs., Aug. 3,} 10:00 a.m.

\section{End of Session 11}

\section{Session 12: Interactions of Convective Clouds with Near-Environment-II}

Chai,man: Geoffrey E. Hill, Utah State Univ., Logan, Utah.

12.1 Subcloud eddy fluxes and scales of vertical motion in a cumulus environment. Roger F. Reinking, Environmental Research Lab./NOAA, Boulder, Colo.

12.2 Aircraft turbulence measurements in and below cumulus congestus over mountainous terrain. William R. Cotton, D. C. Hahn, and R. Banta, Colorado State Univ., Ft. Collins, Colo.

12.3 Parameterizing subgrid turbulent mixing in a simulation of an industrially spawned cumulus cloud. Paul M. Tag, Naval Environmental Prediction Research Facility, Monterey; and Francis W. Murray and L. Randall Koenig, The Rand Corp., Santa Monica, Calif.

12.4 Factors influencing the nature of precipitation at cloud base in Montana. E. S. Lobl and D. M. Takeuchi, Meteorology Research, Inc., Altadena, Calif.

12.5 Self-precipitation of snow from cooling towers. L. Randall Koenig, The Rand Corp., Santa Monica, Calif.

End of Session 12

\section{Coffee Break}

Session 13: Interactions of Convective Clouds with Meso- and Regional-Scales-1

Chairman: David Atlas, Goddard Space Flight Center/NASA, Greenbelt, Md.

13.1 Aircraft penetrations of cumulonimbus clouds during GATE. Edward J. Zipser and Alan H. Miller, NCAR, Boulder, Colo.

13.2 Mesoscale vertical air motions in intense tropical convection. Colleen A. Leary and Robert A. Houze, Jr., Univ. of Washington, Seattle, Wash.

13.3 The characteristics of evolving mesoscale systems over mountainous terrain as revealed by radar and PAM. R. George and William R. Cotton, Colorado State Univ., Ft. Collins, Colo.

13.4 A radar case study analysis of a heavily precipitating quasi-stationary convective storm system. K. Knupp, Kelvin S. Danielson, and William R. Cotton, Colorado State Univ., Ft. Collins, Colo.

13.5 Mesoscale cloud systems over northeast Colorado in relation to synoptic-scale, lowlevel flow patterns over Kansas/Oklahoma. Alf C. Modahl, NCAR, Boulder, Colo.

13.6 The evolution of a multicellular convective cloud mass: A case study. Bernice Ackerman and Herbert A. Greenman, Illinois State Water Survey, Urbana, Ill.

13.7 On the periodicity of appearance of successive cells in multicellular storms. D. Ramond, Lab. Associé de Meteorologie Physique, Univ. Clermont II, France.

13.8 Model cloud distributions in an anisotropic environment. Gary L. Achtemeier, Illinois State Water Survey, Urbana, Ill.

13.9 Release of potential instability by mesoscale triggering: An objective model simulation. David A. Matthews, Bureau of Reclamation, Denver, Colo.

13.10 A multisensor, three-dimensional analysis of a meso-high development. John C. Lease and David A. Matthews, Bureau of Reclamation, Denver, Colo.

End of Session 13 
Thurs., Aug. 3, 1:30 p.m.

Thurs., Aug. 3,

2:35 p.m.

Thurs., Aug. 3,

2:35-3:00 p.m.

Thurs., Aug. 3, 3:00 p.m.
Thurs., Aug. 3,

4:32 p.m.

Thurs., Aug. 3,

Evening

Fri., Aug. 4,

8:30 a.m.
Session 14: Interactions of Convective Clouds with Meso- and Regional-Scales-II

Chairman: Harold D. Orville, South Dakota School of Mines and Technology, Rapid City, S.Dak.

14.1 An application of the Simpson-Wiggert cloud model to METROMEX hi-cu data. Stephen F. Mueller, Univ. of Chicago, Chicago, Ill.

14.2 A scale interaction model for moist convection. David J. Raymond, New Mexico Institute of Mining and Technology, Socorro, N.Mex.

14.3 A three-dimensional simulation of deep convection over south Florida. G. Tripoli and William R. Cotton, Colorado State Univ., Ft. Collins, Colo.

14.4 Treatment of cloudiness in regional-scale numerical weather prediction. Carl W. Kreitzberg and R. Gary Rasmussen, Drexel Univ., Philadelphia, Pa.

End of Session 14

\section{Coffee Break}

\section{Session 15: Severe Convective Storms}

Chairman: Edwin Kessler, National Severe Storms Lab./NOAA, Norman, Okla.

15.1 Precipitation development in a severe, continental, multicell hail and rainstorm. Charles A. Knight, F. I. Harris, J. C. Fankhauser, and Nancy C. Knight, NCAR, Boulder, Colo.

15.2 The Colorado hailstorm of 22 July 1976: Storm circulation, evolution, and hydrometeor growth. G. B. Foote, Andrew J. Heymsfield, C. G. Wade, D. J. Musil, T. J. Kelly, and H. W. Frank, NCAR, Boulder, Colo.

15.3 Growth and recirculation of precipitation in an evolving convective storm. James E. Dye, NCAR, Boulder, Colo.; L. Jay Miller, Wave Propagation Lab./NOAA, Boulder, Colo.; Brooks E. Martner, Univ. of Wyoming, Laramie, Wyo.; and Zev Levin, Tel Aviv Univ., Ramat Aviv, Israel.

15.4 The production of rain and hail in numerical simulations of hail cells. Harold D. Orville, R. D. Farley, F. J. Kopp, and J. H. Hirsch, South Dakota School of Mines and Technology, Rapid City, S.Dak.

15.5 The influence of microphysical processes on storm splitting and structure. Robert Wilhelmson, Univ. of Illinois, Urbana, Ill.; and Joseph Klemp, NCAR, Boulder, Colo.

End of Session 15

Boat Tour, Indian Salmon Bake, and Indian Dances

\section{Session 16: Atmospheric Electricity-I}

Chairman: Heinz W. Kasemir, Environmental Research Lab./NOAA, Boulder, Colo.

16.1 Field and ion current measurements in regions of high charge density near direct current transmission lines. T. Dan Bracken and B. C. Furumasu, Bonneville Power Administration, Portland, Oreg.

16.2 Balloon measurements of the air-earth current density at the South Pole before and after a solar flare. William E. Cobb, Atmospheric Physics and Chemistry Lab./ NOAA, Boulder, Colo.

16.3 An analytical model for fair weather atmosphere electricity. William L. Boeck, NCAR, Boulder, Colo. 
16.4 The structure of small ion clusters in humid atmospheres and the relationship to infrared absorption and the initiation of lightning discharge. James L. Kassner, Jr., Univ. of Missouri, Rolla, Mo.

16.5 The effect of the initial energy on positive streamer propagation. A. S. Sadik and J. A. Bicknell, UMIST, Manchester, England.

16.6 Corona discharge and thunderstorm fields. Heinz W. Kasemir, Atmospheric Physics and Chemistry Lab./NOAA, Boulder, Colo.

Fri., Aug. 4,

9:45-10:15 a.m.

\section{Fri., Aug. 4,} 10:15 a.m.

Fri., Aug. 4,

11:57 a.m.

\section{Fri., Aug. 4, \\ 1:30 p.m.}

\section{Session 16 (continued)}

16.7 A cooperative study of an unusual lightning flash at Kennedy Space Center during TRIP 1976. W. H. Beasley, Martin A. Uman, J. A. Tiller, Y. T. Lin, E. Philip Krider, C. D. Weidman, Paul R. Krehbiel, Marx Brook, A. A. Few, Jr., J. L. Bohannon, C. L. Lennon, H. A. Poehler, W. Jafferis, J. R. Gulick, and J. R. Nicholson, Univ. of Florida, Gainesville, Fla.

16.8 Doppler radar and electrical radiation observations of thunderstorms. Roger M. Lhermitte, Univ. of Miami, Miami, Fla.

16.9 The temporal structure of $H F$ and $V H F$ radiations during intracloud lightning discharges. E. Philip Krider and C. D. Weidman, Univ. of Arizona, Tucson, Ariz.; and D. M. LeVine, Goddard Space Flight Center/NASA, Greenbelt, Md.

16.10 Thundercloud charge distributions-Inferences from the intracloud structure of lightning channels. Arthur A. Few, D. R. MacGorman, and J. L. Bohannon, Rice Univ., Houston, Tex.

16.11 Correiations between reflectivity contours and lightning channels for a Colorado storm on 25 July 1972. D. R. MacGorman and Arthur A. Few, Rice Univ., Houston, Tex.

\section{End of Session 16}

\section{Session 17: Atmospheric Electricity-II}

Chairman: Arthur A. Few, Rice Univ., Houston, Tex.

17.1 Atmospheric electric field strength and ice crystal charge associated with precipitation at Inuvik, N.W.T. S. R. Shewchuk, Saskatchewan Research Council, Saskatoon, Sask., Canada; and T. Endow and K. Kikuchi, Hokkaido Univ., Sapporo, Japan.

17.2 Vector electric field measurements inside thunderstorms-Vertical profiles with balloon electric field sensors. Arthur A. Few, M. E. Weber, and H. J. Christian, Rice Univ., Houston, Tex.

17.3 Cloud-to-ground lightning frequencies over south Florida. Michael W. Maier and Albert G. Boulanger, National Hurricane and Experimental Meteorology Lab./ NOAA, Coral Gables, Fla.

17.4 Radio-located lightning related to radar-observed precipitation. J. S. Marshall, E. J. Stansbury, and S. Radhakant, Macdonald College, Montreal, Que., Canada.

17.5 Lightning and precipitation and the life history of isolated thunderstorms. Ronald C. Grosh, Illinois State Water Survey, Urbana, Ill. 
17.6 Electrical, microphysical, and dynamical conditions in clouds during summer monsoon at a hill station. A. Mary Selvam, G. K. Manohar, B. K. Bandyopadhyay, R. S. Reddy, R. Vijayakumar, A. S. Ramachandra Murty, and Bh. V. Ramana Murty, Indian Institute of Tropical Meteorology, Poona, India.

\section{Fri., Aug. 4, 3:00-3:15 p.m.}

Fri., Aug. 4,

3:15 p.m.

\section{Fri., Aug. 4, 4:45 p.m.}

\section{Fri., Aug. 4, 4:45-4:50 p.m.}

\section{Coffee Break}

\section{Session 17 (continued)}

17.7 Numerical modeling of hailstorm electrification. C. S. Chiu 1, South Dakota School of Mines and Technology, Rapid City, S.Dak.

17.8 A time-dependent, one-dimensional model of an electrified warm cloud. Israel Tzur and Zev Levin, Tel Aviv Univ., Ramat Aviv, Israel.

17.9 Electric fields and particle charges in thunderstorms. W. Gaskell, A. J. Illingworth, J. Latham, and B. J. P. Marshall, UMIST, Manchester, England.

17.10 Oceanic tropical thunderstorm electricity at Ponape, Micronesia. T. Takahashi, Univ. of Hawaii, Hilo, Hawaii.

17.11 Inductive or noninductive electrification of thunderstorms? J. Kuettner and D. Sartor, NCAR, Boulder, Colo.; and Zev Levin, Tel Aviv Univ., Ramat Aviv, Israel.

End of Session 17

Closing Remarks

\section{ABSTRACTS}

\section{Session 1: Cloud active nuclei and atmospheric aerosol}

1.1 A saturation hygrometer

H. E. GERBER

1.2 Detailed evaluation of Allee-type CCN counter

\section{G. LANGER ET AL.}

For the study of hydrometeor evolution in fogs and clouds, the measurement of relative humidity $(\mathrm{RH})$ in a range centered at $\sim 100 \%$ would be useful. Existing measuring means lose accuracy above $95 \% \mathrm{RH}$, while none measure above $100 \%$. A saturation hygrometer that operates in a supersaturated environment as well as just below $100 \% \mathrm{RH}$ was developed and is described. The main features of the hygrometer are: 1) a thin mirror coated with hydrophobic film on which salt particles of a predetermined size are deposited; 2) a thermo-optical servo system consisting of a laser for illuminating the mirror, a sensor for measuring light scattered by the droplets formed by the salt particles, and IR diodes for heating the mirror; 3) a housing through which air is aspirated past the mirror; and 4) calibration means consisting of a wet box that gives an $\mathrm{RH}$ of $100 \%$.

During operation in a supersaturated environment, the IR heater warms the mirror sufficiently to keep the salt solution droplets at their calibration size. The temperature increase of the mirror is the measure of $\mathrm{RH}$. Below $100 \% \mathrm{RH}$, the intensity of the scattered light is the measure of $\mathrm{RH}$.

Results of laboratory calibrations with a thermal-gradient diffusion chamber are presented. The influences of fog droplets, blackbody radiation, and unwanted condensation on the usefulness of the hygrometer were considered and are described.

The Allee-type cloud condensation nucleus (CCN) counter is a relatively simple and inexpensive instrument that uses the photographic method to record droplet concentration and that employs no sophisticated temperature controls nor sequencing of operation. Recently, it has found extensive use in field operations on the ground and on aircraft. At this time, the device was improved in compliance with theoretical knowledge, while not compromising its original simplicity. A detailed evaluation was then carried out beyond the original intercomparison at the 1970 Ice and Condensation Nucleus Workshop. The evaluation involved verification of flow pattern effects, preconditioning of the incoming air, and proper supersaturation measurement. The device was tested with known numbers of monodisperse nuclei to verify the corresponding

1 Deceased. Discussion to be led by H. D. Orville. 
1.3 A comparison of hydrophobic and hydrophilic filters using a continuous flow filter chamber

\section{R. R. CZYS}

1.4 Relationship between dry aerosol size, critical supersaturation, and size at high relative humidity

\section{W. A. HOPPEL}

\subsection{Concentration} fluctuation of marine aerosol in the planetary boundary layer

\section{J. PODZIMEK}

1.6 Evidence of mass transport through West Coast inversion

\section{J. GOODMAN}

cloud droplet count from the photographs. The critical size of $\mathrm{NaCl}$ nuclei at a given supersaturation was determined to compare with the theoretical size. The activation time for aerosols of varying solubility was determined, and common cloud seeding chemicals were evaluated for their CCN activity. Finally, four of the counters were intercompared.

The University of Chicago Cloud Physics Laboratory simultaneously exposed pairs of Sartorius hydrophobic and Millipore hydrophilic filters during Project METROMEX. An outer annular area of each filter holder was sealed. Sample air flowed through only the central portion of each filter. The blank outer area of each filter provided a background or "control" count of ice crystals for each measurement.

Counts of crystals from the sample area of the hydrophobic filters gave an overall average $25 \%$ greater and a standard deviation $16 \%$ greater than the hydrophilic filters. Counts of crystals from the control area of the hydrophobic filters gave an overall average $59 \%$ greater and a standard deviation $72 \%$ greater than the hydrophilic filters. The number of crystals counted in the control area of any particular filter exceeded the number of crystals counted in its sample area $12 \%$ of the time for the hydrophobic filters compared to $6 \%$ of the time for the hydrophilic filters. The overall average signal-to-noise ratio was found to be a factor of 2.7 better for the hydrophilic filters. After adjusting for background, filter by filter, the overall average concentration given by the hydrophobic filters was found to be only $1.2 \%$ greater than the overall average concentration given by the hydrophilic filters.

The overall average concentration of ice-forming nuclei measured by a Millipore hydrophilic filter was found to be nearly identical to the overall average concentration measured by a Sartorius hydrophobic filter, when a continuous flow filter chamber was used and when adjustments were made, filter by filter, for background. These data showed the Millipore hydrophilic filters to be the better type of filter since they introduced a lower, less variable background count of ice crystals and showed a higher overall average signal-to-noise ratio.

Size distributions of aerosols between radii of $0.008 \mu \mathrm{m}$ and $1 \mu \mathrm{m}$ were taken with the mobility analyzer and an optical particle counter together with CCN supersaturation spectra on a transAtlantic cruise aboard the USNS Hayes. Along the East Coast, many of the aerosol particles had radii smaller than $2 \times 10^{-6} \mathrm{~cm}$ and were not active as CCN. One-hundred miles off the New Jersey coast, the modal size was $>2 \times 10^{-6} \mathrm{~cm}$, and the number of CCN active at $0.8 \%$ supersaturation accounted for nearly the total aerosol population. The coagulation of small aerosols to form larger aerosols active as CCN is discussed in terms of a coagulative model and growth by addition of gas phase reaction products.

Ground and aircraft measurements of maritime aerosol above the seashore of Padre Island (Texas) in May 1975 were aimed to study the concentration and size distribution changes of marine aerosol during a sea breeze situation. Because the studied particle size range $(0.25-10 \mu \mathrm{m}$ radius) contains the cloud-active aerosol and particles affecting the propagation of electromagnetic waves as well, attention was paid to the representativeness of the aerosol sampling in dependence to environmental conditions.

Three sets of data obtained on 16, 17, and 18 May at the levels of $15 \mathrm{~m}, 150 \mathrm{~m}, 300 \mathrm{~m}, 600 \mathrm{~m}$, and $1700 \mathrm{~m}$ over the ocean are analyzed and compared with a similar measurement over the mainland. A simple frequency analysis of the concentration curves of giant particles shows that the most representative wavelength characterizing the turbulent elements lies between $2.5 \mathrm{~km}$ and $5.0 \mathrm{~km}$. Longer wavelengths, the amplitudes of which are dependent upon the stability of the atmospheric boundary layer, are superimposed to the basic frequency.

A different pattern of the aersol concentration curves was found for particulates with radii $<0.7 \mu \mathrm{m}$. The higher correlation with the relative humidity field reveals that a portion of these particulates are hygroscopic and can be detected by the counter only if the relative humidity surpasses their critical supersaturation value. This statement is also supported by the analysis of the vertical profiles of the aerosol concentration.

The discussion of the aerosol sampling procedures enables us to recommend the appropriate sampling times during a horizontal flight and conditions not deviating much from those described in the paper. A possible interpretation of the stated aerosol inhomogenities for cloud formation is briefly mentioned.

There is increasing evidence that significant vertical transport of mass occurs both within and across the interface of the West Coast temperature inversion. For the past 4 years, the $250 \mathrm{~m}$ high Mt. Sutro Tower, which is located atop a $250 \mathrm{~m}$ hill in the center of San Francisco, has been used as an observation platform for microphysical and meteorological data. During much of the summer, the tower protrudes through the coastal marine layer into the capping subsidence inversion maintained by the semipermanent Pacific high. The observations involved: 1) simultaneous 
1.7 Summer climatology of aerosols and nuclei in the central High Plains of the United States

\section{C. ROGERS AND G. VALI}

1.8 Giant nuclei and warm rain initiation

\section{B. JOHNSON}

1.9 Ice pellet melting: Ejection of microdroplets

\section{R. J. CHENG}

1.10 Meteorological impact of the pollutants from a copper smelter

\section{F. PARUNGO ET AL.}

samplings of condensation nuclei at the tower base and at the tower top; and 2) fluorescent particle tracers released upwind of the tower, both below and within the inversion. The diurnal variations of the condensation nuclei above and below the inversion base proved to be well correlated. The condensation nuclei concentration in the inversion layer was found to be primarily a function of the vertical distance of the sampling site from the inversion base and by the strength of the inversion. The fluorescent particle experiments proved that the transport of particles across the inversion occurs in both directions.

An extensive set of aerosol and nuclei measurements was obtained at the surface and in the lower troposphere near $104^{\circ} \mathrm{W}, 41^{\circ} \mathrm{N}$, as part of the National Hail Research Experiment (NHRE) during June and July of 1976. The aerosol and nuclei data-gathering network consisted of two fixed, rural surface sampling stations located $\sim 70 \mathrm{~km}$ apart, two instrumented surface vehicles, and three instrumented aircraft. Measurements were taken of Aitken nuclei, cloud condensation nuclei, ice nuclei, aersol size distribution and concentration, and the standard meteorological data. The aircraft also made cloud physical observations and collected aerosol samples in aluminized mylar bags for surface analysis of CCN and aerosol size distributions. This data set is very large and relatively homogeneous in both space and time.

Analyses to date indicate that: 1) The geometric means $\left(\bar{X}_{g}\right)$ and the geometric standard deviations $\left(S_{g}\right)$ of the various measurements compare favorably with the results of other researchers for summer continental air masses. The variability with this data set (as given by $S_{q}$ ) is somewhat less than other workers have found. 2) In general, aerosol and nucleus concentrations are fairly homogeneous within the well-mixed layer on horizontal scales of $\sim 100 \mathrm{~km}$ and over time periods of 2-6 h. Except for local anomalies at the surface, fluctuations in concentrations are relatively small $\left(S_{g} \sim 2\right)$. Monotonic trends over several days are discernible at times. 3) Slow time trends in ice nucleus and CCN concentrations are paralleled by changes in aerosol concentrations.

Further analysis of this data set will emphasize examination of the interrelationships between the measurements, including meteorological factors, with an aim of shedding light on aerosol and nuclei origins and lifetimes.

When ingested into a cloud, giant and ultragiant aerosol particles will form a "tail" of giant drops on the large end of the cloud droplet distribution. In continental areas, these Brobdingnagian particles are predominately insoluble. Even so, their extreme size makes it possible for them to collect smaller cloud droplets without the necessity of additional condensation growth. Although few in number, the giant drops formed on these nuclei can serve as coalescence embryos, which can be instrumental in the initial production of precipitation in warm clouds.

Using observed concentrations of giant and ultragiant aerosol particles as input data, it is shown that collection of cloud droplets by these embryos can result in concentrations of precipitation-sized drops sufficient to produce radar detectable reflectivities in clouds $<3 \mathrm{~km}$ thick, in spite of total droplet concentrations as high as $1000 \mathrm{~cm}^{-3}$.

During the melting process, numerous air bubbles are released and accelerated radially from the surface of an ice pellet. Atmospheric particulates that were embedded in the ice pellet during growth period tend to become attached on the surface of these air bubbles. Microdroplets are then generated by the bursting of these air bubbles through the surrounding water-air interface.

The observations of the releasing of numerous air bubbles, the subsequent ejection of droplets, the recycling of atmospheric particulates in this process, and the electrical property of these droplets are suggested to be important for the nucleation process and the electrification of the atmosphere.

To study the meteorological impact of the pollutants released by Kennecott Copper Smelter, Salt Lake City, Utah, we flew an instrumented aircraft in the plume at different distances from the stacks. Aitken nuclei, cloud condensation nuclei, and $\mathrm{SO}_{2}$ concentration were measured in situ. Aerosol samples were collected on Nuclepore filters to study the morphology, concentration, size distribution, and elemental composition of the plume aerosols with an electron microscope interfaced with an X-ray energy spectrometer. We also measured ice nucleation activity of the aerosol with a thermal diffusion chamber. The chemical and physical properties were related to the cloud condensation nucleus (CCN) and ice nucleus (IN) activities.

The plume aerosol consists of a high concentration $\left(10^{4} \mathrm{~cm}^{-3}\right)$ of submicron sulfuric acid mists, which adsorb moisture at subsaturation and thus are active haze- and fog-forming nuclei. At farther distances, more sulfuric acid aerosol is formed by gas-to-particle conversion. The acid is then neutralized by atmospheric ammonia producing ammonium sulfate, which forms either individual particles or a coating on the existing particles. The process not only increases the concentration of CCN but also broadens the size distribution of the sulfur-containing particles that are active CCN. Ice nucleus concentration in the plume is more than 1 order of mag- 


\subsection{Precipitation scavenging of aerosol particles}

\section{F. RADKE ET AL.}

1.12 The hydrodynamic influence on phoretic scavenging of aerosol particles by cloud drops

\section{K. H. LEONG AND}

K. V. BEARD nitude higher than background. The IN activity increases with atmospheric residence times by evaporating the adsorbed gases.

Reviewing local climatological data for the last 85 years, we suggest that copper smelter plume pollutants may inadvertently modify the regional weather.

Airborne measurements have been made of aerosol particle size distributions $(0.01-60 \mu \mathrm{m}$ diameter) in the plumes from several coal power plants, a large kraft paper mill, and a volcanic eruption before and after the plumes were intercepted by rain or snow showers. Measurements of the scavenging of natural aerosol particles by a convective shower have also been obtained. Also measured were the size distributions of the precipitation particles and, in the case of snow showers, the nature of the ice crystals was recorded. These measurements have been used to deduce the scavenging rates and collection efficiencies of the aerosol particles by precipitation.

The results from seven case studies (collected over a period of three years) will be presented. Despite large variations in the nature of the aerosol and precipitation particles, the scavenging rates and collection efficiencies as a function of aerosol particle size show marked similarities with some well-defined maximum and minimum values. For aerosol particles $>1 \mu \mathrm{m}$ in diameter, the experimental results are similar to the predictions for scavenging by impaction; but for the submicron aerosol particles, the rates of removal are generally much higher than current theories predict.

Collection efficiencies for aerosol particles $(0.1-10 \mu \mathrm{m}$ radius) scavenged by evaporating cloud drops $(10-40 \mu \mathrm{m}$ radius) were determined theoretically. Use was made of the analytical flow field of Proudman and Pearson and the analytical diffusion field of Rimmer. The thermophoretic and diffusiophoretic forces were chosen to represent the range of values expected from the uncertainty in the literature. Calculations were made as a function of ambient relative humidity, and particle density and thermal conductivity. The resulting collision efficiencies demonstrate how the effects of particle inertia, gravity, and hydrodynamics can significantly alter the efficiencies based on pure phoresis.

\section{Session 2: Cloud particles: Liquid}

2.1 Realism of droplet and crystal populations in laboratory clouds-A review and suggested future work

\section{E. E. HINDMAN II AND W. G. FINNEGAN}

2.2 An improved droplet generator

T. W. CANNON AND

W. W. GROTEWOLD
Chambers cooled below $0^{\circ} \mathrm{C}$ in which water droplet clouds exist have been used since 1946 as the primary laboratory tool to determine the response of the clouds to man-made ice-crystal-forming nuclei (IN). In most cases, the response of the IN to the laboratory clouds was assumed, a priori, to be the expected response of the IN to atmospheric clouds. However, this assumption is not valid unless the droplet populations of the laboratory and atmospheric clouds are similar. Although data from atmospheric clouds are abundant, the extent to which the droplet populations of the laboratory clouds reproduce the droplet populations of atmospheric clouds has not been determined because of the absence of data from the laboratory clouds, due primarily to sampling difficulties. Impaction devices, which are all that have been available until recently, disturb the cloud and require exceedingly difficult data reduction. However, automatic electricaloptical (E-O) instruments, which do not disturb the cloud significantly, have been developed and can be used to determine the populations of droplets in laboratory clouds. The E-O instruments have been used in warm, atmospheric clouds, and the results agree with data obtained with manually operated impactors. The E-O devices can size and count both submicron and supermicron droplets, thereby expanding the measurement capability.

Recent measurements with an E-O instrument in a laboratory cloud and in coastal fogs indicate that the droplet populations of the laboratory cloud somewhat resemble the populations in the coastal fog. Additional research in cloud generation and maintenance techniques should improve this resemblance.

In the future, the E-O instruments should be able to measure the populations of both droplets and crystals in laboratory clouds. Such information, when compared with similar measurements in atmospheric clouds, will enable the realism of laboratory IN measurements to be determined. Finally, investigations of the interactions of submicron droplets, IN, and the resulting ice crystals in laboratory clouds should provide information to unravel the mysteries of ice crystal formation in supercooled clouds containing man-made IN.

Improvements have been made in the NCAR droplet generator described by Abbott and Cannon. These improvements include cam drive, replacement of the straight wire with ball-tipped wire, and improved fluid level adjustment. The improvements result in greater reliability and ease of adjustment over the original speaker-driven model. Drops ranging from $6 \mu \mathrm{m}$ to $\sim 1 \mathrm{~mm}$ diameter may be generated depending on ball size and spring tension.

The improved drop generator and its operation and methods of determining drop size will be described. The generator has been used to calibrate the sailplane and T-28 cloud particle cameras. The calibrations were used to determine sample volume as a function of drop size, 
2.3 Water droplet growth on $\mathrm{NaCl}$ nuclei

\section{A. VIETTI}

2.4 The collision and coalescence of cloud droplets

\section{T. S. TUNG AND \\ K. V. BEARD}

2.5 Further numerical studies on the effect of electric charges and electric fields on the collision efficiency of cloud drops

\section{R. J. SCHLAMP ET AL.}

ratio of drop size to dot-pair separation, smallest droplet size detected, and size limit of drop ice distinguishability. The techniques and results of these calibrations will be presented.

Measurements of diffusional droplet growth initiated from salt nuclei were made in an expansion cloud chamber whose experimental volume is $1 \mathrm{~m}^{3}$. The chamber, operating at room temperature, produced supersaturation ratios in the range of 1.02-1.03. Droplet growth was tracked by a light-scattering technique that provides the direct observation of growth from $0.326 \mu \mathrm{m}$ radius in $\sim 0.2 \mu \mathrm{m}$ intervals to when the droplets cease growing at $\sim 5.0-7.0 \mu \mathrm{m}$ radius. Simultaneous pressure and temperature data obtained from the cloud chamber are used to calculate droplet growth for comparison to the experimentally obtained curves. The sticking or condensation coefficient and the solute mass are treated as parameters whose values are changed to bring about agreement between theory and experiment.

The results of the research indicate that the value for the sticking coefficient for growth on nuclei that contain salt is in the range of 0.10-0.03. The larger values for this coefficient usually are found for nuclei that were generated within a few hours prior to the measurement. The lower values for the coefficient usually are found when the nuclei were allowed to stand in the chamber overnight. In this latter case, the droplet concentration is also much smaller. There is also evidence to indicate that when the salt concentration in the nebulizer used to generate the salt nuclei is large enough, the sticking coefficient is in the vicinity of 0.03 independent of the residence time.

The influence of the solute effect on droplet growth is observed and seems to agree well with theory. The number of moles of salt per droplet seems to be in the vicinity of $10^{-17}$ and appears to be independent of the salt concentration in the nebulizer.

The collection efficiency of cloud droplets was determined experimentally by means of a chemical tracer technique. Measurements were made on drops produced by a vibrating orifice generator of $25-100 \mu \mathrm{m}$ radius falling through a cloud of monodisperse droplets of $3-15 \mu \mathrm{m}$ radius. The results were compared to available theoretical collision efficiencies of rigid spheres in order to find the actual coalescence efficiencies. The findings were incorporated into the microphysical, warm rain model of Ochs and Yao to assess the sensitivity of various precipitation parameters on the collection efficiency.

The numerical model of Schlamp et al. for determining the collision efficiency of electrically charged or uncharged cloud drops in the presence or absence of a vertical electric field has been extended to study the two following cases, both of which include the presence of a vertical electric field due to a net positive charge in the upper part of the cloud and a net negative charge in the lower part of the cloud: 1) The larger drop is negatively charged and is initially above the smaller drop, which is positively charged; 2) the larger drop is negatively charged and is initially below the smaller drop, which is again positively charged. Also, for the purpose of resolving more accurately the critical electric charge on the drops and the critical electric field necessary to significantly affect the collision efficiency, additional computations for charged drops in the absence of an electric field and for uncharged drops in the presence of a vertical electric field have been carried out.

The sizes of drops considered range from $1 \mu \mathrm{m}$ to $118 \mu \mathrm{m}$ in radius. The magnitude of the electric charges on the drops range from 0 esu to $2.8 \times 10^{-4} \mathrm{esu}$, and the electric fields range in strength from $0 \mathrm{~V} \mathrm{~cm}^{-1}$ to $3429 \mathrm{~V} \mathrm{~cm}^{-1}$, which include the charges and fields typically observed in thunderstorms.

It is found that electric fields and charges even with relatively modest values have a profound effect upon the collision efficiency. The results of case 1 are significantly different from either of those of case 2 or of Schlamp et al.

Some of the critical problems surrounding the initial stages of cloud droplet interaction and the subsequent growth of drops to form rain are considered. Can drops of equal size collide? Do kernel functions tend to zero as the ratios of droplet/drop radii, $a=R_{2} / R_{1}$, tend to zero? Are there any differences in the behavior of droplet pairs in a typically continental vs. a typically maritime environment? If so, what are the consequences?

The collisional problem of cloud droplets under the Oseen approximation is solved for pairs of drops of radii $10 \leq R_{1} \leq 55 \mu \mathrm{m}$ and radii ratios $0.1 \leq a \leq 1.0$ for two characteristic environmental conditions: a typical continental case, and a typical maritime case. These two cases also serve to illustrate the height dependence of the kernel function, which is very important for cloud systems of large depths. 
These studies have shown that indeed two drops of equal size can collide, and collisions for all other pairs are height dependent. Analyses were conducted for initial separations ranging from a few drop radii $R_{1}$ apart to radii up to $100 R_{1}$ apart. Two cases, $30 R_{1}$ and $60 R_{1}$, are presented. These nonzero collision efficiencies for drops of equal size indicate that the usual definition of the kernel function-as the product of the collision efficiency times the difference of the terminal velocities of the respective particles-is in error; otherwise, collision events of this sort would be disregarded. Mean collisional velocities are then calculated for each pair by using actual interaction velocities. The net result is a kernel function different from zero for particles of equal size.

When the same drop interactions are calculated for different environmental conditions (different height, pressure, and temperature), both the collision efficiencies and the collisional velocities vary. This variation is more noticeable for drops of equal and nearly equal size $(a \geq 0.85)$.

These kernel results as a function of environmental conditions (continental vs. maritime height dependence) are used to study the growth behavior of different cloud droplet populations. Conclusions regarding possible differences in measured rain intensity vs. droplet size for maritime vs. continental clouds as well as evolution characteristics, the onset of drops of precipitation size, and the implications for weather modification are also presented.

2.7 The influence of cloud base temperature on droplet concentration

\section{B. JOHNSON}

2.8 The influence of turbulent mixing on droplet evolution in clouds

\section{R. C. CORBIN ET AL.}

2.9 Small-scale variability of the cloud droplet spectra in cumulus clouds

\section{A. R. RODI}

In a growing cloud, the number of droplets activated is governed by the number, size, and chemical composition of the condensation nuclei; the speed of the updraft; and the temperature at cloud base. Colder cloud bases or faster updrafts will result in a more rapid initial rise in the supersaturation (expressed in percent) and activation of more condensation nuclei. All other factors being equal, clouds with colder bases will activate more droplets than clouds having warmer bases. The magnitude of this effect is illustrated by results from a detailed computer model of the initial phases of cloud formation, and by analytical expressions for drop concentration based on the work of Twomey and Squires, but modified to allow variable cloud-base temperatures.

For a given nuclei distribution and updraft velocity, a change of cloud-base temperature from $+15^{\circ} \mathrm{C}$ to $0^{\circ} \mathrm{C}$ results in $\sim 25 \%$ more droplets being activated. Reduction of cloud-base temperature from $+15^{\circ} \mathrm{C}$ to $-10^{\circ} \mathrm{C}$ results in increases in droplet concentration of $>50 \%$.

A series of experiments has been performed in which a cloud of droplets formed either by condensation or by means of a spinning top were drawn through a cylindrical tunnel. During the passage of the cloud, undersaturated air of prescribed humidity and temperature could be introduced into it at selected rates through various nozzles at a number of points along the length of the tunnel. Alternatively, saturated air warmer than the cloud could be introduced. The spectral evolution was studied using an optical scattering device, an electrostatic disdrometer, and a coated slide technique.

The principal observation was that the mixing process was highly inhomogeneous. Some droplets from all size categories were completely evaporated during the admixture of undersaturated air, while others were negligibly affected. The dispersion of the observable spectrum remained fairly constant during this mixing process.

The experiments led to the formulation of a rudimentary model of the evolution of cloud droplet spectra in the presence of inhomogeneous mixing into the cloud of environmental air. This mixing process can be considered in terms of fluctuations in supersaturation not tied to fluctuations in vertical air velocity. The model appears to be capable of explaining qualitatively some of the major features of droplet evolution-such as spectral broadening with increasing height above cloud base-with which the classical description of homogeneous mixing is seemingly inconsistent. Also, it makes certain predictions about spectral fluctuations in closely adjacent regions of cloud. These have been substantiated by field measurements made from both a mountain laboratory and a glider.

An optical scattering spectrometer capable of measuring the cloud droplet spectrum in each $10 \mathrm{~m}$ of flight path was used to obtain continuous measurements in growing small cumuli. These penetrations, made in Montana during the summer 1977 High Plains Experiment (HIPLEX), have revealed in many cases uniform cloud droplet spectra across most of the cloud horizontal dimension. Only at the cloud boundary is there strong indication of interaction of the cloud environment with the spectrum.

In this study, the structure of the droplet spectrum at $10 \mathrm{~m}$ and larger scales will be presented. The correlations of the droplet concentrations with thermodynamic and motion variables, and their implications, particularly to the lateral entrainment process, will be discussed. Liquid water measurements from the optical spectrometer also will be compared with soot-coated slide samples, $J-W$ liquid water measurements, and the calculated adiabatic values. 
2.10 Three-dimensional numerical simulations of cloud-base turbulence with condensation theory

\section{T. L. CLARK AND W. D. HALL}

A fully three-dimensional numerical model is used to study the role that turbulence plays in the evolution of the droplet spectra near cloud base. The purpose of this experiment is to test the contention of workers such as Stephanov that turbulent mixing may be the mechanism that produces the observed broad cloud droplet spectra.

The basic dynamics and thermodynamics are treated using second-order time and spatial differencing methods. The effects of turbulence, as well as larger cloud scale effects, are simulated by using a semi-random dynamic forcing function in the lower wave numbers. Subsequent energy transfers in the model allow kinetic energy to flow into the higher wave number space, which eventually produce turbulent dissipation rates, $\epsilon$, from $\sim 10-100 \mathrm{~cm}^{2} / \mathrm{s}^{3}$. The total domain size is $200 \mathrm{~m}$ on each side with either $5 \mathrm{~m}$ grids (high resolution case) or $10 \mathrm{~m}$ grids (low resolution case). A mean vertical velocity of $2 \mathrm{~m} / \mathrm{s}$ is imposed on the vertical flow. The small domain is intended to represent a very small portion of the cloud-base region of a convective cloud. The boundary conditions $\mathbf{V}, p^{\prime}, \theta$, and $q_{v}$ are cyclic in the horizontal, and the deviations from the horizontal averages are cyclic in the vertical.

The cloud physics of condensation theory is treated using a single lognormal distribution function. CCN are treated by advecting a cumulative distribution, $\eta$. Activation is assumed to follow an empirical power law where local activation occurs if $\mathrm{C}_{1} S^{c} \cdot>N$, where $S$ is the supersaturation and $N$ is the local number concentration of droplets. The supersaturation is treated in a consistent manner with respect to the dynamics, thermodynamics, and condensation rate; i.e., the method of Clark is employed.

Results to be presented include: mean profiles of most dynamic, thermodynamic, and cloud physical variables; profiles of horizontally averaged velocity correlations; the correlations $\overline{S^{\prime} W^{\prime}}, \overline{S^{\prime} U^{\prime}}, \overline{S^{\prime} V^{\prime}}$; and profiles of the horizontally averaged coefficient of dispersion for the droplet distributions as a function of turbulent dissipation rate.

2.11 On the microstructurestability characteristics of clouds over an equatorial region

\section{K. K. KANUGA}

A systematic study has been made of the chemical composition of rainwater samples collected at four locations along the path of main air currents from the Kenyan coast of East Africa to the eastern shores of Lake Victoria. The chemical constituents analyzed are: chloride, sulphate, sodium, calcium, and potassium. The results of the analysis are presented and discussed.

The study suggests that the clouds inland have a tendency to become colloidally more stable due to gradual depletion of giant chloride aerosols and due to addition of certain other relatively smaller aerosols, as the cloud air drifts from the coast to the stations well inland. The inference, though indirect, contributes significantly to our knowledge of understanding the microstructure-stability characteristics of the clouds over the region where the measurements by the most direct methods have been very limited.

The results of the present study compare favorably with the features observed elsewhere in the world.

\section{Session 3: Cloud particles: Solid}

3.1 Ice crystal growth kinetics and accommodation coefficients

N. FUKUTA
3.2 The influence of the carrier gas velocity, diffusivity, and thermal conductivity on ice crystal habit

\section{W. KELLER AND}

J. HALLETT
Ice crystal growth in the atmosphere proceeds under influences of two accommodation coefficients that involve mass and heat exchanges, i.e., the deposition coefficient and the thermal accommodation coefficient. A new method was developed to determine the deposition coefficient of water vapor on clean, cleaved surfaces of single ice crystals. The method involved accurate determination of temperature gradients in ice crystals and of temperature difference in a narrow crack formed along a cleavage plane. During the experiment, the temperature difference remained constant in contrast to the changing surface temperature in some previous studies. Measurements were made on the basal plane of the crystal at several selected temperatures. The determined values of the deposition coefficient varied in accordance with the basic habit of ice crystal growth. Advantages and limits of the method employed in this study will be explained. The roles played by both the deposition and thermal accommodation coefficients in the ice crystal growth kinetics will be discussed using spheroidal ice crystal models. Since the deposition coefficient is a macroscopic quantity describing an overall efficiency for capture of water molecules arriving at the ice crystal surface, the relationship between the coefficient and microscopic processes on the surface, such as surface migration, capture of water molecules at steps, and twodimensional nucleation, will also be discussed.

A study of ice crystals grown from the vapor in a diffusion chamber where temperature, supersaturation, and air velocity are varied independently shows that the introduction of a carrier gas velocity is not equivalent to increasing the diffusivity of water vapor through air. On the other hand, the carrier gas velocity does not enhance growth by just lowering the crystal surface temperature, i.e., through an effective increase in the thermal conductivity. The experiments described in this study show that the introduction of a carrier gas velocity leads to increased growth rates. However, unlike an increase in the diffusivity, the introduction of a carrier gas velocity also leads to an increase in the development of skeletal or dendritic structures. These 
results are interpreted in terms of differences in the local diffusion boundary layer and vapor density gradients across the crystal surface. A model is presented to explain these differences.

The results of this study may be applied to the growth of small ice crystals in mid-level clouds. That is, since the diffusivity of water vapor through air is inversely proportional to the ambient atmospheric pressure, it can vary by as much as a factor of 3 between the surface and the $-15^{\circ} \mathrm{C}$ level in tropical environments. Furthermore, since ice crystal terminal fall speeds in the atmosphere may typically be $20-30 \mathrm{~cm} \mathrm{~s}^{-1}$, the effect of the relative air motion on both the ice crystal linear growth rates and secondary habit is substantial.

3.3 An observational study of the accretional habits of ice crystals having a simple geometric shape

\section{R. E. D'ERRICO AND}

\section{A. H. AUER}

3.4 Formation mechanism of ice crystals in the cloudless atmosphere

\section{T. OHTAKE ET AL.}

3.5 Observations of cirrus particle characteristics occurring with halos
M. GLASS AND
D. J. VARLEY

An empirical investigation of: 1) an accretional threshold dimension of different ice crystal types having simple geometric shape, 2) a spectrum of cloud droplets collected by each, and 3) the spatial distribution of collected droplets over ice crystal surface area was pursued. Formvar replicas of five basic ice crystal types, which included simple hexagonal plates (Pla), thick hexagonal plates $(\mathrm{C} 1 \mathrm{~g})$, sheath $(\mathrm{N} 1 \mathrm{c})$, hollow columns (C1f), and broad-branched (P1c) ice crystals, were observed with a fine adjustment light microscope. These replicas were primarily collected at the University of Wyoming's Elk Mt. Outdoor Laboratory, and Pole Mountain in the Laramie Range, Wyo. Ice crystal threshold size was evaluated either by comparison of rimed and unrimed ice crystals of similar species, or by the determination of a functional relationship between axis dimension with the number of accreted droplets. Accreted droplet size was documented by $5 \mu \mathrm{m}$ intervals, and the droplets' spatial distribution according to equal ice crystal surface area divisions. Using a criterion of major axis dimension, thick place $(\sim 80 \mu \mathrm{m})$, hollow columnar $(\sim 80 \mu \mathrm{m})$, thin plate $(\sim 140 \mu \mathrm{m})$, broad-branched $(\sim 190 \mu \mathrm{m})$, and sheath $(\sim 230 \mu \mathrm{m})$, ice crystals were found to constitute a rank of the species studied with respect to the onset of accretion. A functional relationship was determined between the onset of accretion and ice crystal characteristic dimensions. This provides a simple parameterization of this phenomenon. Although some $5 \mu \mathrm{m}$ droplets (diameters $<7.5 \mu \mathrm{m}$ ) were observed attached to ice crystals, a $10 \mu \mathrm{m}$ diameter appears to be a minimum size, important in the accretion process. An increase in mean droplet diameter $(15-25 \mu \mathrm{m})$, as well as the dispersion about the mean (standard deviation from $\sim 5 \mu \mathrm{m}$ to $10 \mu \mathrm{m}$ ) from planar (Pla, C1g, Plc) to columnar (N1c, C1f) type crystals, was observed. Finally, the spatial distribution of accreted droplets indicated that planar type crystals had preferential riming towards the edge of the basal surface, whereas columnar crystals showed a more even distribution over the prism surface.

In the polar and subpolar areas, ice crystals have frequently been observed precipitating from clear skies. The entire formation mechanism for these ice crystals has never been described, in spite of extensive observations. A research airplane instrumented with a Knollenberg particle spectrometer, a cloud particle replicator, a dew point hygrometer, a cloud condensation nucleus counter, etc., was utilized for the study in the vicinity of Barrow, Alaska, in addition to the ground observations at Barrow.

Two water vapor sources were identified: 1) open leads of arctic pack ice, and 2) human activities (heating and automobile exhaust) from the arctic villages. Water droplets, condensed from the two water vapor sources, are subsequently frozen in the cold environment and grow to a larger crystal size in the high humidity (ice saturation) environment. This occurs over a long distance to where the ice crystals are observed precipitating from the clear sky.

Ice crystals observed at Barrow, where no clouds were observed, were columnar and bullet shaped, several hundred microns in size; ice crystals from villages were columns and plates $30-150 \mu \mathrm{m}$ in size, and have a diurnal variation in concentrations in accordance with the human activity.

Patchy stratus clouds that formed over the open leads could explain the variation of ice crystal concentrations. Observations of ice crystals collected both on the ground and from the airplane verified the freezing of water droplets. This mechanism is not applicable to the ice crystals precipitating from the Antarctic cloudless atmosphere.

Cirrus cloud particles were observed using both one- and two-dimensional Particle Measuring Systems (PMS) probes, a DRI particle replicator, and photographs of optical phenomena produced by these particles during a flight by the Air Force Geophysics Laboratory MC-130E cloud physics research aircraft.

Particle size spectra and number density are presented using data from both probe systems. The implication of these distributions concerning particle growth history is discussed.

Comparisons of shape characteristics obtained from the PMS two-dimensional probe and the particle replicator are made. These results are compared with ice crystal shapes theoretically expected with the occurrence of halos and related optical phenomena. It is shown that only a small fraction of the particles appear to have the pristine shapes usually thought to be associated with the formation of halos. 


\section{Session 4: Precipitation particles: Growth and size spectra}

4.1 Terminal fall velocity and drag coefficient of deformed drops

\section{T. E. HOFFER AND \\ P. GILLASPY}

4.2 Raindrop breakup: The energy of disruption

\section{Y. LEE AND}

A. N. DINGLE

4.3 The collection efficiency of similarly sized precipitation drops

H. T. OCHS AND

K. V. BEARD

4.4 A wind tunnel study on the growth of graupel

J. C. PFLAUM AND

H. R. PRUPPACHER
Experimental measurements of the terminal velocity of freely falling liquid drops in the size range 700-1000 $\mu \mathrm{m}$ diameter are presented. The measurements were made with a vertical fall column $\sim 11 \mathrm{~m}$ in height. Fall velocity was determined by timing the passage of a drop through a series of laser beams. The deformation was determined photographically. In the size range considered, drop shape begins to differ significantly from sphericity. As the drop begins to deform, the drag coefficient depends additionally upon the degree of deformation. The effect of drop deformation on the drag coefficient is discussed for drops of water and other liquids.

The experimental results are compared with theoretical expression for onset of deformation and terminal velocity. Other important parameters are discussed.

The mechanics of drop breakup are explored in terms of mechanical energy involved in drop collisions. Relevant energy terms include the kinetic, oscillational, and rotational components in addition to surface energy. The oscillational and rotational terms are of comparable magnitude, whereas surface and kinetic energies are 2 and 4 orders of magnitude larger, respectively.

Conservation of momentum and of energy are invoked to analyze the processes following drop collision. The energy difference before and after collision gives rise to a term called the energy of disruption, which, if large enough, will cause the breakup of the merged drop-water mass.

The threshold energy required for breakup is defined and is found to compare favorably with experimental results.

Experimental collection efficiencies for drops at terminal velocity were measured using a photographic technique from drop pairs produced by a vibrating orifice generator. Efficiencies were obtained in the previously unexplored regime of collector drops between 100 and $500 \mu \mathrm{m}$ radius and size ratios $>0.5$. The microphysical warm rain model of Ochs has shown that the calculated radar reflectivity and precipitation rate are very sensitive to values of the collection efficiency of similar size precipitation drops. This model was used to determine the effect of the current experimental uncertainty on predicted reflectivities and precipitation rates.

The UCLA Cloud Tunnel, in which hydrometeors can be freely suspended in a vertical air stream, was used to study graupel grown from frozen drops for a variety of growth conditions. The following parameters were varied: 1) initial frozen drop size, 2) ambient temperature, 3) liquid water content, and 4) growth time. The various combinations yielded a total of 16 separate growth experiments, each consisting of 10 individual growth events.

An experimental method is described from which the growth rates, collection efficiencies, and densities of the graupel were derived. These quantities are analyzed and discussed with regard to their dependency on growth conditions.

An analytical model of the vapor deposition and aggregation growth of snowflakes in a steadystate precipitation shaft can be formulated and solved by assuming the following: 1) All water made available in the updraft is converted to snow via vapor deposition growth. 2) Snowflake aggregation is due to gravitational collection. 3) The size distribution is exponential such that $n(D)=N \exp (-\lambda D)$, where $n(D) d D$ is the concentration of snowflakes of diameter $D$ in the size interval $D+d D$.

Analytical solutions for the distributional parameters, $N$ and $\lambda$, can be found by simultaneously solving the equations for conservation of mass and radar reflectivity, which are derived from a generalized form of the stochastic collection equation. For the case of a linear lapse rate, weak updraft, saturated atmosphere, $N$ and $\lambda$ are found as functions of height below a reference level. This model, which is best applied to stratiform snow situations, suggests the existence of equilibrium snow-size spectra. The model results compare very favorably to the University of Chicago's airborne observations of snow-size spectra in Midwest extratropical cyclones.

Aircraft observations of rain showers from warm clouds around the island of Hawaii have revealed three findings: 1) precipitation from band clouds is of longer duration and greater intensity and is initiated from shallower clouds than is precipitation from isolated clouds; 2) rainfall intensity decreases at the center of the cloud; and 3) a bimodal raindrop size distribution is coincident with the time of intense rainfall.

Observations of the cloud droplet size distribution near the cloud top showed less liquid water content in band clouds than in isolated clouds. However, larger numbers of newly formed small
4.6 Warm rain showers in Hawaii

\section{T. TAKAHASHI}


cloud droplets appear to persist longer in band clouds. The longer life of new turret at the cloud top in cloud band seems to favor the formation of larger drops in the vicinity of the cloud top.

Although the reason for weaker rainfall intensity at the cloud center is not known, the bimodal distribution of raindrop sizes at the time of intense rainfall has been well simulated in an axisymmetric cloud model that includes collision breakup.

4.7 Drop-size distributions in Kenyan rain showers

\section{K. K. KANUGA AND \\ F. O. AGUMBA}

4.8 Characterization of raindrop-size distributions

\section{M. TAKEUCHI}

4.9 The evolution of raindrop spectra in warmbased convective storms as observed and numerically modeled

\section{R. E. CARBONE AND L. D. NELSON}

Measurements of drop-size distributions in complete rain showers were made at four meteorologically different locations in Kenya: on the coast; on the southeastern slopes of the Kenyan Highlands; in the Rift Valley; and on the western slopes of the Kenyan Highlands, near the crest. The observed distributions are presented and are compared with the theoretical deductions. The results indicate that not all the observed distributions have a simple exponential form.

The other meteorological parameters relevant to this study such as rainfall intensities, liquid water content, and median drop diameter are also computed and discussed.

Cloud base raindrop-size data obtained from convective clouds in the High Plains are analyzed. It is found that the data are well characterized by the gamma function, $N(D)=N_{0}$ $\left(D / D_{*}\right)^{a} \exp (-\Lambda D)$, where $N(D) \Delta D$ represents the number concentration of drops in the diameter range $D$ to $D+\Delta D ; D_{*}$ denotes a constant; and $N_{1}, \Lambda$, and $\alpha$ represent coefficients that are related to rainfall rate, $R$. Through use of the simple power (log-log) relationships of radar reflectivity factor, $Z$, vs. $R$ and water content, $Q$, vs. $R$, techniques developed in the analyses minimize inherent instrument sampling errors and indicate that the values of the coefficients of the gamma distribution function are not necessarily related to $R$ by the simple power law but by a nonlinear relationship.

Aside from showing that the gamma function realistically describes surface raindrop-size distributions from a variety of synoptic storm conditions for various geographical locations, the analysis discloses that the values of the coefficients are highly dependent upon dominating precipitation growth processes and upon the dynamic stage of cloud or storm development. Physical processes exhibiting strong influence include drop breakup, coalescence, evaporation, and vertical wind sorting. The effects of these processes thus result in quantitative explanations of the observed temporal, synoptic, and geographic variations found in the values of coefficient and exponent of the $Z$ vs. $R$ relationship and provide means through which hypothesized microphysical seeding effects may perhaps be evaluated.

Airborne optical spectrometer measurements of raindrop spectra were performed in Texas together with $10 \mathrm{~cm}$ and $3 \mathrm{~cm}$ radar observations. The observations reveal large drop spectra emanating from cloud base with low concentrations of small drops compared to Marshall and Palmer distributions. Systematic patterns of exponential spectrum parameters $\left(N_{0}\right.$ and $\left.\lambda\right)$ are revealed to constitute a "parametric cycle" in time and space. Drop spectrum form is attributed to updraft sorting of smaller drops and the resultant dominance of spontaneous breakup in subsequent spectral evolution. Recent theoretical studies by Srivastava partially support this conclusion.

A one-dimensional, time-dependent numerical model was exercized for initial conditions simulating the observations. The resultant spectra emanating from the model were quantitatively similar to the measurements and exhibited temporal evolution consistent with the observed parametric cycle.

Implications for estimation of spectral moments such as rainfall rate, liquid water content, and radar reflectivity factor are discussed briefly.

Measurements of the size spectra of particles in frontal clouds have been made with Knollenberg probes aboard aircraft flying through precipitating frontal clouds at temperatures ranging from $-43^{\circ} \mathrm{C}$ to $+6.5^{\circ} \mathrm{C}$. These measurements, which were obtained as part of the CYCLES Project, show that particles $\gtrsim 1 \mathrm{~mm}$ in dimension closely follow a Marshall-Palmer exponential size distribution. The parameters of the distribution are correlated with temperature. The mean and variance of the particle-size distribution above the melting layer increase with increasing temperature, indicating the growth of particles as they drift downward and an increase in the spread of the distribution as the larger particles grow by collection. Further evidence for the latter process is that the concentration of smaller particles decreases with increasing ambient temperature. Implications of these results for cloud modeling are discussed. 


\section{Session 5: Precipitation particles: Hailstones}

5.1 Total hydrometeor spectra in a hailstorm and implications for precipitation growth processes

\section{J. MUSIL ET AL.}

5.2 Airborne vs. ground hail sizes

J. R. MILLER, JR., ET AL.

5.3 Analysis parameters for accreted ice

\section{E. ASHWORTH ET AL.}

5.4 Experiments on the factors involved in interpreting natural hail crystal textures

\section{A. KNIGHT ET AL.}

Some measurements are reported of entire hydrometeor spectra in a hailstorm, and their implications are considered regarding the development of precipitation in the storm. The measurements were made with an armored T-28 aircraft during the 1976 National Hail Research Experiment. The hydrometeors are divided into four categories ranging from cloud droplets to hailstones. A Johnson-Williams liquid water concentration meter sensed cloud droplets up to $30 \mu \mathrm{m}$ in diameter. A Particle Measurement Systems two-dimensional optical array spectrometer was used for particles up to about $1 \mathrm{~mm}$; a combination of two-dimensional probe and foil impactor data, for particles up to a few $\mathrm{mm}$; and a combination of foil impactor and laser hail spectrometer data, for larger hydrometeors. Particle number and mass concentrations were computed for each category.

Previous investigations have shown that cloud liquid water provides the primary material for the growth of graupel and hail in Colorado thunderstorms. At the levels where the measurements are made $\left(-10^{\circ} \mathrm{C}\right.$ to $\left.-15^{\circ} \mathrm{C}\right)$, raindrops are rare and the importance of cloud ice particles is probably minor. The rates of cloud water depletion by accretion by particles in each larger size category were calculated. It appears that the largest hydrometeors usually win the competition for the available cloud water. These results indicate that larger particles must be introduced into the primary growth areas to affect the precipitation mechanism. In some cases, the storm may be more efficient at doing this naturally than any practical artificial means.

Comparisons between hail measured by a T-28 aircraft laser hail spectrometer and a surface hail pad network were made using data collected in northeast Colorado as part of the National Hail Research Experiment. Examination of the airborne and surface pad distributions reveals that greater proportions of both large and small stones were measured in the air than one would expect from the surface pad data. Fewer stones in the size ranges of $1-2 \mathrm{~cm}$ diameter were observed aloft. The T-28 was usually flying between $5.5 \mathrm{~km}$ and $6.5 \mathrm{~km}$ at temperatures between $-8^{\circ} \mathrm{C}$ and $-15^{\circ} \mathrm{C}$. Further, comparisons between surface and airborne hail data in the proximity of the aircraft's flight path are discussed.

Several quantitative parameters that are relevant to the fabric of natural and artificial accretions have been investigated. Their relationship to the growth conditions of laboratory-grown samples has been sought in terms of the ambient temperature $T_{a}$ and the temperature $T_{d}$ of the growing surface. Mean crystal area $\bar{\sigma}$ and mean maximum crystal length $\bar{l}$ have been included in the study, together with the mean crystal width $\bar{w}$ (as opposed to the mean maximum width used by Macklin and co-workers). Two additional parameters, the modified mean width $\overline{w^{\prime}}$, which is a measure of the two-dimensional solid angle subtended by the crystals, and the shape factor $\bar{f}\left(=\bar{l} / \overline{w^{\prime}}\right)$, have been defined.

Rye and Macklin found $\bar{l}$ to be a more systematic function of the growth conditions than the mean maximum crystal width. However, $\bar{w}$ was studied because it can be used more easily in an analysis, and intuitively it is expected to be less sensitive to the curtailment of a growth at a particular set of conditions. The modified mean width possesses these same advantages. Our results indicate that the $\bar{w}=\bar{w}\left(T_{a}, T_{d}\right)$ relationship does indeed contain considerable uncertainty, but the $\overline{w^{\prime}}=\overline{w^{\prime}}\left(T_{a}, T_{d}\right)$ relationship is defined at least as precisely as the $\bar{l}=\bar{l}\left(T_{a}\right.$, $T_{d}$ ) relationship.

The shape factor $\bar{f}$ has three attributes. Often it is difficult to determine whether small regions in a section are tiny separate crystals or a substructure of major crystals. Subjective decisions must be made, and they can change the value of $\bar{l}$ radically. It has been discovered that $\bar{f}$ has sensibly the same value for both the major crystals and the ambiguous small crystals or substructures. Thus, the value of $\bar{f}$ is virtually independent of subjective crystal boundary choices; it is the only parameter of the ones considered with this property. Also, $\bar{f}$ appears to be dependent only upon $T_{d}$, a conclusion that lends itself to physically acceptable interpretations. Finally, it has been found that $\bar{f}$ is very sensitive to the treatment of the sample. In many cases, it can be used to estimate the degree of annealing of an accreted ice sample.

Macklin et al. have devised a scheme of interpreting hailstone growth environments, based in large part upon measurement of crystal sizes in the ice. Laboratory experiments to check three major assumptions in the use of crystal size are reported herein. These assumptions are: 1) that recrystallization is a negligible influence upon crystal size; 2) that ice crystal collisions do not affect crystal size in dry growth (mean hailstone temperature $<0^{\circ} \mathrm{C}$ ); and 3 ) that rotation or gyration rate is not an important influence upon crystal size. The experiments demonstrate that the third assumption is valid, while the first two are not. Recrystallization in fresh accretional growth simulating the dry growth of hailstones is extremely rapid. When the de- 
posits are annealed at the melting point, the changes are by far the most rapid; major changes in crystal sizes and textures may occur within $2 \mathrm{~min}$, and total recrystallization may occur within 10-30 min. The recrystallization tends to reduce crystal size in originally coarse-grained ice by nucleation of new grains, and to increase it in originally fine-grained ice by grain growth. The manner of collection and storage of hailstones is very important to the eventual interpretation of their internal structures, but even the best collection technique (immediate quenching) is not complete insurance against recrystallization. Recrystallization textures are, however, easily recognizable.

Experiments also show that collision with ice crystals in dry growth can lead to marked reduction in grain size.

5.5 South African Lowveld hailstone embryos

\section{N. C. KNIGHT AND}

C. A. KNIGHT
The embryos from 1318 hailstones collected in Nelspruit, South Africa, from 29 storm complexes have been classified. Further collections from Oklahoma have also been analyzed. The results confirm our previous conclusion that there are distinct climatological differences in hail embryo types. The collections from Nelspruit in the South African Lowveld show high percentages of embryos that appear to be large frozen drops, quite similar to those found in Oklahoma. This is in contrast to the extensive Colorado collection, which has a high percent of graupel embryos. The results are also analyzed and discussed in terms of hailstone size. Possible reasons for the differences are discussed.

\section{Session 6: Fogs}

6.1 Fog microphysical measurements on the West Coast

\section{J. G. HUDSON}

6.2 Microphysics of stratocumulus clouds as revealed by the real-time CCN spectrum

measurements

\section{K. SAXENA AND \\ N. FUKUTA}

A series of optical particle counter (OPC) measurements in fog at several locations along the U.S. West Coast exhibited wide variations in microstructure. These variations ranged from a classic marine fog measured onboard ship off the Oregon coast to a polluted "haze" in San Diego. The former was composed almost exclusively of large drops $(r>5 \mu \mathrm{m})$, while the latter contained many (often 500 drops $>1 \mu \mathrm{m}$ ) micron and submicron drops. The fogs with more marine type microstructures showed a clear distinction between unactivated haze drops and activated cloud drops, while other fogs did not show such a clear distinction between haze and cloud drops. In the continental or polluted type fogs, the unactivated drops played a much more important role in visibility reduction.

Simultaneous measurements of CCN and FCN spectra showed that variations in the concentrations of these particles were responsible for much of the microstructure variation. FCN are the subset of CCN that has critical supersaturations, $S_{c}$, below that of CCN $(<0.1 \%)$. Simultaneous FCN spectra and drop concentrations revealed that the effective supersaturation in many of these fogs was in the range of a few hundredths of a percent. This is to be expected for clouds formed in the weaker updrafts that are associated with these layer-type clouds.

FCN were measured with an isothermal haze chamber (IHC). Since this method and the drop size measurements both depend on OPC sizing, a more precise calibration procedure has been developed.

Diurnal, seasonal, and areal variations in CGN and FGN concentrations are displayed from the continuous records at these coastal locations.

The stratocumulus clouds are so persistent off the California coast during the months of June through August that they may be dynamically regarded as a steady-state phenomenon. In order to gather evidence to test Lilly's cloud-topped mixed layer model, a field program was launched during June 1976. Real-time measurements of cloud condensation nuclei (CCN) spectrum were carried out with the help of our CCN spectrometer, which was installed aboard the NCAR aircraft Electra. Simultaneous measurements of cloud droplet size distributions made with the help of Knollenberg probes are also available for these flights. Before embarking upon the measurements, the presence of stratus clouds was detected through the satellite imagery, and the flights were conducted when a GOES image showed the presence of stratus clouds close to the coast. Five flights were made during a total of $30 \mathrm{~h}$. Three of these flights were planned to accomplish measurements before and after the sunrise in order to study the effect of radiative cooling. Flight patterns were so selected as to provide comprehensive vertical profiles of the CCN spectrum. It was observed in two cases that the stratus deck did lower to the ocean surface resulting in the coastal fog. The vertical soundings have shown that after sunrise, some of the stratus cloud tops started evaporating, thus enhancing the CCN concentration noticeably at the lower end of the spectrum of critical supersaturations. This effect got stronger as the day progressed, pointing to the possibility of a diurnal cycle of stratus evaporation and condensation. Our measurements help establish the flux of CCN and reveal that, from microphysical viewpoint, the coastal stratocumulus clouds are far from being a steady-state phenomenon. 
6.3 Particle size distributions in three fogs

\section{G. L. TRUSTY AND}

T. H. COSDEN

6.4 Cloud and fog studies using remote sensors in San Diego

\section{R. NOONKESTER}

6.5 Airborne measurements in marine stratus

\section{P. B. WAGNER AND J. W. TELFORD}

6.6 On the formation of convective marine fog

\section{S. K. CHAI AND \\ J. W. TELFORD}

6.7 Cloud physics and boundary layer measurements in radiation fogs

\section{G. G. LALA ET AL.}

Using Particle Measuring Systems (PMS) particle spectrometers, measurements have been made of particle size distributions in fogs on the coast of northern California at Arcata, aboard a ship off the coast of Nova Scotia, and $4 \mathrm{mi}$ inland from San Clemente, Calif. With two of the PMS instruments operating simultaneously, continuous distributions were obtained from $0.1 \mu \mathrm{m}$ radius to $15.0 \mu \mathrm{m}$ radius. A PDP-11/34 operates on line to display size distributions in the field. Other preprocessing electronics store the particle information and meteorological parameters on tape for later analysis. The measurement system is described, and the distributions are compared from the three fogs.

Since 1968 when the FM-CW radar first obtained clear-air echoes, considerable data have been obtained and studies have been made concerning clouds, convection, and marine fog in coastal environments. Simultaneous observations have been made with the radar, lidars, high-power radars, acoustic echosounders, acoustic (bistatic) wind sensors, a ceilometer using a film recording technique, and radiosondes. This paper illustrates the advantages of simultaneous measurements by surface-based remote sensors in coastal regions and presents some results concerning stratus and convective clouds and marine fog.

Characteristic radar and acoustic echoes have been identified that can usually be associated with cloud tops and surface-based convection. Monitoring echoes associated with cloud tops permits continuous measurements of cloud thickness and often permits estimates of cloud thickness changes (development or dissipation) to be made by temporal extrapolation when continuous, reliable estimates of the cloud-base height are available. Continuous cloud-base heights have been provided by special film records of lidar and rotating-beam ceilometer returns. Monitoring echoes associated with surface-based convection may permit reliable estimates of the time of cloud formation to be made, provided good estimates of the convective condensation level and the atmospheric structure above the convective layer are available. Examples will be presented and discussed.

Simultaneous measurements by an acoustic wind sensor, an acoustic echosounder, an FM-CW radar, and ceilometer have revealed the dissipation of a thin, stratus cloud when a strong wind shear penetrated the inversion-capped cloud and have revealed the interaction of a convective layer with a subsidence inversion when the convective layer approached within $150 \mathrm{~m}$ of the inversion base during the formation of thin, scattered clouds beneath the subsidence inversion. These measurements and cloud structure observations during fog will be presented.

Flights were made above, in, and beneath low-level marine stratus along the northern California coast. The detailed measurements of winds, water, and air temperatures and mixing ratios provide a comprehensive view of the stratus environment as well as analysis of wave-like top surface cloud structure that is frequently observed.

Convective marine fog has been observed by many observers. Previous theoretical investigators have concentrated on the formation of advective fog under the influence of eddy diffusion. In this paper, a numerical model is introduced to simulate the convective fog formation over increasing sea-surface temperature with the sea warmer than the air. Cloud can form and spread downwards in these conditions. The cloud-base lowering speed due to the water vapor flux from the sea surface is calculated as the layer tends to saturation. The higher sea-surface temperature gives the energy for the convective motion. The height of the convecting layer, the horizontal pressure gradient, and the sea-surface temperature gradient are three controlling factors for the convective field.

The entrainment of overlying dry air into the convecting region at the inversion base is also considered.

During the fall of 1977 , field research was conducted on the campus of the State University of New York at Albany to measure the characteristics of the boundary layer near the ground and to monitor changes in the visibility and drop-size distribution during fog and haze. Continuous measurements of temperature and humidity were made at 6 levels in the lowest $3 \mathrm{~m}$, as well as measurements of the surface and soil temperatures. Wind speed and direction measurements were made at $1 \mathrm{~m}$ and $4 \mathrm{~m}$ levels, and vertical velocity measurements were made at the $2.5 \mathrm{~m}$ level. Other supporting variables monitored were soil moisture content, net radiation, and dew deposition. Cloud physics measurements included drop-size distribution, aerosol populations, and visibility. Visibility was measured continuously using an AEG Scattered-Light Meter. Droplet-size distributions were obtained via the simultaneous operation of two Royco 225 Optical Particle Counters, which resulted in a 10-channel system covering the size range from $0.3 \mu \mathrm{m}$ 
to $15 \mu \mathrm{m}$. Data on larger droplet sizes were obtained by impaction of droplets on gelatin-coated slides. Several complete and informative fog data sets were obtained.

During a typical radiation night, several short-duration events involving changes in the visibility, drop size, temperature, humidity, and winds were observed. Decreasing visibility was accompanied by slightly decreasing temperatures throughout the $3 \mathrm{~m}$ layers, accompanied by increasing relative humidity. During these periods, the winds were light $\left(<1 \mathrm{~m} \mathrm{~s}^{-1}\right)$ and relatively steady, and the vertical velocity was below $20 \mathrm{~cm} \mathrm{~s}^{-1}$. Corresponding droplet-size data taken during these events show increasing droplet concentration with a shift in the spectrum to larger sizes. Several events involving sudden increases in the wind speed and gustiness with greater vertical velocities were accompanied by the opposite effects on the temperature, humidity, and visibility. Periods of calm wind, below the anemometer threshold, were usually not accompanied by changes in the visibility, and the temperatures were steady except for the surface and $10 \mathrm{~cm}$ level, which showed increased cooling.

Liquid water content (LWC) was obtained by integrating the drop-size distribution and alternately by using several functions relating LWC to visibility and properties of the drop-size distribution; the applicability of these empirical functions is discussed. Visibility is shown to respond strongly to slight changes in relative humidity and in the number of droplets $>0.5 \mu \mathrm{m}$ diameter.

6.8 Vertical inhomogeneity in atmospheric fog and haze

\section{R. G. PINNICK ET AL.}

Vertical structure of the size distribution and number concentration of droplets in atmospheric fog and haze near Grafenwöhr, West Germany, was measured with a tethered balloon-borne, light-scattering aerosol counter for periods spanning parts of 8 days in February 1976. Particular attention has been given to the calibration of the counter (a commercially available Knollenberg probe model CSAS), which is suitable for measurement of droplets with radii $0.2-16 \mu \mathrm{m}$. For haze ( $\approx 15 \mathrm{~km}$ visibility) conditions, little vertical variation is seen; but for low visibility $(<1 \mathrm{~km})$ fog conditions, significant vertical increases in concentration of droplets with radii $>4 \mu \mathrm{m}$ are seen over the first $150 \mathrm{~m}$ altitude. For haze, the droplet-size distribution is approximated by a lognormal with geometric mean radius $r_{g} \approx 0.2 \mu \mathrm{m}$ and geometric standard deviation $\sigma_{g} \approx 1.9$. For fog, a bimodal distribution is found with a relative maximum for the larger droplet mode at radii of $4-6 \mu \mathrm{m}$ and corresponding values $r_{g} \approx 5 \mu \mathrm{m}$ and $\sigma_{g} \approx 1.6$. Liquid water content values for haze and fog range from $10^{-4} \mathrm{~g} \mathrm{~m}^{-3}$ to $0.45 \mathrm{~g} \mathrm{~m}^{-3}$. At a definite wavelength, determined by the radius of the largest droplets present, it is shown that there is a unique linear relationship between extinction coefficient and liquid water content, independent of particle size distribution.

\section{Session 7: Orographic clouds and precipitation}

7.1 Microphysical and dynamical characteristics of winter storms over the Sierra Nevada

\section{J. D. MARWITZ ET AL.}

Observations of the microphysical and dynamical characteristics of storms over the American River Basin area of the Sierra Nevada were made during the 1977-78 winter season. These observations were made with the newly instrumented Super 200 King Air cloud physics aircraft.

To complement the airborne cloud physics data, a mobile ground cloud physics observer collects ice crystal and other data along I-80. The ground cloud physics data are necessary because flight safety precludes flying the aircraft below $\sim 1 \mathrm{~km}$ AGL.

To demonstrate the large temporal and spatial variability in Sierra storms, some preliminary data from the storm of 14-15 December 1977 will be presented. Liquid water contents as high as $2.5 \mathrm{~g} \mathrm{~m}^{-3}$, droplet concentrations of $300 \mathrm{~cm}^{-3}$, ice particle concentrations of 100 per liter, and vertical updrafts of $6 \mathrm{~m} \mathrm{~s}^{-1}$ were observed.

The relations among these measurements, the location within the storm, and stage of development of the storm will be discussed. Some preliminary implications of these results will be discussed in regard to artificially enchancing snowfall from these storms.
7.2 The needle anomaly in Sierra Nevada snowfall

\section{R. F. REINKING}

Needlelike snow crystals, which form in clouds between $-4^{\circ} \mathrm{C}$ and $-8^{\circ} \mathrm{C}$ accounted for $47.7 \%$ of the ice particles sampled from several Sierra Nevada snowstorms, despite persistence of colder cloud regimes that would normally produce the most snow according to temperature-concentration spectra of natural ice crystal nuclei. The concentrations of needles and sheaths frequently exceeded 10 per liter, whereas the worldwide average ice nucleus spectrum would predict $10^{-2}$ per liter at most. The profusion of needles and sheaths may have resulted from cloud seeding in most cases; however, some unseeded precipitation episodes also produced high concentrations. Thus, the possibility of needle and sheath multiplication of the crystal population may arise when cloud droplets accreting and freezing on existing crystals eject ice spinters, according to the Hallett-Mossop mechanism.

The observed snow crystal concentrations are discussed in terms of seeding operations and microphysical restrictions on the Hallett-Mossop mechanism. One case study demonstrates how a trapping inversion within the cloud system may keep seeding material in the $-4^{\circ} \mathrm{C}$ to $-8^{\circ} \mathrm{C}$ 


\author{
7.3 Modification of \\ orographic flow in winter \\ by precipitation
}

\section{G. E. HILL}

7.4 Numerical simulation of clouds and snowfall over mountainous terrain

\section{F. CHAPPELL ET AL.}

regime and prevent the seeding of higher and colder zones. It is also shown that the relative fallspeeds of droplets and needlelike crystals are not sufficient to cause splintering, if the Hallett-Mossop restriction on collision velocity holds. The mechanism apparently operates, as crystals from colder parts of cloud develop high fallspeeds with the assistance of riming, and then fall through the needle regime. Thus, rimed needlelike crystals can be the result but not the source of such secondary ice particles, unless microscale turbulence can induce large crystaldroplet accelerations. The meaning of the findings is discussed with respect to cloud seeding to enhance water supply.

Observational evidence is presented that identifies the occurrence of strong precipitationforced circulations during winter orographic storms. Vertical motion is measured in the lowest $3 \mathrm{~km}$ by parachute dropsonde. It is shown by analysis of several case studies that precipitation in the mountains is greatly reduced following the development of such circulations.

The development of precipitation-forced circulations occurs first at low levels and expands upward to near mountain levels. Both the original updraft and the downdraft beneath are subsequently weakened; at that time, there is a rapid reduction of precipitation. In most instances, a weak low-level updraft and a secondary maximum of precipitation redevelop.

A three-dimensional numerical mesoscale model has been developed with the capability to simulate clouds, snowfall, and airflow over mountainous terrain. The 15-level primitive equation model makes use of a transformed sigma coordinate system to give greater vertical resolution in the lowest levels. Predictive equations for three categories of ice include the effects of condensation, evaporation, sedimentation, sublimation, and ice growth by deposition and accretion of supercooled water. The microphysical equations are coupled back to the dynamical equations so that effects of ice growth on air flow can be determined.

The model has been initialized with San Juan Mountain terrain for the lower boundary and rawinsonde data taken during the Colorado River Pilot Project. Results of these model runs are displayed, discussed, and compared with precipitation data from the San Juan Mountain area.

\section{Session 8: Cyclonic storms}

8.1 Some observations of precipitation systems associated with cyclones based on ground

observations of snow crystals

\section{A. ONO}

8.2 The University of Washington's CYCLES Project: An overview

\section{P. V. HOBBS}

For the study of cloud and precipitation systems associated with cyclones, the types of snow crystals and their trend of evolution were observed on the ground.

The gross features of the large-scale atmospheric processes, as depicted by the synoptic analysis, are revealed clearly in the sequence and trend of the snow crystal type with time. The initial high-level, cold region, columnar type is followed by a secondary growth level below (plate type) and the abrupt disappearance of high-level forms. However, the snow crystal observations reveal important details of cloud and precipitation systems undetected in an analysis of infrequent aerological radisonde observations.

Of special interest is a finding that ice crystal multiplication processes are quite active in precipitation systems associated with cyclones. Snowflakes composed of warm region, long columnar crystals $(300-3000 \mu \mathrm{m})$ were frequently observed during snow storms. The high concentrations of crystals (20 per liter) and the growth habit of the crystals clearly indicate some active crystal multiplication processes at work in lower supercooled clouds. While the evidence is yet unclear concerning the mechanism involved, this process points to the importance for the precipitation rate on the ground.

The University of Washington's CYCLES (Cyclonic Extratropical Storms) Project is concerned with detailed studies of the synoptic-, meso-, and microscale processes associated with the formaiion of clouds and precipitation in the cyclonic storms that originate over the Pacific Ocean and move across the Pacific Northwest. The field portion of this project consists of simultaneous observations and measurements (over ocean and land) from satellites, two instrumented research aircraft, several radars (conventional and Doppler), serial rawinsondes, and a network of groundbased measuring stations. The satellite and radar observations allow mesoscale cloud and precipitation features to be identified in real time; a ground control center then directs the aircraft into these features. Measurements from the University of Washington's B-23 research aircraft are telemetered to the control center in order to provide real-time information on the internal structure of the mesoscale features.

In postanalyses, selected storms are analyzed in detail to document the mesoscale and microscale structures of cyclonic storms and in attempts to unravel the relative importance of dynamics and microphysics in the cloud and precipitation processes. The highlights of some of our findings in the CYCLES Project will be briefly described in this overview; more detailed descriptions of selected topics will be given in the four following papers at this conference. 
8.3 Air motions, mesoscale structure, and cloud microphysics associated with a cold front

\section{P. V. HOBBS ET AL.}

8.4 Generating cells and precipitation growth in mesoscale rainbands

\section{P. H. HERZEGH AND P. V. HOBBS}

8.5 Microphysical and dynamical structure of mesoscale cloud features in extratropical cyclones

\section{T. J. MATEJKA ET AL.}

As part of the University of Washington's CYCLES Project, simultaneous radar (conventional and Doppler), airborne, rawinsonde, ground synoptic, and satellite imagery data were collected during the passage of a well-defined cold front across western Washington on 17 November 1976. These data have been analyzed, using several new analytical techniques, to obtain detailed information on the horizontal and vertical wind fields, the mesoscale organization of precipitation, and the structure of the clouds associated with the front.

Accurate tracking of the cold front was possible as the wind shift that accompanied the surface front appeared as a marked line of discontinuity in the velocity field depicted by the color display Doppler radar. Two updraft regions were identified: 1) an intense and small-scale updraft, which was associated with the surface front; and 2) a weaker and larger scale updraft, which was situated above the cold frontal surface. The intense updraft was associated with a broken line of cellular precipitation $\sim 4 \mathrm{~km}$ wide and $\sim 3 \mathrm{~km}$ high, which moved with the velocity of the wind directly above the surface front. Small mesoscale bands of precipitation, $25-50 \mathrm{~km}$ wide and $5 \mathrm{~km}$ high, were associated with the weaker updrafts aloft; within these bands were smaller areas of heavier precipitation that moved with the velocity of the winds between 500 and $700 \mathrm{mb}$. The bands themselves moved forward relative to the surface front.

Multilevel aircraft passes at different altitudes through the frontal system provide information on the microstructure of the clouds and precipitation growth mechanisms within the frontal system.

An important development in the history of cloud physics has been Bergeron's concept of the "seeder-feeder" cloud system. Early radar observations by Marshall and others showed that "seeder" clouds, in the form of generating cells, are frequently embedded within the upper portions of the stratiform clouds associated with warm-frontal precipitation. Long snow trails usually emanate from these generating cells. Using radar and aircraft measurements, our group has studied the interactions between these trails and the cloud layers below and has verified the importance of the seeder-feeder process in warm-frontal mesoscale rainbands. However, the roles of generating cells and the seeder-feeder process in other types of rainbands have been unclear.

In this paper, we examine field data collected in other mesoscale rainbands as part of the University of Washington's CYCLES Project. Simultaneous measurements by two instrumented aircraft, a Doppler radar, and serial rawinsondes were made near Seattle, Wash., in two frontal systems containing mesoscale rainbands that produced $10 \mathrm{~min}$ average precipitation rates up to $6 \mathrm{~mm} \mathrm{~h}^{-1}$. Reflectivity factor measurements by vertically pointing radar revealed the presence of generating cells and snow trails embedded in the upper regions of the coldfrontal rainbands. Airborne particle size spectrum measurements obtained throughout the lepth of the rainbands indicated that the ice particles originating in the generating cells aloft continued to grow as they fell through lower, widespread cloud layers, in a manner similar to the seeder-feeder process observed in warm-frontal rainbands. The data are examined to determine the growth modes of the ice particles in the generating cells and in the snow trails.

The precipitation in extratropical cyclones often displays a strong propensity toward mesoscale organization, particularly in the form of cloud and rainbands. Several generic types of bands have been distinguished, for example, warm-frontal, cold-frontal, warm-sector, post-frontal, and bands associated with surges of cold air aloft ahead of occluded fronts.

Airborne data collected in various types of bands in a number of the cyclonic storms studied in the CYCLES Project have revealed patterns of cloud liquid water content, ice particle concentration, and vertical air motion for each type of band. These patterns are explainable in terms of the frontal structure and dynamics of the bands. Dynamically active (convective) mesoscale regions, where liquid water is condensed, can be clearly distinguished from dynamically less active regions; in the latter case, the ratios of ice to liquid water are generally much higher. In each type of band, there is a systematic association between regions with ice particle concentrations greater than about 1 per liter and mesoscale rainfall.

\section{Session 9: Microstructure of convective clouds-I}

9.1 Relationship of ice to water at $-10^{\circ} \mathrm{C}$ during initial penetrations of a population of Florida cumuli

\section{R. I. SAX AND}

V. W. KELLER
During the course of the 1976 field season of NOAA's Florida Area Cumulus Experiment (FACE), penetrations were carried out near the $-10^{\circ} \mathrm{C}$ isotherm level into a number of growing convective clouds. Measurements of cloud droplet water content and raindrop, ice crystal, and graupel concentrations were acquired using a Johnson-Williams heated wire in combination with a Formvar replicator. The relationship of these four microphysical parameters has been found to vary depending upon the point in its life history at which the cloud was penetrated. Since, in Florida, cloud-base temperature (and hence cloud depth from base to the $-10^{\circ} \mathrm{C}$ penetration 


\subsection{Microphysical} characteristics of individual tropical cumuli developing over land and over water: A comparison case study

\section{P. T. WILLIS AND R. I. SAX}

9.3 Microphysics of invigorated cumulus development

\section{LAMB ET AL.}

\subsection{Microstructure of an "accumulation zone" in a tropical Cb cloud}

\section{J. F. GAYET AND} R. G. SOULAGE

9.5 Time duration of the microstructure of $\mathrm{a} \mathrm{Cb}$ cloud in middle latitude

\section{J. F. GAYET}

9.6 Single-level microstructure of prefrontal and postfrontal Illinois cumuli

\section{R. I. SAX ET AL.}

level) varies little from day to day, the mass of water contained in cloud-sized droplets (able to be sensed with the heated wire device) provides a rough measure of the age of the cloud at the time of sampling. It will be shown that "young" clouds growing through $-10^{\circ} \mathrm{C}$ and containing copious amounts of cloud water are virtually free of raindrops and ice, whereas older clouds contain progressively more rain, graupel, and ice crystals in that order. Inferences will be drawn regarding the evolution of rain to graupel to crystals in the context of a postulated secondary ice production mechanism.

Significant differences in microstructure at altitudes near the melting level have been observed between fairly isolated cumulus clouds developing over land (Florida peninsula) and oceanic convective clouds that are incorporated within organized larger scale systems such as tropical storms and hurricanes. Project LOCUS (Land-Ocean Cumulus Study) was initiated during the summer of 1977 with the goal of eventually determining to what extent the observed microphysical differences are a function mainly of the uniqueness of land-ocean properties (e.g., heating or aerosol characteristics) or are a function mainly of the degree of mesoscale organization accompanying the convection.

This paper reports on results from a series of penetrations carried out near the $-5^{\circ} \mathrm{C}$ isotherm level into two fairly isolated cumulus clouds of similar size developing on the same afternoon, one over open water $\sim 100 \mathrm{~km}$ southeast of Miami and the other over land $\sim 100 \mathrm{~km}$ northwest of Miami. The "ocean cloud" was penetrated successively five times throughout $20 \mathrm{~min}$ of its life history from the point at which it first grew through $-5^{\circ} \mathrm{C}$ until the point at which it finally collapsed below $-5^{\circ} \mathrm{C}$ and dissipated. The "land cloud" developed as part of a small group and was successively penetrated five times during a $14 \mathrm{~min}$ span from the point at which it first grew through $-5^{\circ} \mathrm{C}$ until it could no longer be identified as the original tower within the growing complex. The microphysical characteristics of these two cumuli were examined to compare the evolution of the following parameters near the $-5^{\circ} \mathrm{C}$ level: 1) updraft structure; 2) cloud droplet water content; 3) total liquid water content; 4) raindrop water content; and 5) cloud and raindrop-size distributions.

Rapid growth of a cumulus tower may well have its origins in the detailed microphysical processes of cloud element formation. Although the mechanistic link between the microphysics and the cloud dynamics is almost certainly the release of the latent heats of condensation and fusion, the crucial variable is the rate at which the heat is released in a given portion of the cloud. This variable is strongly dependent upon the glaciation mechanisms of the cloud and involves the Brownian capture of freezing nuclei, the secondary production and hydrodynamic capture of ice particles, and the riming of graupel particles. A simple conceptual model emphasizes the essential distinctions to be made between clouds naturally and artificially glaciated and shows that the rate of heat released by fusional processes tends to dominate that by depositional growth, particularly in seeded cases. Data from recent field observations in Florida are used to validate the model concepts.

As part of Laboratoire Associé de Météorologie Physique's Tropical Cloud Experiment (MOUSSAFRICA 77) in Ivory Coast, 17 cumulonimbus were penetrated at different levels above $0^{\circ} \mathrm{C}$ with a DC-7 aircraft equipped with three Knollenberg probes (ASSP, CDP, and PSP) and a Ruskin probe to measure the drop spectra and the liquid water content of the cloud. One of these was particularly severe. The trajectory of the aircraft in the cloud relative to the photographs of the radar echo and the cloud shows that it was penetrated in the mature zone. Along a path of $1000 \mathrm{~m}$, the liquid water content was $>10 \mathrm{~g} \mathrm{~m}^{-3}$ (maximum at $19 \mathrm{~g} \mathrm{~m}^{-3}$ ) while corresponding to a ratio of $\sim 2$ between the real and the adiabatic liquid water content. These values characterize an "accumulation zone."

A cloud, rapidly changing from the cumulus congestus stage to the multicellular cumulonimbus stage, was penetrated 10 times at the same level $\left(-5^{\circ} \mathrm{C}\right)$ with a $\mathrm{DC}-7$ aircraft instrumented for microphysical, thermodynamical, and dynamical measurements. The results show the variation of the microstructure of the cloud in relation to the vertical air speed of each cell from the growing stage to the dissipating stage. The growth is characterized by a periodic formation of new individual cells on the upstream flank of the cloud.

During two afternoons of July 1977, the NOAA P-3 aircraft was used as a platform to carry out penetrations into convective complexes developing in central and southern Illinois. Penetrations were conducted near the $-10^{\circ} \mathrm{C}$ isotherm level, and measurements of updraft profile, cloud water content, cloud and rainwater drop-size distribution, and graupel and crystalline ice concentrations were obtained. A cold front moved through the observational area near the conclusion of the first flight day, and by the second day, the air in the low- and midtroposphere 
had dried out substantially. The cumuli developing in southerly maritime flow in advance of the front were found, on initial penetration, to contain large amounts of water in cloud-sized droplets coincident with vigorous updrafts and little ice or rainwater. Clouds tended to be organized in small groups, and each tower retained a sharply defined cauliflower appearance as it grew through the $-10^{\circ} \mathrm{C}$ level. In contrast, on the following day with northwesterly continental flow behind the front, bases were somewhat higher and the clouds struggled to grow to $-10^{\circ} \mathrm{C}$. Those that did were isolated, "fuzzy" in appearance, and contained considerably lower amounts of cloud water and much weaker updrafts than did the convective elements developing on the previous day. The presence of ice and rainwater on initial penetration was observed occasionally. A comparison of the evolution of the microphysical features of cumuli developing on these two very different types of days will be documented from multipass data. Inferences will be drawn with respect to the natural ice formation mechanism(s) thought likely to be operating in cumuli in the Illinois environment.

\section{Session 10: Microstructure of convective clouds-II}

10.121 June 1976: Case study of precipitation initiation in the NHRE observational area

\section{P. N. JOHNSON ET AL.}

10.2 A possible transient ice collection zone in a singular continental mountain cumulus cloud

\section{J. L. LECOMPTE AND G. J. MULVEY}

10.3 Phase detection of convective cloud hydrometeors using lidar

\section{K. S. DANIELSON AND}

\section{E. DERR}

The characteristics of precipitation initiation in cumulus congestus clouds were investigated with three instrumented aircraft in the National Hail Research Experiment (NHRE) observational area on 21 June 1976. The clouds that were investigated formed in a line near a moving confluence region. The aircraft began penetrations several minutes before first-echo formation and continued for about $30 \mathrm{~min}$. Two of the clouds were chosen for intensive study.

While the same forcing was involved in initiating both the clouds and moist adiabatic updraft cores were observed in both of the clouds, the development of ice precipitation near cloud base was quite different. In cloud 1, a strong updraft (observed maximum of $30 \mathrm{~m} \mathrm{~s}^{-1}$ ) caused ice to develop and the first echo to form near the top of the cloud. Ice was found near cloud base later in the cloud development. In contrast, the first echo of cloud 2 formed at a lower level, and ice was found near cloud base during the first aircraft penetration. This difference was caused by lower updraft velocities and by injection of ice particles into the updraft of cloud 2 from the outflow of an adjacent, older cell.

Precipitation development in these two clouds is compared in relation to the cloud dynamics, interaction with other clouds, and the different ice initiation processes involved.

Microphysical conditions present in singular continental mountain cumuli have been observed in the South Park Area Cumulus Experiment. The spatial and temporal distribution of hydrometeors has been observed along with other microphysical and dynamic properties of the clouds. The implications of these observations on the development of the ice phase in these clouds have been studied.

Measurement systems utilized for this study included the NOAA/NCAR Explorer sailplane instrumented with the Cannon in situ cloud particle camera, Johnson-Williams hot wire liquid water content meter, a reverse flow temperature sensor, and cloud droplet disdrometer; an ice nucleus counter flown on the Colorado State University's Aerocommander; and local rawinsondes. The one-dimensional Lagrangian model developed by Cotton has been used to further interpret the cumulus structure.

This paper presents a case study of the distribution of hydrometeors in one cloud. The size and type of hydrometeors observed, their spatial and temporal distribution, and other meteorological conditions indicate the possibility of a transient ice particle collection zone. This evidence will be discussed in detail.

The NOAA Wave Propagation Laboratory lidar participated in the 1977 South Park Area Cumulus Experiment (SPACE). The lidar was used in conjunction with other instruments including radar and instrumented aircraft to detect important characteristics of summertime convective clouds. Measurement of the height of cloud base, detection of the depth of thin clouds, and determination of the ratio of ice phase cloud hydrometeors to water phase cloud hydrometeors were some of the uses of the lidar.

Hydrometeor phase detection is based on the differential response of the intensity of polarized light when it is reflected off water-phase and ice-phase hydrometeors, respectively. Theoretical studies indicate that phase detection is possible, but field data for verification were not available until the simultaneous instrumented aircraft and lidar observations obtained during SPACE 77. This paper will present data on simultaneous observations of convective clouds by lidar and aircraft. Initial results of lidar-detected cloud characteristics will also be presented. 
10.4 Precipitation mechanisms in summertime storms in the Montana HIPLEX area

\section{W. A. COOPER}

10.5 Turbulent rates of dispersion of ice particles in convective clouds

\section{R. P. LAWSON}

10.6 Cumulus cloud measurements in northern Canada

\section{G. A. ISAAC ET AL.}

Aircraft observations of the hydrometeors in the summertime convective clouds of the Montana area, obtained as part of the High Plains Experiment (HIPLEX), have shown that the precipitation develops primarily via an ice-phase precipitation process. The evidence includes: 1) observations of the hydrometeors in growing stages of the storms, showing that the initial precipitation develops via diffusional and accretional growth of ice particles and that sufficient ice is present to account for precipitation development; 2) penetrations of first-echo regions of clouds, showing that the hydrometeors responsible for the first echo are rimed ice crystals; 3 ) measurements of the droplet spectra, showing that the spectra are not favorable to and do not indicate the presence of a coalescence process; 4) observations of the larger precipitation elements in the region of the cloud near $-10^{\circ} \mathrm{C}$, showing that the precipitation is almost always graupel and that raindrops are extremely rare; and 5) inspections of some graupel collections, showing the absence of frozen drop centers and the frequent presence of ice crystals in the graupel.

Aircraft data from the 1976 and 1977 High Plains Experiment (HIPLEX) were used to document the dispersion of ice particles through cumulus clouds seeded from "on top" with either AgI or $\mathrm{CO}_{2}$. In 1976, ice particle concentrations were continuously sampled by repeated aircraft cloud passes with cross-polarized ice particle probes and one-dimensional Particle Measuring Systems (PMS) cloud spectrometers with discrete samples taken from a decelerator/ice particle collector. The 1977 season emphasized two-dimensional PMS cloud spectrometer measurements with discrete sampling again taken from a decelerator/ice particle collector. For both seasons, the intensity of tubulence data was computed from the fluctuations of air velocity in the aircraft's longitudinal direction.

Comparisons are made of the aircraft-observed spread of ice particles and depletions of cloud water content with theoretical computations. The diffusion equation is applied in finite differ ence form to compute eddy diffusivities through clouds. The intensity of turbulence through clouds is considered as a predictor variable in the evaluation of turbulent dispersion.

In 1976, a project was conducted in northern Canada to determine the potential for enhancing rainfall from cumulus clouds. A T-33 turbulence research aircraft, a Twin Otter instrumented for cloud microphysical measurements, and a cloud-base observation aircraft were used. A total of 47 cumulus clouds were examined within $370 \mathrm{~km}$ of Yellowknife, N.W.T., from 28 June to 17 July. The concentration and phase of large particles $(>70 \mu \mathrm{m})$, as well as the turbulence characteristics, observed during each penetration made in supercooled cloud have been summarized. Most of the large particles $(>70 \mu \mathrm{m})$ within these natural cumulus clouds were water drops. Spectra for the longitudinal and lateral components of turbulence fit the $-5 / 3$ power law at wavelengths up to $400 \mathrm{~m}$, whereas the vertical gust spectrum exhibits a steeper slope of approximately -1.85. Eleven clouds were seeded (between $-5^{\circ} \mathrm{C}$ and $-10^{\circ} \mathrm{C}$ ) with AgI by burning TB1 flares in wing mounted pods on the T-33. Seeding did not produce either ice crystals or rain in many of these cumuli. However, measurements of ice crystal and ice nucleus concentrations, and calculations of the growth of precipitation-sized particles, suggest that the AgI nuclei caused rain to form on three occasions $\sim 8-25 \mathrm{~min}$ after seeding. The amount of rain produced by these clouds has been estimated. Studying the processes within seeded clouds has yielded insights into possible natural precipitation formation mechanisms. For example, ice crystals continued to be generated several minutes after the AgI was released, and numerical calculations using diffusional and accretional growth cannot always predict the observed fast growth of millimeter-sized ice particles.

\section{Session 11: Interactions of convective clouds with near-environment-1}

11.1 Observations of moist adiabatic ascent in northeast Colorado cumulus congestus clouds

\section{A. J. HEYMSFIELD ET AL.}

The characteristics of entrainment in and below 11 developing cumulus congestus clouds in the northeastern Colorado area were investigated through use of measurements obtained with the NCAR/NOAA sailplane, supporting aircraft, and rawinsondes. A region of moist adiabatic ascent was found in eight of the most vigorous clouds sampled. A gradual increase was noted in the equivalent potential temperature and the ratio of the liquid water content to the adiabatic value from the edge of the updraft region inward to the moist adiabatic core. The moist adiabatic core was generally found to be noncylindrical. An analysis of the measurements suggested that environmental air was entrained primarily through the sides of the cloud, or laterally, and was mixed inwardly through turbulence, penetrating an increasing distance toward the center of the cloud with height. Previous measurements and conceptual and theoretical models of entrainment are discussed in the context of the present set of measurements.

The moist adiabatic core was positioned nonaxisymmetrically relative to the boundaries of the updraft region. It is suggested that the updraft acts as an obstacle to the horizontal wind, thereby causing the environmental air to flow around the upshear portion of the cell, protecting 
that region from entrainment. A turbulent wake would be expected to occur in the downshear portion of the cell, producing increasing turbulence and mixing in that region.

These measurements and important implications of the study will be discussed.

11.2 Entrainment in some Colorado multicell storms

\section{R. PALUCH}

11.3 Evidence of convective cloud base entrainment of surface suspensoids

J. A. HEIMBACH, JR., AND N. C. STONE

\begin{abstract}
11.4 Time scales of convective clouds
\end{abstract}

\section{G. E. HILL}

11.5 Effects of evaporation, water load, and wind shear on cloud development in a three-dimensional numerical model

\section{K. YAU}

11.6 Application of $\mathrm{VHF}$ pulsed Doppler radar to cloud physics research

\section{K. S. GAGE ET AL.}

The study is limited to cloud regions that are free of ice and precipitation-size drops. The observations were obtained by the NCAR Explorer sailplane in northeast Colorado during the National Hail Research Experiment 1976 field season. The data analyzed consist of $1 \mathrm{~s}(\sim 40 \mathrm{~m})$ average readings of the reverse flow thermometer and the Johnson-Williams hot wire liquid water probe. In the analysis, air parcels are identified by their specific water content (vapor plus liquid) in $\mathrm{g} \mathrm{kg}^{-1}$ of air and by their "wet equivalent potential temperature." The latter is similar to the conventional equivalent potential temperature except that it is derived by assuming that all condensed water remains in the air parcel. Both parameters are independent of altitude as long as there are no ice and precipitation-size drops. The specific water content and the wet equivalent potential temperature of the cloud air are compared with the same quantities computed for nearby soundings. The results suggest that the entrained air comes from upper cloud levels or the cloud tops. The levels from which the entrained air appears to originate vary from one part of the cloud to the next, but tend to remain constant over distances of the order of kilometers. The amount of air entrained shows marked fluctuations on the scale of hundreds of meters. Except near the cloud edges, the data are generally not consistent with lateral entrainment as predicted by the entraining plume or jet models.

During the summer of 1975, an experiment was conducted in the Calgary, Alta., Canada, area to test the hypothesis that inflow regions of cumulonimbus clouds can entrain surface originated suspensoids. A single case is presented that shows that ascension from the surface to cloud base is possible, under the conditions sampled. For the case in point, a silver iodide plume was traced to cloud base, $3050 \mathrm{~m}$ MSL $(-2000 \mathrm{~m} \mathrm{AGL})$ from $8 \mathrm{~km}$ to $15 \mathrm{~km}$ downwind of the source. A summary of other missions carried out under unstable conclitions confirms the ability of surface material to mix vertically; however, targeting was shown to be difficult. The height of vertical mixing was very well correlated to sounding estimates of the mixing depth.

Multicloud ensembles are examined by numerical simulation for characteristic time scales, with surface heating ranging from weak to strong. The simulations are carricd out using the twodimensional slab-symmetric model of Hill. It is shown that simple oscillatory modes occur when heating and instability are weak and that more complex convection systems develop when heating and instability are strong. It is found that time scales of convection are made complicated by precipitation loading and that for deep convection, the overall cloud time scale is several times greater than the time scale of oscillations due to precipitation. It is also found that the time scale of a cloud is affected by the presence of nonfeeder-type surrounding clouds; dissipating surrounding clouds tend to augment the growth of a cloud and vice versa.

A three-dimensional cloud model has been developed to study the interactions of precipitation processes and wind shear in the life history of a cumulus cell. The model incorporates the anelastic deep convection set of equations and Kessler's microphysical parameterization for precipitation growth. Numerical solutions are obtained by the nondiffusive "leap frog" scheme so that turbulent mixing processes can be modeled realistically. A series of experiments is performed. The effects of evaporation, water load, and wind shear on cloud development are assessed by comparison of the results of experiments with these processes included or suppressed.

In the past few years, a new generation of sensitive pulsed Doppler radars have been developed to operate at $\mathrm{VHF}$, with wavelengths of a few meters. These radars receive backscatter primarily from irregularities in the radio refractive index associated with atmospheric turbulence. They can observe routinely well into the stratosphere. This paper is concerned with the application of VHF radars to the observation of winds and turbulence within and outside of convective clouds.

A VHF Doppler radar can routinely monitor the three-dimensional wind field during the passage of a convective cloud. If a VHF radar were used in conjunction with a microwave Doppler radar, the hydrometeor motions and air motions could be observed simultancously. Comparison would enable the fall velocity of hydrometeors relative to the air to be deduced. Sometimes, as on the Sunset radar located near Boulder, Colo., echoes from large hydrometeors are obtained 
simultaneously with air echoes. When this occurs, the fall velocity of the hydrometeors relative to the air can be obtained using only the VHF radar.

The intensity of turbulence can be related to the width of the Doppler spectrum of air motions observed by the radar. Since the VHF Doppler radar can observe within and outside of clouds, in regions of precipitation as well as in regions free of precipitation, it is possible to observe the intensity of turbulence in the environment of the cloud as well as within the cloud. Since these observations are made simultaneously over an extensive range, the morphology of turbulence associated with the cloud can be mapped out. Observations of this type show eddy dissipation rates approaching $10^{4} \mathrm{~cm}^{2} \mathrm{~s}^{-3}$ associated with convective storms near Boulder, Colo.

\section{Session 12: Interactions of convective clouds with near-environment-II}

12.1 Subcloud eddy fluxes and scales of vertical motion in a cumulus environment

\section{R. F. REINKING}

12.2 Aircraft turbulence measurements in and below cumulus congestus over mountainous terrain

\section{W. R. COTTON ET AL.}

12.3 Parameterizing subgrid turbulent mixing in a simulation of an industrially spawned cumulus cloud

\section{P. M. TAG ET AL.}

12.4 Factors influencing the nature of precipitation at cloud base in Montana

\section{E. S. LOBL AND}

D. M. TAKEUCHI
A gust-probe system mounted on a small aircraft was tested on 6 experimental days in Oklahoma springtime convection. Measurements of the intensities and scales of vertical motion and the vertical fluxes of sensible and latent heat were obtained in the boundary layer. A gradual buildup of moisture with increasing cumulus activity and lowering cloud base was observed during one 3-day sequence, and measurements were obtained near cloud base. Some of the spectra of vertical motion reveal roll structures with predominant crosswind scales of $2-5 \mathrm{~km}$. Updrafts and downdrafts of $5-10 \mathrm{~m} \mathrm{~s}^{-1}$ were common, and extreme gradients and variations in absolute humidity were observed: $10-15 \mathrm{~km}$ average vertical fluxes of water vapor (latent heat) were as large as $1 \mathrm{~g} \mathrm{~m}^{-2}\left(2300 \mathrm{~W} \mathrm{~m}^{-2}\right)$, which is equivalent to an evaporation rate of $\sim 10 \mathrm{~cm}$ per day. Details of the results are presented, and specific needs for integrating such measurements of subcloud dynamics with cloud microphysics are discussed.

The NCAR Queenaire 304D, equipped with inertial navigation system and gust probe, was flown in and below cumuli congesti as a part of the Colorado State University South Park Area Cumulus Experiment, July-August 1977 (SPACE 77). The NCAR Queenaire measured the mesoscale mean wind field and state parameters, cloud-scale liquid water content and momentum fluxes, subcloud fluxes of heat and moisture, and surface radiative temperatures. A series of mesoscale "butterfly" patterns were flown at altitudes ranging from $6.6 \mathrm{~km}$ to $2.8 \mathrm{~km}$ MSL (15 m AGL) with legs parallel to the ridges and perpendicular to them.

The data are averaged over $1.0 \mathrm{~km}$ and $10.0 \mathrm{~km}$ segments, and the characteristics of the corresponding mean and eddy contributions to the kinetic energy, momentum, moisture, and heat budgets are described. The results are compared and contrasted with observations reported by Warner over Australia and Pielke and Cotton over south Florida.

This paper reports on the response of a numerical cloud simulation to differing forms of parameterized subgrid scale turbulence. A two-dimensional vorticity model is used to simulate an industrially spawned cumulus cloud that remained in a quasi-steady state and that was observed and sampled by aircraft. These observations serve as a reference for comparison. A reasonable portrait of the observed cloud is produced using a variable eddy exchange coefficient based on the deformation and buoyancy fields. Other simulations using several alternate viscosity parameterizations are analyzed and compared to this control and to observations. A parameterization based on the deformation field only and another based on two-dimensional turbulence theory are examined. In addition, several values of constant eddy coefficient are used. It is determined that although each of the several experiments produces a cloud simulation that is not unreasonable, the control parameterization yields the best overall comparison to observations.

The Bureau of Reclamation has been conducting the High Plains Cooperative Experiment (HIPLEX) for the past three summers. In the 1975 field season, clouds were sampled at all three sites: Miles City, Mont.; Goodland, Kans.; and Big Spring, Tex. In the 1976 and 1977 seasons, concentrated studies were done mostly in Montana. Meteorology Research, Inc., flies the cloud-base aircraft. Airborne sampling included penetrations at about $300 \mathrm{~m}$ above cloud base as well as in the subcloud layer and the precipitation shaft. Sampling of the precipitation shaft consisted of penetrations at levels ranging from cloud base to about $50 \mathrm{~m}$ AGL.

The objectives of this study were to: 1) determine the frequency and extent to which ice exists in the relatively warm subcloud layer; 2) evaluate seeding effects; and 3) provide information for design considerations of HIPLEX. Precipitation originated from two types of clouds: 1) cumulonimbus-large clouds associated with mesosystems passing through the project area; and 2) cumulus congestus and towering cumulus - associated with local convection (heating or mountains). Hail resulted from all Cb's. Their bases were generally between $2 \mathrm{~km}$ and $3 \mathrm{~km}$ 
MSL, with tops reaching the tropopause. Cloud base temperatures ranged from $2^{\circ} \mathrm{C}$ to $5^{\circ} \mathrm{C}$. The $\mathrm{Cu}$ Congestus and $\mathrm{TCu}$ produced snow, and graupel and rain. The orographic clouds generally produced snow. Characteristic of these clouds were their cold $\left(1^{\circ} \mathrm{C}\right.$ to $\left.-6.5^{\circ} \mathrm{C}\right)$ and high bases (3-4.5 km MSL). In contrast, the graupel- and rain-producing clouds had warmer bases $\left(3^{\circ}-11.5^{\circ} \mathrm{C}\right)$. These clouds had deep melting regions, extending down to $\sim 1 \mathrm{~km}$ from cloud base and into the warm $\left(3^{\circ}-10^{\circ} \mathrm{C}\right)$ subcloud environment.

Based on these observations, stability and available moisture are indicated as the primary factors that influence and determine the nature of precipitation in the subcloud regions. These factors are also responsible for the formation of the precipitation bearing clouds. While the Cb's form due to the presence of a mesosystem, the amount of available moisture determines the formation of the graupel- and rain-producing clouds.

12.5 Self-precipitation of snow from cooling towers

\section{R. KOENIG}

Ground-based, airborne, and satellite observations of cooling tower, condensate plumes reveal that the conversion of the vapor and liquid water emissions seldom undergo transition to the ice phase in a manner that results in snow accumulation on the ground. However, sufficient numbers of events, accompanied by observations, have occurred so that the conditions necessary for snowout can be closely defined. These field-determined conditions that do and do not give rise to plume glaciation can be readily understood when these observations are interpreted using current understanding of the initiation and growth of atmospheric ice particles.

Aside from the source strength, the most important factors regulating snowout are ambient temperature and saturation deficit. The first controls both the nucleation of the ice phase and growth rate of the ice particles; the second controls the lifetime of the plume, and hence the time available for particle growth. Atmospheric stability is an important secondary factor and apparently it plays several roles.

The requirement for a long-lasting plume and the great variation of water content within a plume parcel with time may lead to snow accumulation over long distances downwind of the cooling tower. Also because of dynamical interactions with the surrounding air, the flux of snow to the earth's surface may exceed the flux of moisture from the cooling tower by several orders of magnitude.

\section{Session 13: Interactions of convective clouds with meso- and regional-scales-1}

13.1 Aircraft penetrations of cumulonimbus clouds during $G A T E$

\section{E. J. ZIPSER AND}

A. H. MILLER

13.2 Mesoscale vertical air motions in intense tropical convection

C. A. LEARY AND

R. A. HOUZE, JR.

13.3 The characteristics of evolving mesoscale systems over mountainous terrain as revealed by radar and PAM

\section{R. GEORGE AND}

W. R. COTTON
Aircraft penetrated many cumulonimbus clouds and cloud systems during the GATE. Data are examined, mostly from the NOAA C-130 aircraft, that generally included horizontal and vertical velocity, total water content, temperature, and dew point from the low and middle troposphere. Results are presented for the distribution of vertical velocity, updraft and downdraft diameters, and mass flux in updrafts and downdrafts stratified by altitude. It is suggested that, with a few exceptions, the GATE clouds are only moderately vigorous by mid-latitude standards. Evidence for the existence of mesoscale updrafts is noted. Finally, the evidence for and against the existence of undilute cores is discussed.

An integral part of the life cycle of intense tropical convection organized on the mesoscale is the development during the later stages of the convection of an extensive area of horizontally uniform precipitation. We infer that mesoscale (as distinct from cumulus-scale and synopticscale) vertical air motions are associated with this characteristic precipitation pattern. We estimate the magnitudes of these mesoscale vertical velocities and calculate the vertical transports of mass and heat they accomplish. Our computations are based on digital radar, rawinsonde, and aircraft observations obtained during the Global Atmospheric Research Program's Atlantic Tropical Experiment (GATE) for cases that possess extensive, well-defined regions of horizontally uniform precipitation. Up to now, diagnostic methods for computing the vertical profile of heating rate due to intense tropical convection have assumed that the vertical eddy fluxes of mass and heat are entirely cumulus scale. We consider the effects of modifying this assumption to account for the existence of mesoscale vertical air motions associated with extensive area of horizontally uniform precipitation.

An intensive observational study of the evolution of convective mesoscale systems over mountainous terrain was made as a part of the Colorado State University South Park Area Cumulus Experiment during July and August 1977 (SPACE 77). Data obtained over South Park, Colo., included rawinsondes, triple-Doppler and conventional radar, micromet towers, tethered balloons, stereo photogrammetry, satellite data, lidar, multiple aircraft, and surface data taken on a $10 \mathrm{~km}$ grid with the NCAR Portable Automated Mesonet (PAM).

The thrust of this paper is the description of the evolution of the convective mesoscale systems using rawinsonde, radar power data, and surface mesonet data. Several case study days are 
13.4 A radar case study analysis of a heavily precipitating quasistationary convective storm system

\section{K. KNUPP ET AL.}

13.5 Mesoscale cloud systems over northeast Colorado in relation to synoptic-scale, low-level flow patterns over Kansas/ Oklahoma

\section{A. C. MODAHL}

13.6 The evolution of $a$ multicellular convective cloud mass: A case study

B. ACKERMAN AND

H. A. GREENMAN described that exhibit contrasting features of precipitation amounts, cloud and mesoscale organization, propagation, and intensity. In one of the cases, the cumulonimbi remained in the South Park area producing intense precipitation and hail over the region. In a second case, the convective systems rapidly propagated out of South Park producing tornado-level intensity systems over the plains to the east.

The case studies will be compared and contrasted with each other, as well as with cases analyzed by Pielke and Cotton over south Florida.

The 1977 South Park Area Cumulus Experiment (SPACE) used the NCAR CP-3, $5 \mathrm{~cm}$ radar to colléct reflectivity data on convective clouds and convective mesoscale systems in South Park, Colo. A day of particular interest in the 1977 data set is 19 July. On the 19th, an intense precipitating convective system formed in South Park and remained over the area most of the day. The system was extensively studied with CP-3. Data on surface convergence and divergence were collected using the NCAR Portable Automated Mesonet (PAM). George and Cotton, in a companion paper in this conference, have investigated the characteristics of evolving mesoscale systems on this day, as well as other days, utilizing the surface mesonet data (PAM) and PPI mappings of radar power data.

In this paper, CP-3 reflectivity data will be used to determine the general morphology of the precipitation fields including, echo-top growth rates, echo-radius growth, echo intensity, echo duration, and echo dissipation characteristics for 19 July. These data are integrated with the PAM data as described by George and Cotton to determine the impact and importance of previous cloud development, growth, and dissipation on subsequent cloud development, organization, and intensity.

In an effort to find features in the environmental settings that might be used to stratify data into more homogeneous sets, days of the 1972-74 National Hail Research Experiment (NHRE) operational periods were stratified in accordance with classes of cloud systems that affected the NHRE area in northeast Colorado. The arbitrarily defined classes of increasing convective activity were based on phenomenological observations and ranged from clear days to days with hailstorms.

Analysis focused upon moisture flux and its component wind and moisture fields in the subcloud layer from both mesoscale (NHRE rawinsonde) and synoptic-scale (NMC gridded initial condition) viewpoints. Time-dependent systematic differences between the hail and no-hail settings, especially that of the moisture flux, in the NHRE area suggested linkage with low-level wind patterns over Kansas and Oklahoma in the northward-flowing circulation around the Bermuda semi-permanent high-pressure area. Isotach fields of the $850 \mathrm{mb}$ total wind and $u$ and $y$ wind components along a horizontal cross section extending southeastward from the NHRE area to Oklahoma City were prepared for each day of the experiment. Preparation of mean cross sections for the noted classes showed such a linkage.

In particular, the following results were obtained: 1) Over the NHRE area, there was a near-surface marked mesoscale increase of easterly ( $u$ component) moisture flux during the day on hailfall days, but not on other days, based on over 225 cases. The hail-associated easterly moisture flux magnitude was larger than the no-hail flux by a factor of 5 , at the time of hailfall. The southerly ( $v$ component) moisture flux was stronger during thunderstorm and hailfall periods than during nonstorm conditions with, however, less significant differences than for the $u$ component. 2) There was a statistically significant higher value of the synoptic-scale southerly (v component) $850 \mathrm{mb}$ wind speed along the cross section between NHRE and Oklahoma City, compared to that on no-hail days, based on a total of nearly 200 cases. The synoptic-scale $u$ component showed essentially no difference between samples. 3) Time series analysis showed that low-level southerly winds over Kansas and Oklahoma began to increase 24-36 h prior to thunderstorm and hail occurrence in northeast Colorado, but remained essentially constant for the nonthunderstorm cases. Consideration of individual classes showed an increasing gradation of this mean wind speed with increasing convective class in northeast Colorado.

The importance of such a link to the broad-scale flow for convective activity in northeast Colorado is discussed in terms of the advection of air mass properties (thermodynamic and cloud physical), including possible kinematic contributions, such as horizontal velocity convergence in the forward quadrants of an approaching isotach maximum.

A multicellular convective cloud mass that developed on a summer afternoon in southwestem Illinois has been studied on three scales: the regional scale, the small mesoscale, (cloud line to cloud cell), and the subcell scale. The study is based on an integration of many types of data: measurements made during aircraft penetrations into developing cells, $10 \mathrm{~cm}$ and $3 \mathrm{~cm}$ radar surveillance, rainfall measurements from a dense recording rain gage network, special radiosondes, and the observations from the various National Weather Service networks.

The cloud mass was one of a cluster of showers that developed in deep southwesterly flow 
$\sim 100 \mathrm{mi}$ south of a stationary front. It started as a single small, but rapidly expanding, cell southwest of a mature shower cloud. Although a few towers developed on the northeast side early in the history of the cloud mass, major expansion took place on the southwest side. Individual cells barely moved, in agreement with the light winds through most of the cloud layer, but new cell development caused the cloud mass to propagate upwind.

The peak top of the cloud mass extended $\sim 9 \mathrm{~km}$ for a full hour of the $1 \frac{1}{2} \mathrm{~h}$ duration. Although the maximum height (radar) of $14 \mathrm{~km}$ was reached within the first $15 \mathrm{~min}$, the pcak surface point rainfall rate was associated with a later part of the development, which had a cloud top of $\sim 11 \mathrm{~km}$.

In-cloud aircraft measurements were obtained in the developing cloud areas over a period of $40 \mathrm{~min}$. The highest updrafts measured in subcell size cloud units ranged up to $\sim 6$ or 7 $\mathrm{m} \mathrm{s}^{-1}$, and peak cloud water content, up to $4 \mathrm{~g} \mathrm{~m}^{-3}$. In general, sharp cloud boundaries, high temperatures, and high cloud water contents and updrafts were associated with the new active areas as indicated by radar. More mature areas, as indicated by radar, usually had high precipitation water contents.

13.7 On the periodicity of appearance of successive cells in multicellular storms

\section{RAMOND}

13.8 Model cloud distributions in an anisotropic environment

\section{G. L. ACHTEMEIER}

13.9 Release of potential instability by mesoscale triggering: An objective model simulation

\section{A. MATTHEWS}

The observations of multicellular storms during the Thunderstorm Project (1946-47) have shown that the periodicity of appearance of the successive cells was quasi-constant (concerning at least a set of 32 cases that have been considered) with a mean value of $17.8 \mathrm{~min}$. According to numerical models such as those of Srivastava (1967), Takeda (1969), and Hane (1972), this periodicity should be related to the vertical wind shear and to the inhibiting effect of the precipitation content in the updraft.

The purpose of this paper is to give a theoretical expression of the period of appearance derived from a scale analysis. The interaction between the updraft and its sheared environment is expressed in terms of drag force, a concept that has been used by Hitschfeld (1960) and Newton (1967) and that finds support in the studies of Fujita and Grandoso (1968), Barnes (1969), Fankhauser (1971), Jessup (1972), and Ramond (1977). Under the action of the drag force, the updraft is tilted and the precipitation maximum content has a tendency to be shifted downwind, allowing the upwind part of the updraft (as it is liberated from the water load) to start a new cycle of growth. With the assumption of a critical diameter below which a starting updraft is unable to yield a deep convective cell, the theoretical evaluation of the amplitude of the shift of the precipitation content downwind leads to the following expression of the period of apperance of successive cells: $T \sim K\left(A W_{\max } D\right)^{-\frac{1}{2}}$.

In the above expression, $A$ is the wind shear, $W_{\max }$ is the highest vertical velocity in the updraft, $D$ is the updraft diameter at the end of the growing phase, and $K$ is a coefficient, the value of which depends on the critical diameter of the new updraft. According to observations, this critical value is $\sim 600 \mathrm{~m}$, which is corroborated by the experimental study of Ackermann (1967) and by the results of the numerical model of Holton (1973).

The theoretical value of the period of appearance is confronted with experimental data in various cases of wind shear, including those of the Thunderstorm Project; a good agreement is found.

This paper describes a technique to initialize cloud models to capture destabilizing effects of precipitation-producing migratory weather systems. The spatial and temporal variability of atmospheric structure was simulated by modifying the morning (evening) soundings at two midwestern sites according to hourly surface temperature, moisture, and $5 \mathrm{~h}$ cumulated convergence converted to vertical displacement. Soundings simulated at points on a $375 \mathrm{~km}$ square grid covering much of Illinois and parts of surrounding states were processed with the Krietzberg and Perkey MESOCU one-dimensional cloud model. To the extent that the assumptions made are valid, migratory weather systems typically displace the lower troposphere well beyond the level necessary for spontaneous convection. The magnitudes and spatial distributions of model predicted cloud tops were compared with locations and tops of radar echoes reported in the National Weather Service radar summary charts.

Organized convective cloud development observed in satellite imagery was compared with thermodynamic potential instability from model-processed rawinsonde data. An objective numerical model was used to determine the effect of mesoscale-induced lifting on the release of potential instability and resulting capacity of the atmosphere to support convective cloud development. Cases where significant mesoscale organization (cloud lines, clusters, etc.) were observed had a significantly higher potential for release of convective potential than cases 
having isolated convection or no convective clouds. The model developed by Kreitzberg and Perkey is a useful analytic tool to discriminate between days during which mesoscale triggering (lifting) may induce substantial release of convective potential instability and those where no release is possible. The need for measurement of mesoscale convergence is discussed. Examples of characteristic differences in soundings and effect of mesoscale lifting are presented, and implications for improving stratification of cloud physics and weather modification experiments are discussed.

Geosynchronous satellite images were stratified into days with organized mesoscale convective systems and days with random or no convection. All days were examined for release of potential instability by lifting, using two lifting rates $\left(10\right.$ and $\left.20 \mathrm{~cm}^{-1}\right)$ for a period of $3 \mathrm{~h}$, and these were compared with potential instability and cloud growth for the original unperturbed soundings. Total cloud development (cloud depth, number of clouds, and rainfall) diagnosed by the model was compared for the cases having mesoscale triggering and cases with no mesoscale organization. This comparison showed a significant increase in the effect of lifting on the mesoscale triggered days in contrast to little effect on the random isolated or air mass days.

Results from the model experiments indicate that we can objectively stratify and quantify the effect of mesoscale-synoptic lifting on the release of potential instability.

13.10 A multisensor, three-dimensional analysis of a meso-high development

J. C. LEASE AND

D. A. MATTHEWS
The development of a meso-high in the HIPLEX expcrimental area near Goodland, Kans., has been documented by satellite, cloud physics aircraft, radar, rawinsonde, and surface observations. The dominant structural features, along with their implications to a one-dimensional, quasitime-dependent, cloud-environment interactive model, are described.

An objective model simulation of the effect of lifting on release of potential instability was made using the MESOCU model. This model, developed by Kreitzberg and Perkey, was used to examine a representative local sounding, using the lifted impulse observed along the gust front. Measurements by cloud physics aircraft flying vertically stacked through the gust front have recorded vertical velocities of $5 \mathrm{~m} \mathrm{~s}^{-1}$. Observed cloud top height and changes in temperature and moisture across the moist meso-high downdraft are compared with their model diagnosed counterparts. Preliminary measurements indicate the boundary between air masses is on the order of $200-300 \mathrm{~m}$ wide, with dew point differences of $3^{\circ} \mathrm{C}$. Digital satellite and radar data are also used to document the life cycle of the meso-high and its associated gust front.

The results of these analyses indicate that mesoscale features are extremely important in determining if convective activity will be enhanced or suppressed. In addition, satellite imagery is indispensable in forecasting location and timing of mesoscale convective activity in the High Plains.

\section{Session 14: Interactions of convective clouds with meso- and regional-scales-II}

14.1 An application of the Simpson-Wiggert cloud model to METROMEX hi-cu data

\section{S. F. MUELLER}

14.2 A scale interaction model for moist convection

\section{J. RAYMOND}

During METROMEX, a $3 \mathrm{~cm}$ radar located in Illinois $\sim 60 \mathrm{mi}$ east of St. Louis continuously observed the development of summertime convective clouds. Distributions of the tallest observed echoes in the areas defined as "rural" and "urban" differed markedly. In order to gain some understanding of these differences, it is first necessary to have an understanding of what mechanisms are responsible for the rural "hi-cu" bimodal structure. The use of a onedimensional steady-state cloud model is one way of investigating the properties of the rural atmosphere.

This study uses a 30-day sample from the total number of hi-cu days. The Simpson-Wiggert one-dimensional steady-state cloud model has been run for each day. Effects of different cloud radii and base heights on the cloud-top heights are investigated as well as the effects of glaciation. A comparison between the model results and the actual data for the 30-day sample is made. The results of these comparisons suggest the mechanisms responsible for the rural bimodal distribution.

Moist convection differs from its dry counterpart in that it exhibits metastable behavior. Convection does not occur until moist air is lifted to the condensation level. This allows a degree of instability to form that cannot be sustained by local destabilizing effects once convection is initiated. As a result of this metastable behavior, moist convection either must be transient or must be sustained by gross import of instability from other regions.

Because of this need to import warm moist air, motions of very different scale must be present. The convective motions themselves tend to be narrow but deep, while the modes that import instability will be horizontally extensive. This scale disparity makes conventional numerical modeling techniques almost useless if one desires to model the entire phenomenon.

This paper will describe a model in which the convective elements and feeder flow are treated as being separate, but interacting, entities. The convective elements are simulated with a quasi- 
linear model that yields the various convective fluxes needed to close the feeder flow equations. The latter are implemented here in one-dimensional form with pressure perturbations included. The model is shown to yield statistically steady disturbances under trade wind conditions, consisting of groups of clouds up to several kilometers in diameter. These groups may be related to the cloud groups long observed in the trade winds.

14.3 A three-dimensional simulation of deep convection over south Florida

\section{G. TRIPOLI AND W. R. COTTON}

14.4 Treatment of cloudiness in regional-scale numerical weather prediction

\section{W. KREITZBERG AND R. G. RASMUSSEN}

A three-dimensional numerical model formulated to simulate cumulus convection is presented. A time-splitting numerical integration scheme is utilized to solve a generalized set of fully compressible Boussinesq equations on a terrain following coordinate system. A general description of physical parameterizations of moist physics, surface layer fluxes, and turbulence is given. Lateral and vertical boundary conditions are described.

A case study of deep convection over south Florida, discussed extensively by Cotton and Pielke, is numerically simulated. This case is particularly interesting in that moderate intensity cumulus clouds appeared to propagate in response to the shallow sea breeze disturbance, whereas the most intense cumulonimbi appeared to respond to the deep tropospheric flow field. A detailed description of the dynamic response of the cumulus scale model to deep tropospheric flows is given. Factors affecting cloud movement, downstream redevelopment, and convective intensity are explored. Predicted rainfall rates, amounts, and downdraft intensities are compared with observations.

Cloud prediction, as part of a numerical weather prediction model, is becoming more important as the resolution of these models is increased, as radiational heating at the surface becomes more important, and as the use of solar heating makes surface insolation itself a more important forecast element. This paper reviews the methods being used to treat clouds in a regional-scale model with $35 \mathrm{~km}$ grid size, a $2000 \mathrm{~km}$ domain size, and a $24 \mathrm{~h}$ forecast period.

This numerical forecast system predicts cloud water or ice and rain water or snow concentration explicity in stratiform clouds and uses the sequential-plume cumulus model for parameterized convective cloud cover and precipitation. The microphysics parameterization is rather crude, but the main problems appear to be simple specification of specific humidity in supercooled clouds and treatment of cumulus scale downdrafts.

The main additional problem in these predictions is accurate specification of the initial moisture fields. Satellite data are essential to provide spatial detail in the initial cloud water concentration field. The specification of humidity in cloud-free regions is also a major problem.

Examples of skill demonstrated to date and a provisional ordering of the importance of different problem areas are given.

\section{Session 15: Severe convective storms}

15.1 Precipitation development in a severe, continental, multicell hail and rainstorm

\section{A. KNIGHT ET AL.}

The storm of 22 June 1976, just east of Grover, Colo., produced up to $10 \mathrm{~cm}$ of rain in $1 \mathrm{~h}$, and hailstones $>3 \mathrm{~cm}$ in diameter. It was studied by penetrating and cloud-base aircraft and by three Doppler radars, as well as conventional $10 \mathrm{~cm}$ radars with $2 \mathrm{~min}$ sector scan cycles; and it occurred over a network of surface meteorological instruments. Time-resolved quenched hail samples were obtained close to the precipitation core. The precipitation mechanism of the storm was largely particle growth by riming and accretion of supercooled droplets, with no evidence for liquid coalescence. The storm is probably best described as multicellular, but new cells often originate within preexisting, weak radar echo in the overhang. It is therefore likely that embryos are formed in earlier, less vigorous updrafts and become entrained in the new cells. Some of the major updrafts were associated with the formation of several transitory, radar echo vaults. The regions in which the major hail growth occurred were several kilometers from the vault edge and were thus different from the relation of hail formation to vaults advanced by Browning and others, in which the edge of the vault is the location of the largest hail. Therefore, competition for the liquid water is probably a factor limiting the hail size in the storm, though residence time within updraft is surely another factor. The relative importance of the two is difficult to assess, even with this excellent data set.

On 22 July 1976, thunderstorms developed and moved southward across the National Hail Research Experiment (NHRE) area in northeastern Colorado. Several hailswaths were reported. An intensive study of one of these thunderstorms with surface network data, four Doppler radars, and two meteorological aircraft was done to define the three-dimensional wind structure and evolution, the internal circulation, and the microphysical characteristics of the storm. This data set is probably the most complete ever obtained in a developing hailstorm.

This was a discretely evolving thunderstorm system that was sustained over a $2.5 \mathrm{~h}$ period by
15.2 The Colorado hailstorm of 22 July 1976 : Storm circulation, evolution, and hydrometeor growth

\section{G. B. FOOTE ET AL.}


10 major convective impulses. The majority of these cells developed sufficiently close to the existing storm so that they were quickly absorbed within the storm's high reflectivity core. This gave the storm system, as a whole, a nearly steady appearance in its low and middle levels over much of its lifetime. Transient vaults were noted throughout the lifetime of the cloud.

The triple-Doppler radar analysis indicated flow around the south (front) side of the cell at the midstorm height. This indicated the marked blocking effect exerted by the nearly erect updraft in the environmental winds. General agreement between the Doppler radar-derived vertical velocities and $\mathrm{T}-28$ aircraft-measured vertical velocities was noted.

Six penetrations into the strong updraft regions by the T-28 aircraft were used to define the vertical velocities and hydrometeor characteristics at the midlevels of the storm. Peak updrafts ranged from $25 \mathrm{~m} \mathrm{~s}^{-1}$ to $35 \mathrm{~m} \mathrm{~s}^{-1}$ in the weak echo vaults. Ice particle characteristics ranged from pristine ice particles on the east side of the vault to graupel on the west side of the vault and hail in the strong downdraft regions. Ice crystal concentrations averaged 20 per liter west and east of the peak updraft velocity. No ice particles were observed in the center of the strong updraft regions. Continuous size spectra were noted over 3 orders of magnitude in up- and downdraft regions. A consistent pattern of low $\theta_{e}$ air was noted on the east side of the vault in all penetrations. This suggested entrainment of dry environmental air and ice crystals into the east side of the vault.

The measured three-dimensional wind field and hydrometeor size spectra were used to deduce hail growth trajectories. These trajectories are discussed and compared with the observed high radar reflectivity zones.

15.3 Growth and recirculation of precipitation in an evolving convective storm

\section{J. E. DYE ET AL.}

15.4 The production of rain and hail in numerical simulations of hail cells
On 25 July 1976, two in-cloud microphysical aircraft, two subcloud meteorological aircraft, a high resolution $10 \mathrm{~cm}$ radar, and three Doppler radars simultaneously investigated the development of precipitation and three-dimensional air motions inside a growing convective storm in northeast Colorado. The coordinated aircraft-radar observations span a time of $\sim \mathrm{h}$ starting before the appearance of the first echo, through the growing and mature stages of the system, and into the dissipating stages of the storm. This data set is probably the most complete ever obtained in the early stages of development of a precipitating convective storm.

In-cloud aircraft observations show the chronological development of precipitation from a few ice particles in the upper levels of the newly growing turret through the appearance of millimetric water drops, partially melted ice particles, and small hail in the updraft in later stages of cloud development. These observations strongly suggest recirculation of precipitation particles within the cloud. The main updrafts at all levels were found to be almost coincident with the core of high reflectivity and on the western side of the storm. Updraft strengths varied from 2 to $3 \mathrm{~m} \mathrm{~s}^{-1}$ at cloud base to $15 \mathrm{~m} \mathrm{~s}^{-1}$ at $6-7 \mathrm{~km} \mathrm{MSL}$.

Triple-Doppler radar measurements also show the updrafts to be nearly erect, consistently on the western side of the storm, and of the same magnitude as those observed by the aircraft. Variation in the strength of the updraft with time suggests that the updraft was plumelike, but with buoyant bubbles imbedded in the plume. Horizontal sections of air motion show the updraft is acting somewhat like an obstacle to the environmental midlevel flow and, within the updraft region, aircraft measurements show a clearly defined adiabatic core, with a mixed region on the downshear side of the cloud.

The Doppler observations show the transport of precipitation particles to the east relative to the storm by upper level winds; and in a small region on the eastern edge of the reflectivity core, they distinctly show the likelihood of particle recirculation. Both the aircraft and Doppler radar observations are consistent with the hypothesis that the high reflectivity region and the precipitation particles therein are primarily a result of recirculation within a small region of the storm.

Numerical simulations of realistic storm systems using "bulk water" techniques and deep convection equations have been accomplished over the past few years. Calculations of the production of rain and hail and the many terms contributing to the production have been analyzed and reveal the dominant precipitation processes operative in the High Plains region. Weaknesses in the present simulations are also evident.

The physical processes simulated include: 1) cloud water to rain transformations due to "autoconversion," accretion, and shedding from precipitating ice; 2) rain to precipitating ice transformations due to Bigg freezing or capture of ice crystals by rain and rain accretion by precipitating ice; 3) cloud liquid to precipitating ice transformations due to a Bergeron process and accretion; and 4) other transformations caused by melting and evaporation.

Comparisons of one sounding with another show more dependence on the ice processes in the northern vs. the southern High Plains. Simulated cloud seeding experiments speed up the 
formation of precipitating ice, primarily due to the increased importance of the Bergeron process, and lead to significant differences in accumulated rain and hail at the surface.

The ease with which rain is formed in these models is a weakness affecting the formation of precipitating ice and the simulations of echo weak regions. The elimination of rain in one case will be run to test its effect on the results.

15.5 The influence of microphysical processes on storm splitting and structure

\section{R. WILHELMSON AND J. KLEMP}

A new three-dimensional numerical storm model has been used to investigate the development and structure of isolated, long-lived severe storms. The structure of these storms is similar in many respects to that of the "supercell" schematized by Browning, Fankhauser, and others. For right-moving simulated storms, the updraft rotates cyclonically and the downdraft-induced gust front influences the storm propagation and interacts with the low-level environmental wind to produce the convergence necessary to sustain the storm. The arrangement of the cloud water, rain, and updraft suggests the existence of a vault, hook, and weak echo region.

A model simulation of a severe self-sustaining storm will be presented. The sensitivity of the development and structure to microphysical changes including the elimination of rain, the lack of rain evaporation, and the inclusion of hail is being studied. Sensitivity studies are important for determining how the dynamics and microphysics of long-lasting storms are related and whether the almost steady state of simulated storms can be fixed and used in detailed studies of the growth of hail.

\section{Session 16: Atmospheric electricity-I}

16.1 Field and ion current measurements in regions of high charge density near direct current transmission lines

\section{T. D. BRACKEN AND}

B. C. FURUMASU
Measurements of electric fields, ion currents, and charge densities at ground level under high voltage direct current (HVDC) transmission lines are discussed. Observations are compared with ambient levels. The space charge generated by corona on the conductors of HVDC lines $12 \mathrm{~m}$ in height can produce ground-level electric fields $>40 \mathrm{kV} \mathrm{m}^{-1}$, ion currents $>10^{-7} \mathrm{~A} \mathrm{~m}^{-2}$, and charge densities $>1.6 \times 10^{-8} \mathrm{C} \mathrm{m}^{-3}$. An array of eleven $1 \mathrm{~m}^{2}$ Wilson plates is used to profile the ion current out to $20 \mathrm{~m}$ on either side of the line. Data from these plates, two field meters, two ion counters, and a UVW anemometer are simultaneously recorded with an automatic data acquisition system. Verification of field meter and ion counter performance in regions of high field and charge density by use of a coaxial cage is discussed. Correlations of ion current profiles with wind are presented.

Radiosonde balloon observations of the air-earth current density were made at the AmundsenScott South Pole Station before and after a "2B" solar flare that occurred at 0945 UT, 22 November 1977. The measurements show that the air-earth current density increased at all levels following the solar flare with a particularly enhanced layer of high current at $25-30 \mathrm{~km}$. Within $89 \mathrm{~h}$, the air-earth current gradually returned to its preflare state. The solar flare resulted in a total communications blackout on the Antarctic continent, which suspended aircraft operations and many other activities.

This fortunate documentation of a direct solar influence on the earth's atmospheric electric conditions is discussed with respect to the classical global circuit hypothesis.

The universal time variation is good evidence that fair weather atmospheric electric field responds rapidly to events around the globe. Fair weather atmospheric electricity (AE) shows modulations synchronized with solar phenomena of both periodic and nonperiodic variations. The existence of these correlations highlights a gap in our present knowledge of the interrelations between cloud physics and $\mathrm{AE}$.

A solution has been obtained for Maxwell's equations for time variations with a range of characteristic periods from a few seconds to many years for regions of the troposphere and stratosphere free of current sources. This corresponds to regions where fair weather AE measurements are made. The results are given in terms of a harmonically analyzed separable solution in spherical coordinates for an exponential conductivity profile with boundaries in the stratosphere and on the surface of the earth. A first-order analytical solution has been found for global-scale phenomena with characteristic lengths $>1000 \mathrm{~km}$. The time and spatial variations of the electric field at the boundaries determine the coefficients of the solution. The solutions are sensitive to the ratio of conduction current to displacement current. At low altitudes for short periods, the displacement current dominates and the quasi-static approximation is not valid. In this region, upward propagating electric fields are essentially unattenuated below the altitude where conduction currents are dominant. In the conducting region, which 
lies above the other region, electric fields are exponentially attenuated. This is consistent with a model of a dielectric atmosphere surrounded by a conducting shell, provided that the thickness of the dielectric layer depends on frequency. The dielectric region is nonexistent for field variations with periods longer than a day.

The magnitude of the fair weather AE field is determined by the balance between the integral of all processes removing charge from the earth and the returning currents. The relationship between cloud processes, lightning, and charge transfer from the earth needs further investigation.

The development of charged screening layers on clouds depends on the altitude of the cloud surfaces and the frequency dependence of the fair weather field. Deep convective clouds may have bases in regions of relatively low conductivity and tops in regions of high conductivity.

16.4 The structure of small ion clusters in humid atmospheres and the relationship to infrared absorption and the initiation of lightning discharge

\section{J. L. KASSNER, JR.}

16.5 The effect of the initial energy on positive streamer propagation

\section{A. S. SADIK AND}

\section{J. A. BICKNELL}

16.6 Corona discharge and thunderstorm fields

\section{H. W. KASEMIR}

A number of experiments have been carried out, the results of which are strongly suggestive of the nature of the behavior of small cluster ions. It is becoming increasingly evident that clusters are strongly inhibited from falling into the lowest free energy configurations at temperatures near ambient, due to the very high probability that internal free rotations will be excited for molecules or groups of molecules at the surface. Thus, clusters remain in much higher states of excitation than previously supposed. The gain or loss of internal excitation energy can only be accomplished through interaction with the infrared radiation field and collisions with other gaseous constituents, wherein the probability of leaving these surface groups in a state of zero rotation relative to the remainder of the cluster is exceedingly small. Thus, the probability of forming ring structures that exhibit exceptionally high binding energy at temperatures near ambient is believed to be small.

The role played by ions in $e$-type atmospheric absorption cannot be overlooked. Clusters of all types abound in internal degrees of freedom whose characteristic frequencies fall into the near and far infrared regions. However, the oscillator strengths for these are unknown at present. The presence of ions in the atmosphere means that fairly large sized clusters will be present and will contribute to $e$-type absorption.

High energy cosmic ray showers produce trails of ions through the depth of the atmosphere. These become cluster ions with mobilities in the range $0.5<\omega<1.6 \mathrm{~cm}^{2} / \mathrm{V} \mathrm{s}$ under low field conditions. At higher field strengths, the effective temperature of the ion cluster would rise and the sheath of hydration should ablate. Newly formed ions would never hydrate. Negative ions would either revert to or remain electrons and thus be capable of involvement in prebreakdown phenomena.

Streamers are known to propagate away from positive points (the positive streamer) with a greater facility than from a negative point (the negative streamer). Because the electric field required for a given propagation length is significantly less for positive streamers, it is reasonable to assume that the positive streamer plays a major role in redistributing charge in a thunderstorm and in the development of the stepped leader. The electric field in which a streamer might propagate indefinitely, the critical field, has been discussd by Dawson, Nasser, Phelps, and others, and attempts have been made to measure such a field. Experimental work reported to date has usually involved the generation of positive streamers in a region characterized by a high nonuniform field produced by a high-voltage pulse and the subsequent observation of the propagation distance in a quasi-uniform field. No dependence of the critical field on the initial streamer energy, as measured by pulse voltage, has been observed.

Early results of an experiment designed to investigate streamer characteristics will be presented. A $100 \mathrm{~ns}$ pulse variable over the range $0-20 \mathrm{kV}$ has been used to generate streamers, and over the lower end of the range, a marked dependence of the critical field on initial streamer energy has been observed. Calculations indicate that the potential drop around hydrometers likely to give rise to atmospheric corona is only a few kilovolts, and thus any streamers that are generated under these circumstances are likely to fall within this range. The use of relatively high voltage pulses in previous work is probably the reason why this dependence of critical field on streamer energy was not observable.

It has been recognized for several decades that corona discharges emitted at the ground may play an important role in the electrical structure of a thunderstorm. The relationship between electric field and corona current is nonlinear and even more complicated by the fact that the field has to reach a certain threshold value of several kilovolts per meter before corona discharge is generated. A theoretical solution for the nonlinear differential equation of the corona current has been found for a linear, quadratic, and cubic relation between field and corona current. This theory links certain key parameters such as mobility of ions, electric permittivity of space, corona constant, stationary field value, etc., with each other and predicts certain forms of the recovery of lightning discharges and the attenuation of the influence of corona discharge with 
altitude. These theoretical relationships will be compared with experimental field measurements at the ground and aloft, obtained during the thunderstorm research projects at Kennedy Space Center 1976 and 1977 (TRIP 1 and 2).

16.7 A cooperative study of an unusual lightning flash at Kennedy Space Center during TRIP 1976

W. H. BEASLEY ET AL.

16.8 Doppler radar and electrical radiation observations of thunderstorms

\section{R. M. LHERMITTE}

16.9 The temporal structure of $H F$ and $V H F$ radiations during intracloud lightning discharges

\section{E. P. KRIDER ET AL.}

16.10 Thundercloud charge distributions-Inferences from the intracloud structure of lightning channels

\section{A. A. FEW ET AL.}

16.11 Correlations between reflectivity contours and lightning channels for a Colorado storm on 25 July 1972

\section{R. MACGORMAN} AND A. A. FEW
At $\sim 1620$ UT on 19 July 1976, a typical afternoon thunderstorm formed over Kennedy Space Center (KSC). The storm lasted $\sim 90 \mathrm{~min}$ and produced $\sim 140$ intracloud and cloud-to-ground lightning discharges. One of these struck the KSC $150 \mathrm{~m}$ weather tower at 1659:59 UT. Six independent research groups participating in TRIP 1976 gathered data and made a detailed analysis of the flash that struck the tower. The various independently obtained observations of specific lightning parameters agree very well with one another.

The data used include electric and magnetic fields, thunder, radar, and visual observations. We have determined the locations and magnitudes of charges in the storm clouds neutralized by the flash, the geometry of the channel and the currents flowing in it, the locations of sources of very high frequency radio noise associated with the flash, and the distribution of radar precipitation echoes at the time of the flash.

From the observations we conclude that: 1) the flash had three return strokes followed by an intracloud discharge; 2) the peak currents of the first two strokes were unusually large, $\sim 200$ $\mathrm{kA}$; 3) the total charge transferred to earth by the flash was not unusually large, $\sim 50 \mathrm{C}$; 4) the stepped leader initiating the first stroke was of relatively short duration, only $\sim 3 \mathrm{~ms} ; 5$ ) the charged regions lay in a roughly horizontal layer between $\sim 6 \mathrm{~km}$ and $8 \mathrm{~km}$ heights, where environmental temperatures were between about $-10^{\circ} \mathrm{C}$ and $-20^{\circ} \mathrm{C}$; 6) the overall channel length was $\sim 10 \mathrm{~km}$; 7) most of the VHF radiation was associated with the intracloud discharge; and 8) the charged regions appear to have been in or near regions with strong radar precipitation echoes.

This paper presents and discusses the results of investigations of thunderstorm circulation dynamics and electrical activity conducted by a multiple Doppler radar network and a system capable of observing the locations of electrical radiation sources. The observational data are presented in the form of three-dimensional motion and radar reflectivity fields observed by the multiple Doppler radar network in storm cells that are associated with the production of electrical activity. The electrical storm activity is indicated by the three-dimensional presentation of the rate at which electrical radiation signals are acquired and processed by the system. The results show that electrical activity is associated with glaciation mechanisms occurring in regions where specific structures of adjacent updrafts and downdrafts are found. Several case studies will be presented.

In recent years, several research groups have used the pulsed RF emissions produced by intracloud lightning to reconstruct channel geometries inside clouds. Unfortunately, relatively little work has been done on the physical processes that produce these emissions or on their relationship to the lightning electric field changes. In this paper, data are presented that show typical intracloud RF patterns in correlation with both fast and slow electric field waveforms with microsecond resolution. The time development of the RF during intracloud processes will be shown to be substantially different than during the return stroke portions of cloud-to-ground discharges.

Several lines of research are now converging on the conclusion that the lower thundercloud charge is concentrated in a horizontal layer, which is thin with respect to the dimensions of the cloud. This layer is located above the $0^{\circ} \mathrm{C}$ isotherm and typically near $-10^{\circ} \mathrm{C}$. The upper thundercloud charge is more widely dispersed and hence the more difficult to study. Intracloud lightning channels, reconstructed using acoustic techniques from data acquired during TRIP 76 and 77, have provided us with key information on the distribution of the upper charge. These data and our earlier work with western thunderstorms are reviewed, and a consistent interpretation is proposed. The upper thundercloud charge is diffuse with dimensions of the order of the subzero part of the cloud, and the distribution is strongly influenced by local and environmental winds.

Lightning has been reconstructed acoustically from a storm near New Raymer, Colo., on 25 July 1972 in conjunction with the National Hail Research Experiment. The storm occurred in a strongly sheared environmental wind $\left(3.3 \times 10^{-3} \mathrm{~s}^{-1}\right)$. By comparing the reconstructed lightning with reflectivity contours from the NCAR $10 \mathrm{~cm}$ radar at Grover, it is possible to find correlations between electrical activity and cloud parameters. A significant portion of a typical lightning flash occurred in regions of relatively low reflectivity $(<35 \mathrm{~dB})$ to the north of the active cells. (Mean storm motion was to the southeast.) Very little occurred in regions of high reflectivity $(>45 \mathrm{~dB})$. The storm produced predominantly horizontal lightning channels 
and appeared to influence the alignment of the lightning, having two possible correlations: 1) lightning channels frequently paralleled reflectivity contours; and 2) lightning channels tended to connect a region of low reflectivity north of the storm with regions of increasing reflectivity.

\section{Session 17: Atmospheric electricity-II}

17.1 Atmospheric electric field strength and ice crystal charge associated with precipitation at Inuvik, N.W.T.

\section{S. R. SHEWCHUK ET AL.}

17.2 Vector electric field measurements inside thunderstorms-Vertical profiles with balloon electric field sensors

\section{A. A. FEW ET AL.}

17.3 Cloud-to-ground lightning frequencies over south Florida

M. W. MAIER AND

A. G. BOULANGER

17.4 Radio-located lightning related to radarobserved precipitation

\section{J. S. MARSHALL ET AL.}

The atmospheric electric fields and snow crystal charge have been associated with many of the crystal shapes observed at Inuvik.

Results show that snow crystals of needle and dendritic shape (although possessing discrete amounts of charge and falling at low intensities) have little effect upon the undisturbed value of electric field. It is shown that there is an inverse relation between the sign of atmospheric electric field and the sign of charge on the individual snow crystals. In a calm wind situation, individual crystal charges were measured as high as $10 \mathrm{pC}$ with corresponding electric fields of several hundred volts per meter. Snow fall intensity, snow crystal charge, and atmospheric electric fields are directly related.

Drifting snow effects strongly reverse normal values of electric fields, with characteristic negative spike-type pattern. Duration and magnitude of the field disturbance can be related to wind velocity and turbulence.

The accretion of droplets onto dendritic and stellar crystal forms is shown to reverse the size and magnitude of fair weather field effects. Although crystals normally have maximum charges of $1 \mathrm{pC}$ in a reasonably stable atmosphere, effects as large as $10 \mathrm{pC}$ and of opposite sign were found when the riming process takes place.

A balloon system capable of measuring the vector electric field strength inside thunderstorms has been used to make vertical ascents through thunderstorms over Langmuir Laboratory in 1975, 1976, and 1977. A common feature of the flights has been a negatively charged region above the $0^{\circ} \mathrm{C}$ isotherm. Several simple electrostatic models of varying geometry have been fit to the profiles; the range of values for the total charge in the negatively charged regions of the models was $40-100 \mathrm{C}$. The vertical profiles also allow us to measure directly the potential of the negatively charged region from an integration of the vertical component of the electric field. Measured values for this potential are of order $10^{8} \mathrm{~V}$. The energy dissipated in cloudto-ground lightning flashes is similarly calculated and is found to be on the order of $10^{9} \mathrm{~J}$.

Cloud-to-ground lightning flashes were counted over a $2.0 \times 10^{4} \mathrm{~km}^{2}$ area of south Florida during the summer months of 1976. Simultaneous rain volumes were estimated over roughly the same area using the digitized $10 \mathrm{~cm}$ WSR-57 radar at Miami. The lightning frequencies were stratified by time, rain volume, synoptic condition, and echo motion. Initial results indicate that maximum flashing rates of $1.5-2.0 \times 10^{-3}$ flashes $\mathrm{km}^{-2} \mathrm{~min}^{-1}$ are encountered on days with normally active convection (typical rain volumes of $6-8 \times 10^{7} \mathrm{~m}^{3}$ ). Lightning frequency is found to decrease on highly disturbed and suppressed days. Days with no echo motion exhibit higher lightning frequencies than days with echo motion. A complete review of these results will be presented.

Larsen and Stansbury found convective cells, identified by area $A$ at height $h$ within which the radar reflectivity factor of precipitation exceeds $Z_{L}$, to be sources of lightning. Marshall and Radhakant found a relation between the sferics rate $L$, the area $A$, and range $r: L r^{3 / 5} \propto A^{5 / 3}$. Stansbury and Marshall found that one could weight $A$ to allow for variations of precipitation intensity within $A$. This allowance reduced the index somewhat but did not improve the correlation between $L$ and $A$ significantly. Now we have replaced the area $A$ by a volume, $V=$ $\iint\left(h-h_{\mathrm{o}}\right) d a$; we find $L r^{3 / 5} \propto V$. Again the correlation is not improved, but with the proportionality between $L$ and $V$, it is no longer vital that a thunderstorm complex be broken down into individual storms or lightning generators.

The spatial relation between the precipitation core and the lightning it causes is not simple. Triangulation on individual flashes from two sferics stations, one at the radar and a second distant $57 \mathrm{~km}$, is accurate enough so that this relation can be investigated for such thunderstorms as take an appropriate path past the observing system. 
17.5 Lightning and precipitation and the life history of isolated

thunderstorms

\section{R. C. GROSH}

Detailed and unique observations of isolated thunderstorms were obtained from an array of thunder and lightning detectors, a weather radar, and a dense hailpad and rain gage network. The observations from the radar are analyzed in conjunction with the rain and lightning observations so that time profiles of echo height, echo volume, storm rain-flux rate, and lightning flash rate may all be compared.

The observations were obtained during the Metropolitan Meteorological Experiment (METROMEX). The rain gage network had one hailpad and recording rain gage located at a density of one per $24 \mathrm{~km}^{2}$. The rain gage chart data are analyzed to give $5 \mathrm{~min}$ rain totals and hail occurrences. The storm volumes were radar scanned every $3 \mathrm{~min}$, and echo volume and height were observed with high temporal resolution. The thunder and lightning detector network sensed storm activity continuously.

Observations of one storm studied show that the electrical activity of this nonhail-producing storm was closely related to the volume and height of the precipitation echo and its associated rain flux. This storm lasted $\sim 1 \mathrm{~h}$, reached a height of $11.9 \mathrm{~km}$, had a maximum echo volume of $500 \mathrm{~km}^{3}$, and had a maximum rain flux rate of $2 \times 10^{5} \mathrm{~kg} \mathrm{~s}^{-1}$. Lightning initiated with a burst when the rain flux rate exceeded $10^{5} \mathrm{~kg} \mathrm{~s}^{-1}$, and the echo volume was $\sim 400 \mathrm{~km}^{3}$. The echotop height was $\sim 10.4 \mathrm{~km}$ and well above the freezing level. The peak lightning flash was about one flash per minute during a $15 \mathrm{~min}$ period near the maximum development of the precipitation activity. This storm and others will be described. The long-term goal of the study is to composite the precipitation and electrical observations of many storms with similar durations into an average storm model. An echo and rain-flux model based on at least 25 storms will be presented.

Simultaneous measurements of: 1) vertical electric field, 2) raindrop charge, 3) point discharge current, 4) rain intensity, 5) cloud condensation nuclei, 6) giant size $(r>1 \mu \mathrm{m})$ condensation nuclei, and 7) ice nuclei were made during August 1977 at Mahabaleshwar $\left(17^{\circ} 56^{\prime} \mathrm{N}, 73^{\circ} 40^{\prime} \mathrm{E}\right.$; $1382 \mathrm{~m} \mathrm{ASL}$ ) located on the crest of the western Ghats. The cloud top heights were obtained from radar observations. Values of: 1) entrainment, 2) adiabatic liquid water content, and 3) vertical velocity were theoretically computed using the radiosonde temperature data.

The time variations of the parameters and their differences in cloud and cloud-free air were studied. The possible influence of electrical, microphysical, and dynamical conditions on the cloud and precipitation development was discussed.
17.7 Numerical modeling of hailstorm electrification

\section{S. $\mathrm{CHIU}$}

The slab-symmetric, time-dependent numerical cloud model of Orville and Kopp is modified into an axisymmetric-type cloud model and is further developed to take into account atmospheric electrical effects to study the electrification of hailclouds. In their models, "bulk water" techniques are used for the simulations of cloud formation and precipitation processes. Autoconversion and accretion are used to transform cloud water to rain. Precipitating ice (hail) is formed by the freezing of rain and through an approximation to the Bergeron-Findeisen process to transform cloud liquid to precipitating ice. Accretion of cloud water by rain and accretion of cloud water, cloud ice, and rain by hail are modeled. Wet and dry growth of hail and the shedding of rain from hail are simulated. Cloud water freezes to cloud ice isobarically at a preselected temperature. Evaporation of all forms of cloud particles can occur, and melting of frozen particles is simulated.

In order to simulate the electrical properties of cloud development, in keeping with the model stated above, the main charge carriers are assumed to be the mean size particles of cloud water, cloud ice, rain, and precipitating ice, as well as small positive and negative ions. Cloud particles and precipitating particles of all forms are allowed to be electrically charged by the three main particle charging mechanisms: ion attachment, polarization (inductive) charging, and thermoelectric charging. Charge transports by electrical conduction, air convection, turbulent mixing, and by the particle terminal velocities are all simulated. The small ions are assumed to be generated by cosmic ray ionization at various heights. Ions lose their identity through ionic recombination processes and their attachment to cloud or precipitating particles. To maintain charge conservation, charges are allowed to transfer from one category of charge carrier to another during the processes of autoconversion, accretion, phase change, and water shedding. This study also includes the electrical effects on the air motion and on the terminal velocities of cloud and precipitating particles. Some interesting results have been obtained for the cases when rain and cloud water are involved. Ice processes are now being programed.

1 Deceased. Discussion to be led by H. D. Orville. 
17.8 A time-dependent, one-dimensional model of an electrified warm cloud

I. TZUR AND Z. LEVIN

17.9 Electric fields and particle charges in thunderstorms

\section{W. GASKELL ET AL.}

17.10 Oceanic tropical thunderstorm electricity at Ponape, Micronesia

\section{T. TAKAHASHI}

A one-dimensional, time-dependent model of an electrified warm cloud has been developed. The model contains detailed microphysics of drops' nucleation and growth and some features of the dynamics of the air and the effects of the air motion on the hydrometeors and the ions. The model simulates the production of ions and their recombination. It also considers the diffusion currents of ions to drops, the conduction currents, and the attachment of ions in a convective field to falling drops in the presence of electric fields and charges (Wilson effect). In addition to the ions, the induction-polarization charge separation is also simulated.

We found that the ions dominate the charging of the cloud when the concentration of droplets is small (maritime clouds). This is caused by the relatively small depletion of ions to the drops. The remaining high concentration of free ions results in a decrease of the conductivity of the cloudy air by only 1 order of magnitude relative to the fair weather conditions. The results of the model show that in such a cloud, the electric field growth is small and is controlled mainly by ion charge separation. A positive ion center is developed at cloud top, and a negative charge center is developed nearer to cloud base. Cloud drops carry mostly negative charges due to the higher mobility of the negative ions and the Wilson effect.

When a denser cloud is considered ( $\sim 500$ droplets per cubic centimeter $)$, the ions' attachment to drops increases and the conductivity decreases by $\sim 3$ orders of magnitude. In such a cloud, the electric field develops due to both ion currents and the induction-polarization charging and reaches a value of a few kilovolts per centimeter. "The strong field develops rapidly only when cloud drops grow into precipitation size.

From these results, it is felt that charge separation in clouds is affected by the cloud type and by both ion currents and the induction-polarization charging mechanism. The model shows that neither ion currents nor induction-polarization charging by themselves can separate enough charge to achieve high electric fields. Only when both operate together can the field reach a value of a few kilovolts per centimeter.

The ONR/NMIMT Schweizter airplane has been employed over Florida (as part of the Thunderstorm Research International Program) and over New Mexico in flights through cumulonimbus clouds. Among the major parameters measured were electric field strength $E$ (in three mutually perpendicular directions, using five field mills) and the charge $Q$ and size $d$ of individual precipitation elements. $Q$ was measured by induction, with various safeguards to eliminate collisional effects, and $d$ was measured by means of a photo-optical shadowgraph technique.

The charges carried by individual precipitation elements in the central regions of thunderclouds were generally around several tens of picocoulombs. Charges of both signs were generally found to coexist, but one sign was always strongly dominant; this was usually negative. The associated precipitation charge densities $\rho_{p}$ were typically $\sim 1 \mathrm{nC} \mathrm{m}^{-3}$. The precipitation rates $p$ were in the region $10-30 \mathrm{~mm} \mathrm{~h}^{-1}$, although much lower values of $p$ were sometimes recorded when $\rho_{p}$ was high.

The $Q / d$ coincidence measurements were completely inexplicable in terms of the inductive mechanism of cloud electrification. The individual $Q$ values were often very much larger than the absolute maximum that this mechanism could convey to them, even in fields of breakdown magnitude, and no $Q / d^{2}$ charging pattern was observed.

We conclude that in the clouds studied, precipitation carried sufficient charge to explain the field growth to breakdown, but the mechanism responsible for its charging remained obscure.

A series of laboratory experiments has been performed into the charge transfer accompanying the collisions of ice crystals with a simulated hailstone. A warmer hailstone acquired negative charge, and it was concluded that the charge transfer was probably governed by surface potential differences and not by the thermoelectric effect. These measurements, in conjunction with other studies, suggest that this process may be of primary importance in thunderstorm electrification.

Two field studies have been carried out recently on the island of Ponape $\left(7^{\circ} \mathrm{N}, 158^{\circ} \mathrm{E}\right)$ in Micronesia. The major findings resulting from the first study in 1976 were: 1) ground station observations showed no evidence of lightning from warm clouds-the electrical characteristics of these clouds were the same as those in Hawaiian warm clouds, provided that the cloud-top height was below the $-20^{\circ} \mathrm{C}$ level; 2) when the tops of Ponape clouds reached the $-40^{\circ} \mathrm{C}$ level, lightning was observed, although there were very few strokes; and 3) the relationship between the electric charge and size of raindrops is different from the warm rain electrical case and the raindrop-size distribution is broader than in the nonlightning case.

Laboratory studies of riming, carried out following the 1976 field program, revealed that both the electric charge and the sign of riming are highly dependent on temperature and liquid water content, but independent of the electric field.

During the second field program in 1977, attention was directed to in-cloud studies of light- 
ning from warm clouds of large vertical extent whose formation is permitted by the greater inversion height in the Ponape area. In addition, we sought the reason for the small number of reports of lightning from this area.

Ten electric charge, ice crystal type radiosonde devices were launched into thunderstorms. The electric charge distribution in thunderstorms was the same as that deduced by previous workers. It is proposed that the positive charge, near the freezing level, and the negative charge, near the $-10^{\circ} \mathrm{C}$ level, are carried on graupel, while the upper positive charge is carried on ice crystals. Furthermore, it is suggested that the low level of electrical activity in the Ponape area is due to the high liquid water content of cloud droplets.

17.11 Inductive or noninductive electrification of thunderstorms?

\section{J. KUETTNER ET AL.}

Most of the numerous theories on charge generation in thunderstorms are based on one of two basic mechanisms: the inductive (i.e., polarization) mechanism initiated by the ambient fair weather field, or the noninductive mechanism connected with certain electric (e.g., thermal gradient) particle characteristics. Our numerical study addresses the question of whether one of the two mechanisms gives more realistic results than the other (proper charge distribution, proper polarity, proper field strength) or whether a combination of the two processes is required.

To simulate the time-varying distribution of charges and their transport in a convective cloud, the microphysical processes of particle growth and simultaneous electrification are embedded in a steady-state, two-dimensional vortex circulation. The potential is obtained everywhere in the cloud, and the resulting electric fields are calculated. Computations are made for the collisions of growing solid precipitation (graupel) particles with either supercooled droplets or with ice crystals applying both inductive and noninductive mechanisms. The two mechanisms are studied separately and in combination using both a straight vortex and a vortex with vertical wind shear.

Preliminary results indicate that the noninductive mechanism leads to a more rapid growth of the electric field in the early stages involving either ice-ice or ice-water collisions, but that it does not reach breakdown strength alone in a reasonable length of time. The inductive mechanism in turn may or may not reach breakdown strength alone depending on the size and number of cloud particles, but it frequently evolves into rapidly varying charge distributions with reverse polarity, monopole, or multipole electric fields.

If both processes are combined, the field strength grows significantly faster at all stages of development and, furthermore, seems to result in a stabilization of charge distributions with the proper polarity (positive charges above negative in the main thunderstorm dipole). A moderate vertical shear in the horizontal winds also seems to have a stabilizing effect. It is concluded that, in a thunderstorm, both mechanisms are operating simultaneously. 